\title{
OPTINALYSIS
}

\section{Optinalysis: A New Approach of Multivariate Analysis Through A Looking-Glass}

\author{
Kabir Bindawa Abdullahi \\ Umaru Musa Yar'adua University, Katsina State, Nigeria \\ Email: kabir.abdullahi@umyu.edu.ng
}

\begin{abstract}
Optinalysis, as a method of symmetry detection, is a new advanced computational algorithm that intrametrically (within elements) or intermetrically (between elements) computes and compares two or more multivariate sequences in an unclustered or clustered manner as a mirror-like reflection of each other (optics-like manner), hence the name is driven. Optinalysis is based by the principles of reflection and moment about a symmetrical line which detects symmetry that reflects a similarity measurement. Optinalysis is suitable for quantitative and qualitative data types, with or without replications, provided it conform the algorithmic requirements there provided. Optinalysis can be organized for geometrical, geostatistical and statistical analysis in one-way, two-way, or three-way approach. A simulation comparisons shows that Optinalysis is a simple alternative approach of multivariate analysis of sociometric, demographic, sociodemographic, psychometric, ecological, experimental, genomic, nanoparticle and shape morphometric data. Optinalysis of these data matrix shows very similar results or conclusions with some multivariate analysis such as skewness measure, one-way ANOVA, paired t-test, one sample t-test, Tukey's multiple comparisons, BLAST sequence algorithmic analysis (percentages of identity, similarity, gabs, and positives, and the Needleman-Wunsch score), and Riemannian distance.
\end{abstract}

Keywords: Kabirian Coefficient; Symmetry; Similarity; Geometrical Analysis;

Geostatistical Analysis; Statistical Analysis 
OPTINALYSIS

\section{Introduction}

Lines and points as components of a geometric concept were established and invented by Mathematicians. Symmetry, on the other hand, is everywhere around us. Almost all living creatures such as plants, animals, and even humans are symmetric to a certain degree of geometry. Over time, we have imitated the symmetry of nature in art, architecture, technology and design. Symmetric shapes and patterns just seems to look more beautiful than asymmetric ones. But symmetry is more significant that simply looking beautiful. It lies at the very foundations of our universe, and to the greater impact, can even explain the most fundamental laws of physics (Fraassen, 1989; Mardia, et. al., 2000; Dryden and Mardia, 2016).

Natural and man-made structural entities and objects are everywhere, the information about these interesting structures and objects are routinely gathered and collected all around us, we appreciates the beauty of their nature, shapes, patterns and orientations. We recognize, identify, compare and distinguish amongst them by our innate senses. We often make rational decisions about these structural entities and objects base on their symmetry and structural orientations. Therefore, measure of symmetry is of great and global concern and for a wider interest in a variety of disciplines with theoretical concepts in mathematics and statistics; practical applications in biology, chemistry, medicine, image analysis, archaeology, bioinformatics, geology, particle science, genetics, geography, law, pharmacy and physiotherapy (Goodall, 1991; Bookstein, 1991; Dryden and Mardia, 1998; Cootes and Taylor 2010; Dryden, and Mardia, 2016; and Zheng et. al., 2017).

In the literal texts, going from Weyl (1952); Darvas (2007), a widely accepted general definition of symmetry is not claimed coverable by a single mathematical definition and there is much to learn and to explore before stating whether or not a unique definition is possible. Even the practical definitions of symmetry are often based on strong assumptions and exemplified rather than defined (Petitjean, 2007). However, strong assumptions, such as the existence of the euclidean structure for geometric symmetries, Riemannian distance, Minkowski distance, Mahalanobis distance, simple matching and Jaccard coefficient are some measures of similarity.

Similar and symmetrical entities are invariance to transformational properties such as reflection, rotation, scaling, and translation. The decisions we made about this invariance under different transformations are based on strong assumption with no general formula to explain. Petitjean (2007) associated the topic of symmetry with the classification of symmetries, which should be done on the basis of the symmetry group structure of the object and symmetry is considered as a quantity varying continuously.

In this paper, a new algorithm called Optinalysis, is proposed and explained. Optinalysis torches the most important aspects of geometrical analysis, statistical analysis, and also a new derived concept of geostatistical analysis. Optinalysis does not require the assumption of normality and other statistical or geometric features, but it requires the existence or establishment of a clearly defined sequence order within and/or between the elements of a multivariate sequences. Several examples were examined and analyzed, and in comparison with other standard methods of statistical and geometrical analysis, revealed that Optinalysis presented a uniquely new paradigm of data analysis. 
OPTINALYSIS

\subsection{The Algorithm of Optinalysis}

The paradigm of the concept of symmetry is the mirror image. My image and I are a symmetric pair to each other by their corresponding points that matches within and between them. Other kinds of symmetry exist, but this is the one to start with. It is called isosymmetry.

To make this illustrative and precise, consider the case of one $M$ letter (Figure 1) in a plane. Elements of letter $M\left(a_{n}\right.$ and $\left.a_{n}^{\prime}\right)$ may be related as follows: there is a straight line that separates these elements (the line of reflection) and each point $\left(a_{n}\right)$ within $M$ can be connected to a corresponding point $\left(a_{n}^{\prime}\right)$ within $M$ by means of a line perpendicular to lower base of the letter $M$. The correspondence connects all points $\left(a_{n}\right.$ and $\left.a_{n}^{\prime}\right)$ in $M$ such that corresponding points are equidistant from the line of reflection.

In another illustrative case of two $M$ letters (Figure 2) in a plane. Letter $M_{1}$ and $M_{2}$ may be related as follows: there is a straight line that separates them (the line of reflection) and each point $\left(a_{n}\right)$ in $M_{1}$ can be connected to a corresponding point $\left(b_{n}\right)$ in $M_{2}$ by means of a line perpendicular to lower base of the letter $M$. The correspondence connects all points $\left(a_{n}\right.$ and $\left.b_{n}\right)$ in $M_{1}$ and $M_{2}$ and is such that corresponding points are equidistant from the line of reflection. In space, the definition is similar, but with a plane of reflection. Scholarly works such as Weyl (1952), Darvas (2007), Kendall (1989), Watson (1986), Bookstein 1986, 1991); Kent (1994), Lele and Richtsmeier (2001) and Dryden et. al. (2008) follows same line with this principle.

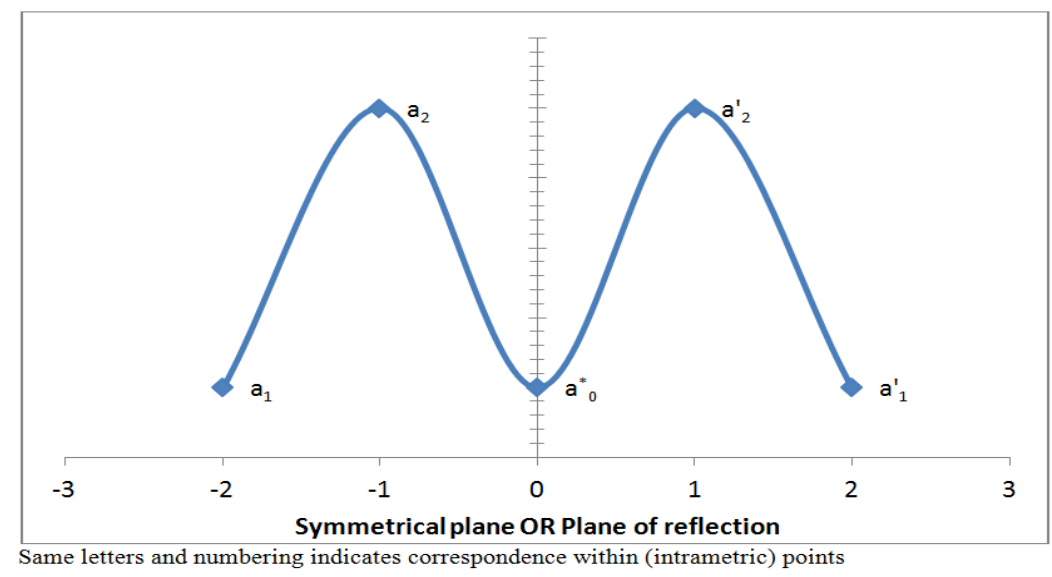

Figure 1: Showing a symmetric correspondence within pair points of letter $M$.

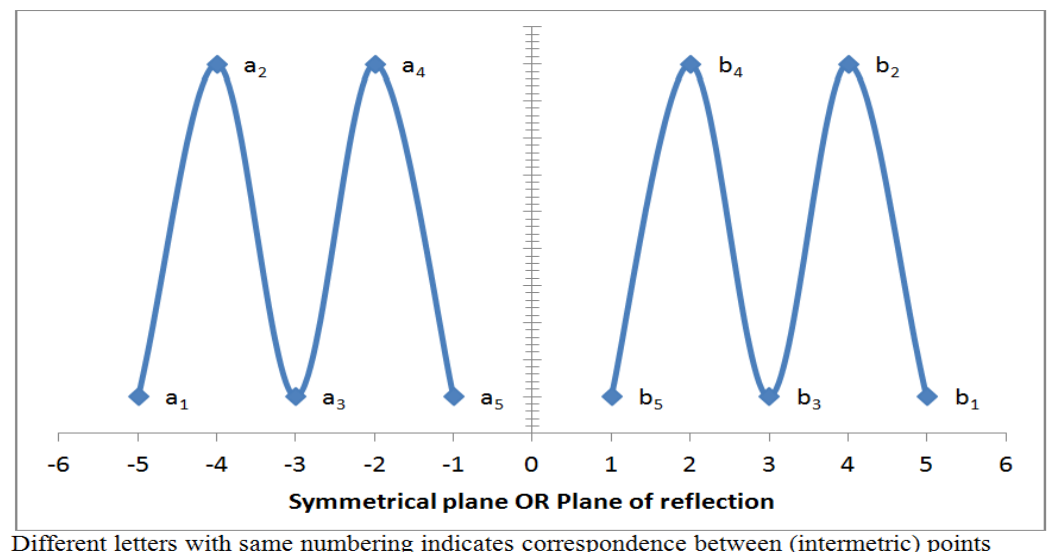

Figure 2: Showing a symmetric correspondence between pair points of two $M$ letters. 
OPTINALYSIS

The Algorithm of Optinalysis is within this tradition and concept of symmetry. Optinalysis attempted to detects symmetry within and/or between the corresponding points of pair of structural elements of sequences. Optinalysis is however designed to intrametrically or intermetrically compare two or more multivariate sequences in an unclustered or clustered manner as a mirror-like reflection of each other (optics-like manner).

\subsection{Step-by-step Computational Approach to Optinalysis}

Step 1: Identify the variables and elements (which can be an experimental observations; frequencies; measurements from interval, ratio, ordinal, or nominal scales; coordinates of landmarks; vector coordinates, or resultant functions to be analyze.

Step 2: If the data set is in nominal form, an appropriate transformation method (e.g, Kabirian (A) or Kabirian (B) algorithmic transformation) must be use to convert the data sequence into a logical and numerical scores. Section 3 presented detail explanations of the algorithm.

Step 3: Identify, establish and organize a logical sequence (sequence order) and arguments within and between the elements of the subject or query sequence(s) of variable(s) and as a well as the reflector sequence of variable(s). Section 5 presented detail explanations on methods of establishing sequence order. If landmark coordinates are involved, then, the sequencing within and between the selected landmarks is organized by the appropriate numbering methods used as described in section 7 of this paper. The choice of sequence order depends on the type of Optinalysis intend to detect (i.e: geometric, geostatistical, or statistical).

Step 4: If the main elements of the comparing sequences are associated with other coelements (e.g, landmark coordinates into $x, y, z)$ points), then, a suitable functions (e.g, geometrical functions, vectors resolution, or any applicable theoretical function) must be used to obtain the resultant elements. Section 14 presented detail explanations.

Step 5: Choose the desired rotation and/or normalization value, if in case the rotation and normalization effects are considered important. Section 12 and 20 respectively presented detail explanations on rotations and normalization of a given sequences.

Step 6: Establish a pairwise reflecting correspondence or alignment within and between the query and the reflector sequences. Section 8 presented detail explanations on the different pairing styles.

Step 7: Quantitatively scale the resultant sequence elements as they were reflectively pairewised or aligned. Section 13 and Table 9-10 presented detail explanations.

Step 8: Compute for the Kabirian coefficient of symmetry (similarity), the probabilities, or percentages. Section 14 presented detail description of the formula for these parametrs.

\subsection{What data sequence can be compared by Optinalysis}

Data sequences from quantitative and qualitative measurements are welcome for Optinalysis.

\subsection{Quantitative Data}

Quantities can be scalar or vectors. For scalar quantities, it is very suitable for statistical Optinalysis. But for geometrical and geostatistical Optinalysis, a clearly defined sequence order within or/and between variables and as well as the elements must be established. On other hand, vector quantities are expressed by their coordinates (in magnitude and direction) in 2-D structure $(x, y)$ or in 3-D structures $(x, y, z)$. For such a vector data to suit Optinalysis, the coordinates (i.e, the elements) need to be resolved. 
OPTINALYSIS

In the case of nominal data (e.g, the nucleotide base sequences of DNA, or the amino acid sequences of protein, or words strings, etc), a suitable algorithms (e.g, Kabirian A and B transformation methods) is neccesary to transform these nominal data to a logically numerical sequences.

\subsection{Qualitative Data}

Qualities such as response rating or ranking scores, colors, and other forms of descriptions, can be compared by Optinalysis provided there have a clearly defined sequence order within or/and between them. The sequence order can be a theoretically established or based on the rating or ranking scale used.

\subsection{Kabirian (A) Algorithmic Transformation}

This involved the use of binormial codes to convert nominal data sequence of vaiables or attributs, in an unclustered or clustered form, into a logical and numerical sequence based on Kabirian (A) algorithmic score. In this algorithmic approach, 0, 1, -1 are used to express reflective or corresponding pairwise matching, mismatching and gaping between two contracting attributes or variables. Two methods works with this algorithm. These are:

\subsection{Unclustering}

It is $\mathrm{s}$ a plain matching, mismatching and gaping reflective correspondence between the aggregate elements of the two pairwise sequences. In this case, each sequence element is compared to its corresponding pair to assign a score that express their matchness, mismatchness and gapness. Reflective Unclustered Match-mismatch-gab Approach (RUMMG-(io)A) is used to describe this technique (Table 2). It aim to inegrate a measure of how much of the sequnce elements matched, mismatched, and gabbed with respect to an organized unclustered sequence order. Table 2 Provided an illustration of how the algorithm works.

Table 1: Algorithm of Reflective Unclustered Match-mismatch-gab Appraoach

\begin{tabular}{llllll}
\hline & Example & \multicolumn{5}{l}{ Scoring } \\
\hline Pairewise & Query Seq. & Reflector Seq & Query Seq. & Reflector Seq & Optinalysis \\
\hline Match & A & A & 1 & 1 & $1.00(100 \%)$ \\
Mismatch & A & G & 1 & 0 & $2.00(0 \%)$ \\
Abberative gab & A & - & 1 & -1 & $0(-100 \%)$ \\
Abberative gab & - & A & -1 & 1 & $0(-100 \%)$ \\
Abberative gab & - & - & -1 & -1 & $1.00(100 \%)$ \\
Non-abberative gab & $\#$ & $\#$ & 0 & 0 & $1.00( \pm 100 \%)$ \\
\hline
\end{tabular}

\subsection{Clustering}

Refers to the associating two or more sequence elements into a one meaningful unit, or cluster, or group. Asteric sign (*) is used to separate between clusters. Within each cluster in consideration, a single or combination of more than one attributes (these attributes are: match, mismatch, or gap) can be observed. Those clusters with only one, only two, and only three attributes are called unimorphic, dimorphic (bimorphic), and trimorphic clusters respectively. The dimorphic and trimorphic clusters form the polymorphic clusters. A polymorphic clusters are judge or ruled during Kabiran algorithmic transformation by reflective clustered matchmismatch-gab appraoach using two resolution types.

Type I Resolution Rule: Where match, mismatch, and gab exist in a give cluster relative to its pairewise, the resultant score for that particular cluster should be resolved by gab rule; if not gab, then by mismatch rule; if none of these two events, then is a match and by match rule. 
OPTINALYSIS

Type II Resolution Rule: Where match, mismatch, and gab exist in a give cluster relative to its pairwise, the resultant score for that particular cluster should be resolved by mismatch rule; if mismatch, then by gab rule; if none of these two events, then is a match and by match rule.

Reflective Cluster Match-mismatch-gab-(io) Approach (RCMMG-(io) is usd to describe this technique (Table 2). It aim to inegrate a measure of how much of the sequnce elements matched, mismatched, and gabbed with respect to an organized clustered sequence order. In an alternative consideration, Reflective Cluster Match-mismatch-gab-(nio) Approach (RCMMG(nio) can be used (Table 3). It also aim to inegrate a measure of how much of the sequnce elements matched, mismatched, and gabbed without respect to an organized cluster sequence order. Table 3 provided an illustrative examples.

Table 2: Algorithm of Reflective Cluster Match-mismatch-gab-(io) Appraoach

\begin{tabular}{|c|c|c|c|c|c|}
\hline & Example & & Scoring & & \\
\hline Pairewise & Query Seq. & Reflector Seq. & Query Seq. & Reflector Seq. & Optinalysis \\
\hline Match & $* \mathrm{ATC}^{*}$ & $*$ ATC* & 1 & 1 & $1.00(100 \%)$ \\
\hline Mismatch & *ATC* & $\begin{array}{l}* \mathrm{ACT} * / * \mathrm{TCA}^{*} / * \mathrm{CTA}^{*} / \\
* \mathrm{AGC} * / * \mathrm{GTC}^{*} / * \mathrm{AAT}^{*}\end{array}$ & 1 & 0 & $2.00(0 \%)$ \\
\hline Abberative gab & $* \mathrm{ATC}^{*}$ & $\begin{array}{l}*_{-}-*^{*} / * \text { - } \mathrm{TC} * / * \mathrm{~A}-\mathrm{C} * / \\
* \mathrm{AT}-* / * \mathrm{AC}-* / * \mathrm{TC}-*\end{array}$ & 1 & $-1 * *$ OR $0 * *$ & $0(-100 \%)$ \\
\hline Abberative gab & $\begin{array}{l}* \text { - - } * / * \text { - TC } * / * \mathrm{~A}-\mathrm{C} * / \\
* \mathrm{AT}-* / * \mathrm{AC}-* / * \mathrm{TC}-*\end{array}$ & $*$ ATC $*$ & $-1 * *$ OR $0 * *$ & 1 & $0(-100 \%)$ \\
\hline Abberative gab & $\begin{array}{l}*_{-}-*^{*} / * \text { - TC } * / * \mathrm{~A}-\mathrm{C} * / \\
* \mathrm{AT}-* / * \mathrm{AC}-* / * \mathrm{TC}-\end{array}$ & $\begin{array}{l}*_{-}-*^{*} / * \text { - } \mathrm{TC} * / * \mathrm{~A}-\mathrm{C} * / \\
* \mathrm{AT}-* / * \mathrm{AC}-* / * \mathrm{TC}-*\end{array}$ & $-1 * *$ OR $0 * *$ & $-1 * *$ OR $0 * *$ & $1.00(100 \%)$ \\
\hline Non-abberative gab & /\#\#\#/ & /\#\#\#/ & 0 & 0 & $1.00( \pm 100 \%)$ \\
\hline
\end{tabular}

Table 3: Algorithm of Reflective Cluster Match-mismatch-gab-(nio) Appraoach

\begin{tabular}{|c|c|c|c|c|c|}
\hline & Example & & Scoring & & \\
\hline Pairewise & Query Seq. & Reflector Seq. & Query Seq. & $\begin{array}{l}\text { Reflector } \\
\text { Seq. }\end{array}$ & Optinalysis \\
\hline Match & $* \mathrm{ATC} *$ & $* \mathrm{ATC} * / * \mathrm{ACT}^{*} / * \mathrm{TCA}^{*} / * \mathrm{CT} *$ & 1 & 1 & $1.00(100 \%)$ \\
\hline Mismatch & $* \mathrm{ATC} *$ & $* \mathrm{AGC} * / * \mathrm{GTC} * / * \mathrm{AAT}^{*}$ & 1 & 0 & $2.00(0 \%)$ \\
\hline Abberative gab & *ATC* & $\begin{array}{l}* *_{-}-* / *-\mathrm{TC} * / * \mathrm{~A}-\mathrm{C} * / \\
* \mathrm{AT}-* / * \mathrm{AC}-* / * \mathrm{TC}-*\end{array}$ & 1 & $-1 * *$ OR $0 * *$ & $0(-100 \%)$ \\
\hline Abberative gab & $\begin{array}{l}* *_{-}-* / *-\mathrm{TC} * / * \mathrm{~A}-\mathrm{C} * / \\
* \mathrm{AT}-* / * \mathrm{AC}-* / * \mathrm{TC}-*\end{array}$ & $*$ ATC* & $\begin{array}{l}-1 * * \\
0 * *\end{array}$ & 1 & $0(-100 \%)$ \\
\hline Abberative gab & $\begin{array}{l}*_{-}--* / * \text { - TC } * / * \mathrm{~A}-\mathrm{C} * / \\
* \mathrm{AT}-* / * \mathrm{AC}-* / * \mathrm{TC}-\end{array}$ & $\begin{array}{l}*_{-}-*^{*} / * \text { - } \mathrm{TC} * / * \mathrm{~A}-\mathrm{C} * / \\
* \mathrm{AT}-* / * \mathrm{AC}-* / * \mathrm{TC}-*\end{array}$ & $\begin{array}{l}-1 * * \\
0 * *\end{array}$ & $-1 * *$ OR $0 * *$ & $1.00(100 \%)$ \\
\hline $\begin{array}{l}\text { Non-abberative } \\
\text { gab }\end{array}$ & /\#\#\#/ & /\#\#\#/ & 0 & 0 & $\begin{array}{l}1.00 \\
( \pm 100 \%)\end{array}$ \\
\hline
\end{tabular}

\subsection{Kabirian (B) Algorithmic Transformation}

This method involve counting the frquency of matched, or mismatched or gapped elements of a clustered sequences as it is compared in pairwise manner. Seven techniques works with this algorithm. These are:

i. Reflective Cluster Match-(io) Frequency Approach (RCM-(io)FA): Estimates how much of the sequence elements are conserved with respect to an organized cluster sequence order. Illustrative examples are in Table 4.

ii. Reflective Cluster Match-(nio) Frequency Approach (RCM-(nio)FA): Estimates how much of the sequence elements are conserved without respect to an organized cluster sequence order. Illustrative examples are in Table 5. 


\section{OPTINALYSIS}

iii. Reflective Cluster Mismatch-(io) Frequency Approach (RCMm-(io)FA): Estimates how much of the sequence elements are abberated or abnormal by inversion or translocation with respect to an organized cluster sequence order. Illustrative examples are in Table 4.

iv. Reflective Cluster Mismatch-(nio) Frequency Approach (RCMm-(nio)FA) Estimates how much of the sequence elements are abberated or abnormal by inversion or translocation without respect to an organized sequence order. Illustrative examples are in Table 5.

v. Reflective Cluster Gab-(io) Frequency Approach (RCG-(io)FA): Estimates how much of the sequence elements are abberated or abnormal by deletion or omission, addition or duplication with respect to an organized cluster sequence order. Illustrative examples are in Table 4.

vi. Reflective Cluster Gab-(nio) Frequency Approach (RCG-(nio)FA): Estimates how much of the sequence elements are abberated or abnormal by deletion or omission without respect to an organized cluster sequence order. Illustrative examples are in Table 5.

vii. Standard Score Approach (SSA): Estimates how much of the sequence elements are similar or equivalent by a given standard scores. Illustrative examples are in Table 6.

Note that, other methods of identity search considered the whole sequence as a cluster not in order, to genetate match, mismatch and gab scores. This modalities and rule distinguishes these approach overs the other well-known and adopted methods. The former works when the sequences are aligned and the later ignore sequence alignment. For each pairewise elements, a score is assigned using the rules in Table 4 and 5.

Table 4: Algorithm of Reflective Cluster Match-(io), Mismatch-(io), Gab-(io) Frequency Appraoach

\begin{tabular}{|c|c|c|c|c|}
\hline \multicolumn{3}{|c|}{ Example } & \multicolumn{2}{|l|}{ Scoring } \\
\hline Pairewise & $\begin{array}{l}\text { Query } \\
\text { Seq. }\end{array}$ & Reflector Seq. & $\begin{array}{l}\text { Query } \\
\text { Seq. }\end{array}$ & Reflector Seq. \\
\hline Match-(io) & *ATC* & 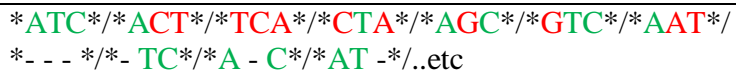 & 3 & $3 / 1 / 0 / 1 / 2 / 2 / 1 / 0 / 2 / 2 / 2$ \\
\hline Mismatch-(io) & *ATC* & $\begin{array}{l}* \mathrm{ATC} * / * \mathrm{ACT} * / * \mathrm{TCA} * / * \mathrm{CTA} * / * \mathrm{AGC} * / * \mathrm{GTC} * / * \mathrm{AAT} * / \\
* \_ \text {- - */*_ } \mathrm{TC} * / * \mathrm{~A}-\mathrm{C} * / * \mathrm{AT}-* / . . \text { etc }\end{array}$ & 3 & $0 / 2 / 3 / 2 / 1 / 1 / 2 / 0 / 0 / 0 / 0$ \\
\hline Gab-(io) & *ATC* & $\begin{array}{l}* \mathrm{ATC} * / * \mathrm{ACT} * / * \mathrm{TCA} * / * \mathrm{CTA} * / * \mathrm{AGC} * / * \mathrm{GTC} * / * \mathrm{AAT}^{*} / \\
* \_ \text {- - */*_ } \mathrm{TC} * / * \mathrm{~A}-\mathrm{C} * / * \mathrm{AT}-* / . . \text { etc }\end{array}$ & 3 & $0 / 0 / 0 / 0 / 1 / 0 / 0 / 3 / 1 / 1 / 1$ \\
\hline Match-(io) & *AT -* & $\begin{array}{l}* \mathrm{ATC} * / * \mathrm{ACT} * / * \mathrm{TCA}^{*} / * \mathrm{CTA} * / * \mathrm{AGC} * / * \mathrm{GTC} * / * \mathrm{AAT}^{*} / \\
* \ldots \text { _ - } * / * \text { - } \mathrm{TC} * / * \mathrm{~A}-\mathrm{C} * / * \mathrm{AT}-* / . . \text { etc }\end{array}$ & 3 & $2 / 1 / 0 / 1 / 1 / 1 / 1 / 1 / 1 / 1 / 2$ \\
\hline Mismatch-(io) & $* \mathrm{AT}-*$ & $\begin{array}{l}* \mathrm{ATC} * / * \mathrm{ACT}^{*} / * \mathrm{TCA} * / * \mathrm{CTA} * / * \mathrm{AGC} * / * \mathrm{GTC} * / * \mathrm{AAT}^{*} / \\
* \ldots \text { _ - * } / * \text { - } \mathrm{TC} * / * \mathrm{~A}-\mathrm{C} * / * \mathrm{AT}-* / . . \mathrm{etc}\end{array}$ & 3 & $1 / 2 / 3 / 2 / 2 / 2 / 2 / 0 / 1 / 1 / 0$ \\
\hline Gab-(io) & $* \mathrm{AT}-*$ & $\begin{array}{l}* \mathrm{ATC} * / * \mathrm{ACT} * / * \mathrm{TCA} * / * \mathrm{CTA} * / * \mathrm{AGC} * / * \mathrm{GTC} * * \mathrm{AAT}^{*} / \\
* \ldots \text { - - * } * * \text { - } \mathrm{TC} * / * \mathrm{~A}-\mathrm{C} * / * \mathrm{AT}-* / . . \mathrm{etc}\end{array}$ & 3 & $0 / 0 / 0 / 0 / 0 / 0 / 0 / 2 / 1 / 1 / 1$ \\
\hline
\end{tabular}


OPTINALYSIS

Table 5: Algorithm of Reflective Cluster Match-(nio), Mismatch-(nio), Gab-(nio) Frequency Appraoach

\begin{tabular}{|c|c|c|c|c|}
\hline & Exampl & & Scoring & \\
\hline Pairewise & $\begin{array}{l}\text { Query } \\
\text { Seq. }\end{array}$ & Reflector Seq. & $\begin{array}{l}\text { Query } \\
\text { Seq. }\end{array}$ & Reflector Seq. \\
\hline Match-(nio) & *ATC* & 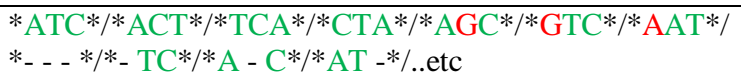 & 3 & $3 / 3 / 3 / 3 / 2 / 2 / 2 / 0 / 2 / 2 / 2$ \\
\hline Mismatch-(nio) & *ATC* & $\begin{array}{l}* \mathrm{ATC}^{*} / * \mathrm{ACT} * / * \mathrm{TCA}^{*} / * \mathrm{CTA} * / * \mathrm{AGC} * / * \mathrm{GTC} * * \mathrm{AAT}^{*} / \\
* \ldots \text { _ - } * / * \text { - } \mathrm{TC} * / * \mathrm{~A}-\mathrm{C} * / * \mathrm{AT}-* / . . \text { etc }\end{array}$ & 3 & $0 / 0 / 0 / 0 / 1 / 1 / 1 / 0 / 0 / 0 / 0$ \\
\hline Gab-(nio) & *ATC* & $\begin{array}{l}* \mathrm{ATC} * * \mathrm{ACT}^{*} / * \mathrm{TCA}^{*} / * \mathrm{CTA} * / * \mathrm{AGC} * / * \mathrm{GTC} * * \mathrm{AAT}^{*} / \\
* \text { _ - - */*- } \mathrm{TC} * * \mathrm{~A}-\mathrm{C} * / * \mathrm{AT}-* / . . \text { etc }\end{array}$ & 3 & $0 / 0 / 0 / 0 / 0 / 0 / 0 / 3 / 1 / 1 / 1$ \\
\hline Match-(nio) & *AT -* & $\begin{array}{l}* \mathrm{ATC} * / * \mathrm{ACT}^{*} / * \mathrm{TCA}^{*} / * \mathrm{CTA} * / * \mathrm{AGC} * / * \mathrm{GTC} * * \mathrm{AAT}^{*} / \\
*{ }_{\text {_ }} \text { - } * / * \text { - } \mathrm{TC} * / * \mathrm{~A}-\mathrm{C} * / * \mathrm{AT}-* / . . \text { etc }\end{array}$ & 3 & $2 / 2 / 2 / 2 / 1 / 1 / 2 / 1 / 2 / 2 / 3$ \\
\hline Mismatch-(nio) & *AT -* & $\begin{array}{l}* \mathrm{ATC} * / * \mathrm{ACT} * / * \mathrm{TCA}^{*} / * \mathrm{CTA} * / * \mathrm{AGC} * / * \mathrm{GTC} * / * \mathrm{AAT} * / \\
* \ldots \text { _ } * / * \text { - } \mathrm{TC} * / * \mathrm{~A}-\mathrm{C} * / * \mathrm{AT}-* / . . \text { etc }\end{array}$ & 3 & $1 / 1 / 1 / 1 / 2 / 2 / 1 / 0 / 1 / 1 / 0$ \\
\hline Gab-(nio) & *AT -* & $\begin{array}{l}* \mathrm{ATC} * / * \mathrm{ACT} * / * \mathrm{TCA}^{*} / * \mathrm{CTA} * / * \mathrm{AGC} * / * \mathrm{GTC} * / * \mathrm{AAT} * / \\
* \text { _ _ } * / * \text { - } \mathrm{TC} * / * \mathrm{~A}-\mathrm{C} * / * \mathrm{AT}-* / . . \text { etc }\end{array}$ & 3 & $0 / 0 / 0 / 0 / 0 / 0 / 0 / 2 / 0 / 0 / 0$ \\
\hline
\end{tabular}

Table 5: Molecular Mass Score Approach

\begin{tabular}{|c|c|c|}
\hline DNA Bases and Gabs & Molecular Mass Score Approach & Remarks \\
\hline Adenine $(\mathrm{A})$ & $\approx 135 \mathrm{~g} / \mathrm{mol}$ & \\
\hline Tymine $(\mathrm{T})$ & $\approx 126 \mathrm{~g} / \mathrm{mol}$ & \\
\hline Cytosine (C) & $\approx 111 \mathrm{~g} / \mathrm{mol}$ & \\
\hline Guinine (G) & $\approx 151 \mathrm{~g} / \mathrm{mol}$ & \\
\hline Uracil (U) & $\approx 112 \mathrm{~g} / \mathrm{mol}$ & \\
\hline All other Gabs & 0 & \\
\hline
\end{tabular}

Note: Ranking is based on molecular mass of the nitrogen bases.

\subsection{Unification}

During Kabirian (B) algorithmic transformation, clusters may have unequal number of elements, called ambiguous clusters (Seen Table 7 and its application in word semantics in section 22.6). These ambiguous clusters result to an ambiguous and unjustified results. To solve this transformation barrier, a technique called Unification is introduced to resolve only those ambiguous clusters by deliberate addition of a neutral effect to the similarity (match) attribute. Non-abberative gaps, symbolized by ' $\#$ ' is used pairwisely in each of the affected and ambiguous clusters.

Table 7: Unification of ambiguous clusters

\begin{tabular}{|l|l|l|l|}
\hline Example & Sequence & No. of elements in each cluster & Remarks \\
\hline Sequence I & Psy*cho*lo*gy & $3 * 3 * 2 * 2$ & Unequal clusters setting \\
\hline Sequence II & Bio*in*for*ma*tics & $3 * 2 * 3 * 2 * 4$ & Unequal clusters setting \\
\hline Sequence I & Psy*cho*lo\#*gy\# & $3 * 3 * 3 * 3$ & Unified clusters \\
\hline Sequence II & Bio\#*in\#\#*for\#*ma\#\#tics & $4 * 4 * 4 * 4 * 4$ & Unified clusters \\
\hline
\end{tabular}

\subsection{Selecting an Appropriate Sequence Order for the Data Set \\ 5.1 Theoretical Order}

The order is based on the geometrical orientations, or theoretical explanations or natural phenomena. For instance, nucleotide base and amino acid sequences, systematic numbering of shape landmark coordinates, socio-demographic hierarchies established by Abdullahi (2019b), chemical concentrations, rating and ranking response descriptors are some examples. In this 
OPTINALYSIS

case, the position and pattern orientation of each element of the attribute is preserve and kept in its natural order. This is important for geometrical and geostatistical Optinalysis.

\subsection{Ascending/descending Order}

The position and pattern orientation of all elements or group of elements of the sequence is reorganized in ascending or descending order. It disregards the inherent sequence of the data set. This is important for geostatistical and statistical Optinalysis.

5.2.1 Ascend/descend within: the reorganization is within each group or data set (replicates or repeated measurements) of elements of the comparing sequences, but the inherent order between the variables are conserved. Thus, it only disregards the inherent sequence within the data set. This is mainly important for geometrical and geostatistical Optinalysis that involved replications or repeated measurements of observation. It is called type (I) geometrical or geostatistical Optinalysis if ascending order is chosen, while it is called type (II) geometrical or geostatistical Optinalysis if descending order is used.

5.2.2 Ascend/descend between: the reorganization is within and between all the elements of the comparing sequences, with or without a replications or repeated measurements. It disregards the inherent sequence within and between the data set. This is important for statistical Optinalysis. It is called type (I) statistical Optinalysis if ascending order is chosen, while it is called type (II) statistical Optinalysis if descending order is used.

\subsection{Acquiring the Symmetry Groups (Landmarks) Based on Geometrical Scale.}

For a any data to fit the requirements for Geometrical and Geostatistical Optinalysis, the landmarks has to be in a geometrical scale (the scale invariant format). A geometrical scale is uniform point measurement (without variation due to graphic scaling effect) from the left to right, from the upper to lower points of the selected landmarks about a symmetrical line/plane. Two (2) types of geometrical scaling, namely positive and negative geometrical scaling, were indentified to be fit for geometric Optinalysis. A uniform geometric scaling can be acquired on any geometrical coordinate graphs such as Bookstein and Procrustes landmark coordinates if the axes are scale edited to a uniform vector. Note that, any edited axis can bear either a positive or a negative integer. Figures 3-8 are the graphical illustration of each geometrical scale type.

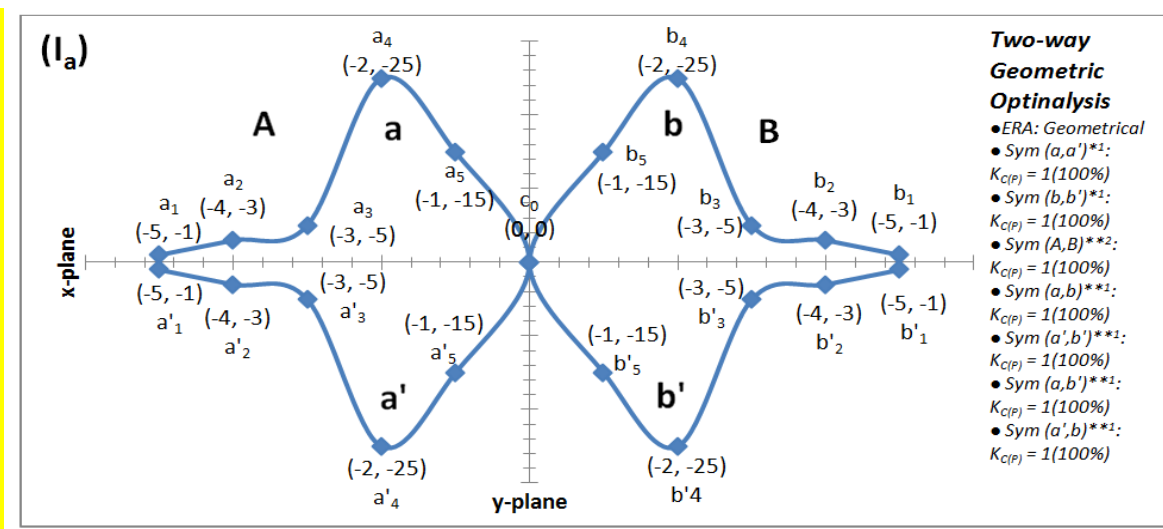

*Symmetry of same lettered correspondence expresses intrametric symmetry

**Symmetry of different lettered correspondence expresses intermetric symmetry

${ }^{1}$ Horizontal numbering style

${ }^{2}$ Vertical numbering style

Figure 3: Shows negative geometrical scaling 


\section{OPTINALYSIS}

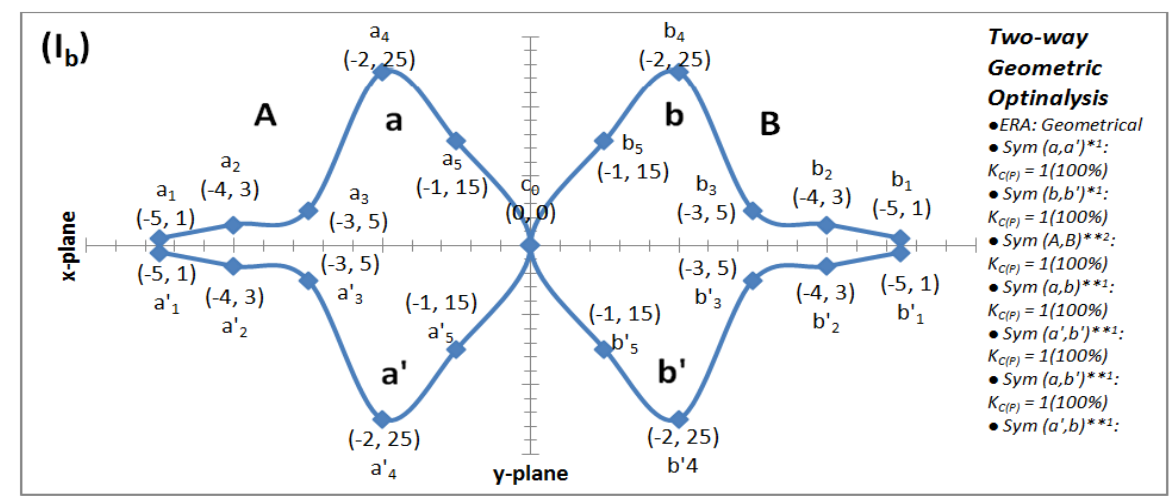

*Symmetry of same lettered correspondence expresses intrametric symmetry

**Symmetry of different lettered correspondence expresses intermetric symmetry

${ }^{1}$ Horizontal numbering style

${ }^{2}$ Vertical numbering style

Figure 4: Shows negative geometrical scaling

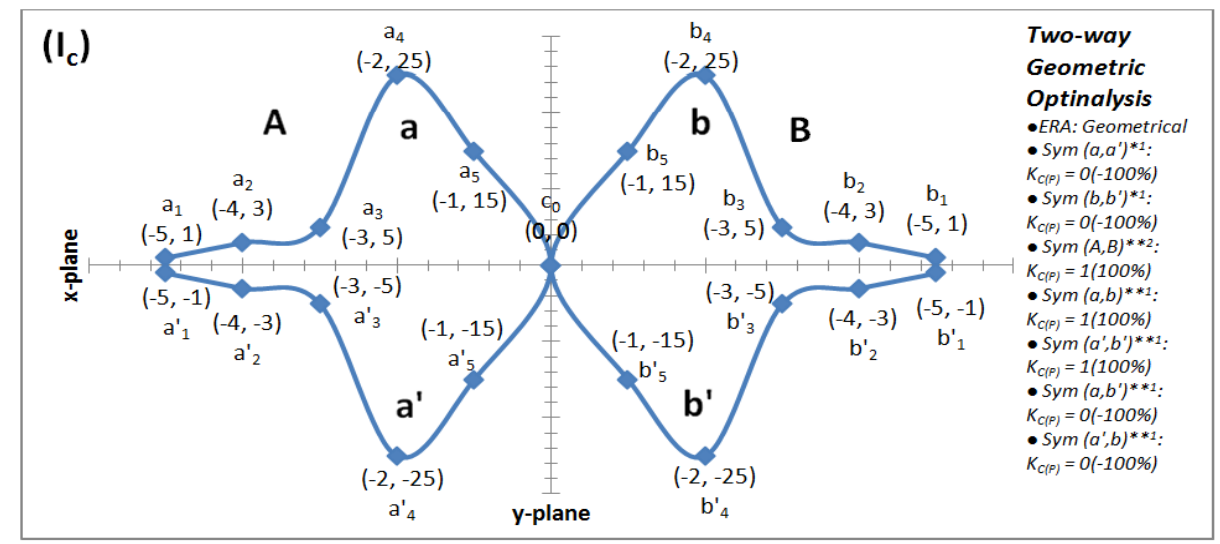

*Symmetry of same lettered correspondence expresses intrametric symmetry

**Symmetry of different lettered correspondence expresses intermetric symmetry

${ }^{1}$ Horizontal numbering style

${ }^{2}$ Vertical numbering style

Figure 5: Shows negative geometrical scaling

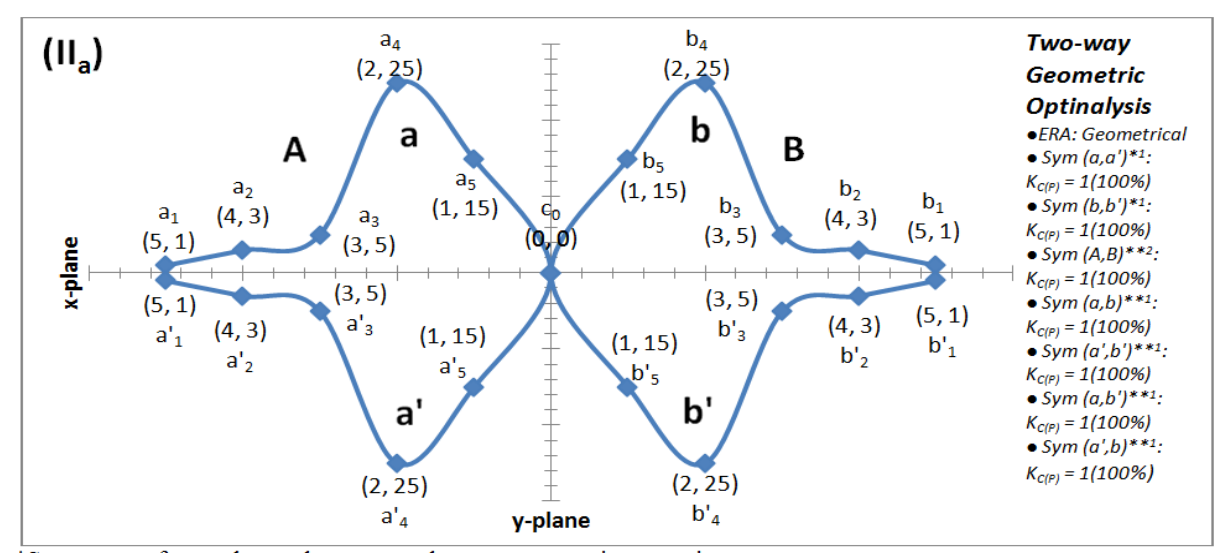

*Symmetry of same lettered correspondence expresses intrametric symmetry

**Symmetry of different lettered correspondence expresses intermetric symmetry

${ }^{1}$ Horizontal numbering style

${ }^{2}$ Vertical numbering style

Figure 6: Shows positive geometrical scaling 


\section{OPTINALYSIS}

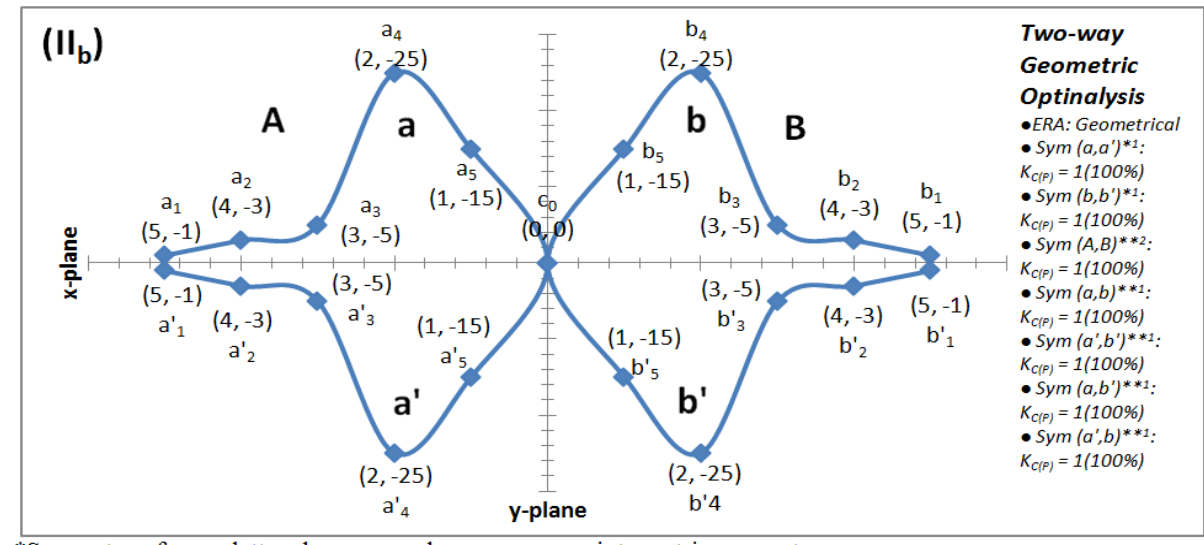

*Symmetry of same lettered correspondence expresses intrametric symmetry

**Symmetry of different lettered correspondence expresses intermetric symmetry

${ }^{1}$ Horizontal numbering style

${ }^{2}$ Vertical numbering style

Figure 7: Shows positive geometrical scaling

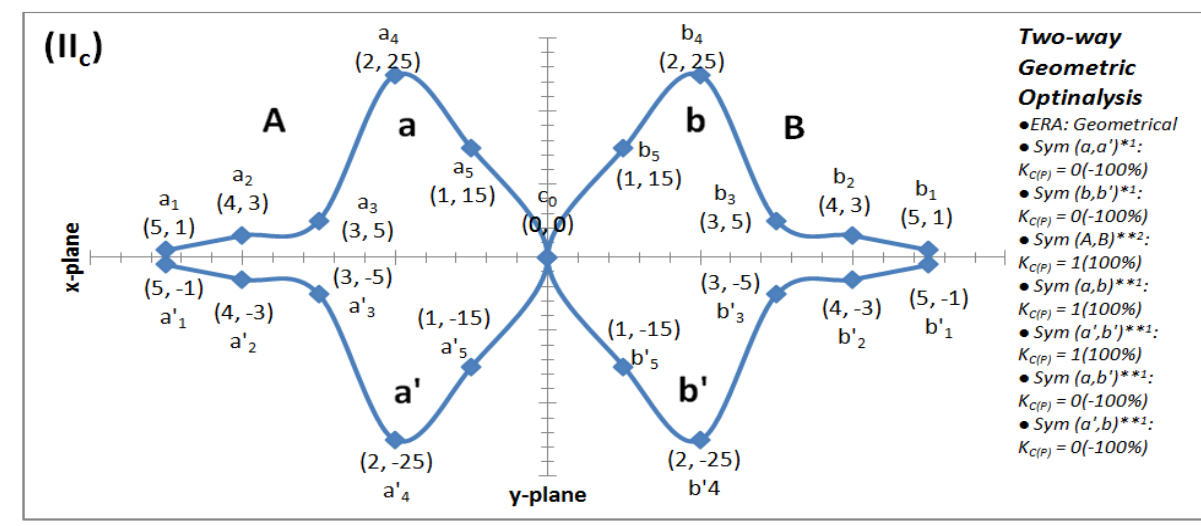

*Symmetry of same lettered correspondence expresses intrametric symmetry

**Symmetry of different lettered correspondence expresses intermetric symmetry

${ }^{1}$ Horizontal numbering style

${ }^{2}$ Vertical numbering style

Figure 8: Shows positive geometrical scaling

\subsection{Numbering of Symmetry Groups (Landmarks)}

The choice of appropriate numbering style is crucial way of designing how elements of the data set pairewisely corresponds and reflects. The numbering style also guide what plane (axis) of symmetry are the elements reflects. Here are some styles of landmark numbering.

\subsection{Methods of Landmark Numbering and Reflection about an Axis}

Where geometrical and geostatistical symmetry detection involves the use of symmetry groups/points/landmarks, a systematic numbering style is essential for the establishment of a clear sequence structure and a distinct 'head' and 'tail'. A clearly defined 'head' and 'tail' points allow for appropriate sequence pairing. And a clearly defined systematic numbering tells what planes are the sequences elements are designed to reflect about and also associate the functional relationship within and between the main elements and the co-elements. Vertical and horizontal numberings all express symmetry about x-plane, y-plane and z-plane, and are suitable for intrametric and intermetric symmetry detection by geometric Optinalysis. While the cyclic numbering express symmetry about z-plane and are more suitable for intermetric geometric 
OPTINALYSIS

Optinalysis. Three (3) different numbering styles were identified and demonstrated in Figures 913.

7.1.1 Horizontal numbering: In this style, the numbering of elements starts from the left to the right, or from the right to the left. Where two or more elements lies tangent to the moving direction, those elements most away the symmetrical plane are prioritized over those most closer to the symmetrical plane in consideration. Figure 9 provided examples of horizontal numbering for intermetric Optinalysis.

7.1.2 Vertical numbering: In this style, the numbering of elements starts from the upper to the lower or from the lower to the upper once. Where two or more elements lies tangent to the moving direction, those elements most away the symmetrical plane are prioritized over those most closer to the symmetrical plane in consideration. Figures 10 and 11 provided examples of vertical numbering example for intermetric Optinalysis

7.1.3 Cyclic numbering: In this style, the numbering of elements starts from any point/side (e.g, left, right, upper, or lower) and moving in clockwise or anti-clockwise direction. Where two or more elements lies tangent to the moving direction, those elements most away the symmetrical plane are prioritized over those most closer to the symmetrical plane in consideration. Figures 12 and 13 provided examples of cyclic numbering for intermetric Optinalysis.

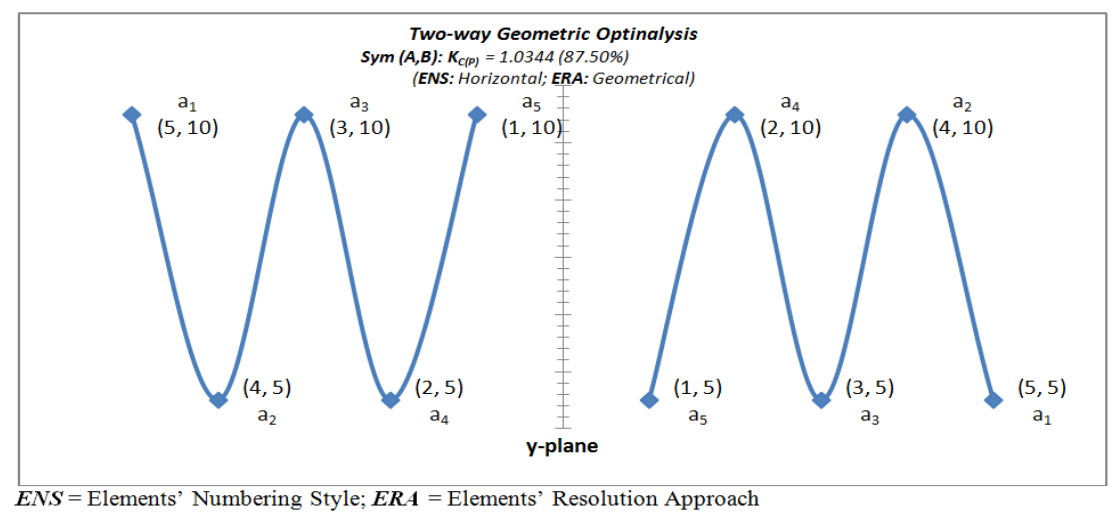

Figure 9: Shows an intermetric symmetry between A and B structures about y-plane. The numbering style is horizontal

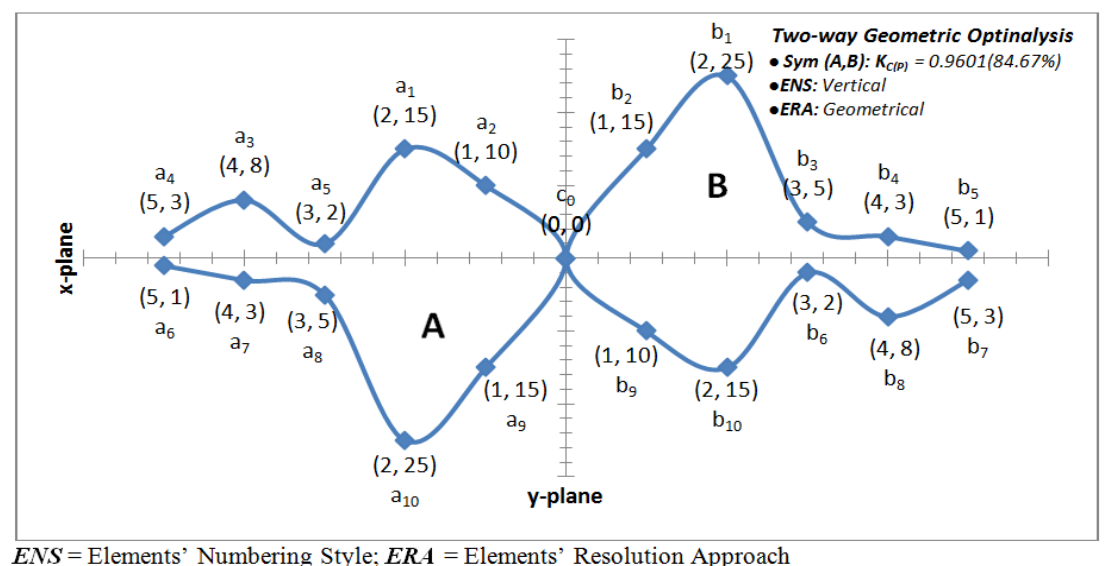

ENS = Elements' Numbering Style; $\boldsymbol{E R A}=$ Elements' Resolution Approach

Figure 10: Shows an intermetric symmetry between A and B structures about y-plane. The numbering style is vertical. 


\section{OPTINALYSIS}

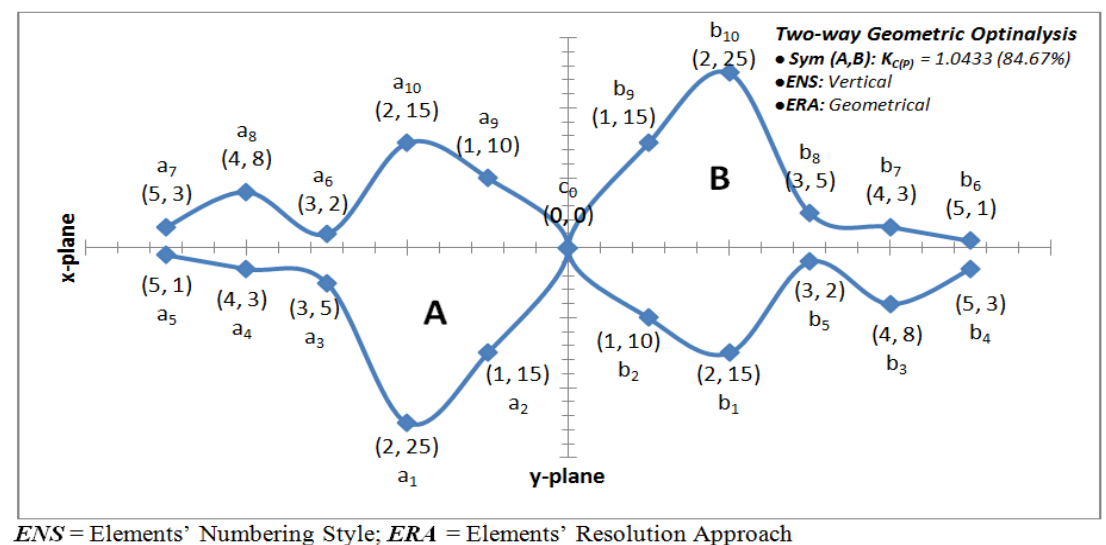

Figure 11: Shows an intermetric symmetry between A and B structures about y-plane. The numbering style is vertical.

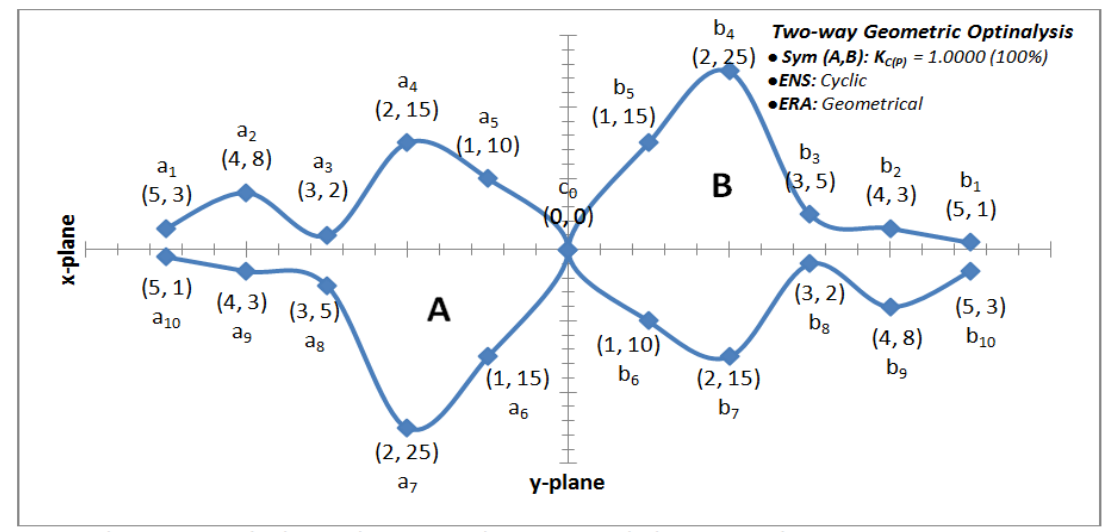

$\boldsymbol{E N S}=$ Elements' Numbering Style; $\boldsymbol{E R \boldsymbol { A }}=$ Elements' Resolution Approach

Figure 12: Shows an intermetric symmetry between A and B structures about y-plane. The numbering style is cyclic, moving in clockwise and in the other hand anti-clockwise directions about an X-plane.

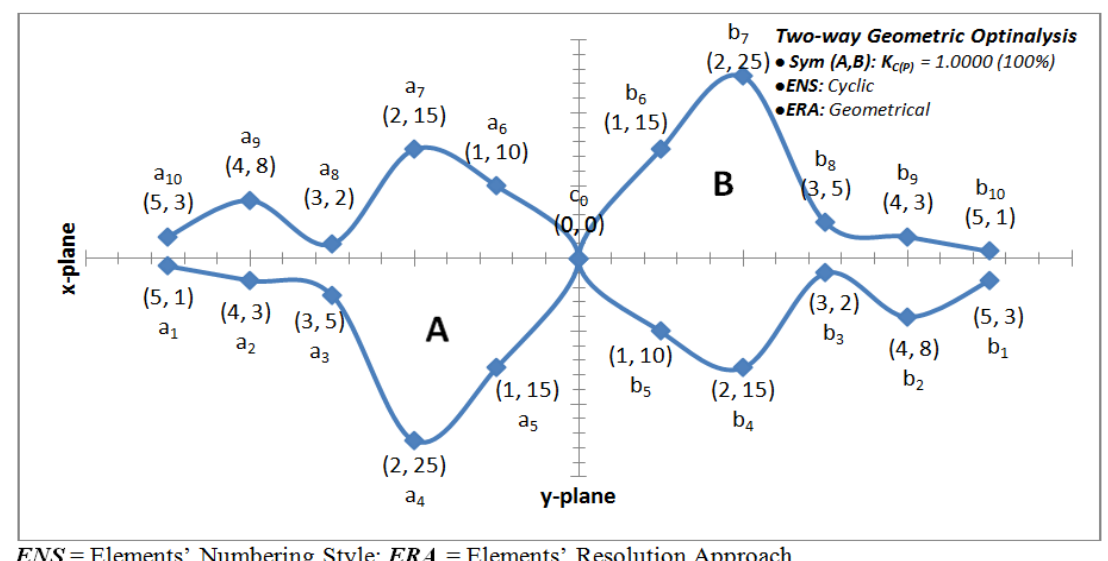

Figure 13: Shows an intermetric symmetry between A and B structures about z-plane. The numbering style is cyclic, moving in clockwise and in the other hand anti-clockwise directions about an X-plane. 
OPTINALYSIS

\subsection{Pairing Styles}

Pairing style tells us how the sequences of two intermetric elements pairewisely reflect. A pairwised sequences symmetry can be detected on different pairing style. The choice of appropriate pairing style depends on the consideration made on where (i.e, beginning or end of the sequence elements) should be more sensitive to any imbalances/changes or otherwise. Pericentral rotation and numbering style can help achieve a desired sequence pairing. Here are the styles in symmetry detection.

8.1 Head-to-head Pairing (H-H): one ends of the two pairing sequences called the head (the start point) are both allowed to be on the most sensitive node. Pericentral E-rotation can help achieve this sequence pairing.

$$
\bigwedge_{W \text { or } B}^{( \pm N)}:
$$

8.2 Tail-to-tail Pairing (T-T): one ends of the two pairing sequences called the tail (the end point) are both allowed to be on the most sensitive node. Pericentral E-rotation can help achieve this sequence pairing.

$$
\bigvee_{( \pm N)}^{W \text { or }}{ }^{B}
$$

8.3 Head-to-tail Pairing (H-T) or Tail-to-head Pairing (T-H): one of the ends of the two pairing sequences called the head or tail (the start or end point) is allowed to be on the most sensitive node and other on the less sensitive node. Pericentral S-rotation can help achieve this sequence pairing.

\subsection{Sensitivity points}

Sensitivity point is any node that when considered a variable can exert a certain degree of imbalances in the distribution of elements (variables) about a dividing line or plane. Each node has its own unique characteristic sensitivity which increases away from the central node and decreases towards the central node(s). Sensitivity of a point generally decreased with increase in sequence elements. Figure 14 is an illustrative example.

The nodes with components $R_{1}, D_{3}, a_{1}$ and $R_{7}, D_{3}, b_{1}$ are the most sensitive points of the upper and lower stems respectively. The node with components $\mathrm{R}_{4} \mathrm{D}_{0} \mathrm{C}_{1}$ is the central node.

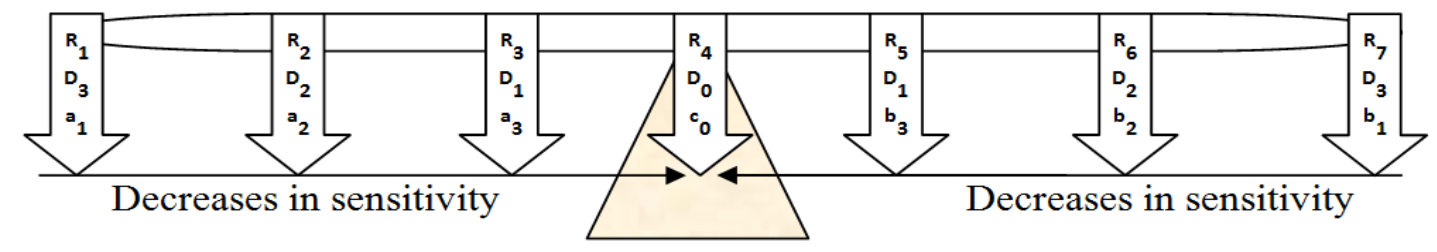

Note: $\mathbf{R}_{\mathbf{n}}=$ Quantitative scale; $\mathbf{D}_{\mathbf{n}}=$ Displacements; $\mathbf{a n}_{\mathbf{n}}$ and $\mathbf{b}_{\mathbf{n}}$ are paired variables/elements; $\mathbf{c}_{\mathbf{n}}=$ Central variable

Figure 14: Sensitivity points of sequence elements.

\subsection{Reflection and Moments}

All symmetrical structures reflect momentarily (i.e, in same moment or in same total moments) about a symmetrical plane/point. Reflection can be: (1) Normal reflection, characterized by a plane mirror reflection, equidistance reflection from the central node, (2) Rescaled reflection, characterized by the reduction in magnitude and increase in displacement or 


\section{OPTINALYSIS}

increase in magnitude and reduction in displacement. Normal reflection is what produces eusymmetric structures, while re-scaled reflection is what produces pseudo-symmetric structures. Eu-symmetrical entities reflects equidistance from the central node, plane mirror image of each other, the subject and the reflector sequences have the same moments about the symmetrical plane/axis, and geometrically and geostatistically stable to E-rotation. While pseudo-symmetrical entities do not reflects equidistance from the central node, spherical mirror image of each other, the subject and the reflector sequences also have the same moments about the symmetrical plane/axis, and are geometrically and geostatistically instable to E-rotation.

Reflection and moments are two companion mechanisms upon which the principle of Optinalysis operates.

If the query moment is equal to the reflector moment, then two comparing entities are geometrically, geostatistically and statistically symmetrical intrametrically.

$$
a_{n} \times D_{n}=a_{n}^{\prime} \times D_{n}
$$

And/or if the total query moments is equal to the total reflector moments, then two comparing entities are geometrically, geostatistically and statistically symmetrical intrametrically.

$$
\sum\left(a_{n} \times D_{n}\right)=\sum\left(a_{n \times}^{\prime} D_{n}\right)
$$

If the query moment is equal to the reflector moment, then two comparing entities are geometrically, geostatistically and statistically symmetrical intermetrically.

$$
a_{n} \times D_{n}=b_{n} \times D_{n}
$$

And/or the total query moments is equal to the total reflector moments, then two comparing entities are geometrically, geostatistically and statistically symmetrical intermetrically.

$$
\sum\left(a_{n} \times D_{n}\right)=\sum\left(b_{n} \times D_{n}\right)
$$

Suppose we refer to Figure 3 , we find that intrametrically (within the sequence elements), $a_{1}$ is normally reflected momentarily about x-plane as $a_{1}^{\prime}$ $a_{2}$ is normally reflected momentarily about x-plane as $a_{2}^{\prime}$ $a_{3}$ is normally reflected momentarily about x-plane as $a_{3}^{\prime}$ $a_{4}$ is normally reflected momentarily about x-plane as $a_{4}^{\prime}$ $a_{5}$ is normally reflected momentarily about x-plane as $a^{\prime}{ }_{5}$ $b_{1}$ is normally reflected momentarily about x-plane as $b_{1}^{\prime}$ $b_{2}$ is normally reflected momentarily about x-plane as $b^{\prime}{ }_{2}$ $b_{3}$ is normally reflected momentarily about x-plane as $b^{\prime}{ }_{3}$ $b_{4}$ is normally reflected momentarily about x-plane as $b^{\prime}{ }_{4}$ $b_{5}$ is normally reflected momentarily about x-plane as $b^{\prime}{ }_{5}$

And also intermetrically (between the sequence elements), $a_{1}$ is normally reflected momentarily about y-plane as $b_{1}$ $a_{2}$ is normally reflected momentarily about y-plane as $b_{2}$ $a_{3}$ is normally reflected momentarily about y-plane as $b_{3}$ $a_{4}$ is normally reflected momentarily about y-plane as $b_{4}$ $a_{5}$ is normally reflected momentarily about y-plane as $b_{5}$ $a_{1}^{\prime}$ is normally reflected momentarily about y-plane as $b_{1}^{\prime}$ $a_{2}^{\prime}$ is normally reflected momentarily about y-plane as $b^{\prime}{ }_{2}$ $a_{3}^{\prime}$ is normally reflected momentarily about y-plane as $b_{3}^{\prime}$ $a_{4}^{\prime}$ is normally reflected momentarily about y-plane as $b_{4}^{\prime}$ $a^{\prime}{ }_{5}$ is normally reflected momentarily about y-plane as $b^{\prime}{ }_{5}$ elements),

In another case in Figure 15, we can find that intrametrically (within the sequence 


\section{OPTINALYSIS}

$a_{1}$ is spherically reflected momentarily about y-plane as $a_{3}^{\prime}$ $a_{2}$ is spherically reflected momentarily about y-plane as $a_{4}^{\prime}$ $a_{3}$ is spherically reflected momentarily about y-plane as $a_{1}^{\prime}$ $a_{4}$ is spherically reflected momentarily about y-plane as $a_{2}^{\prime}$

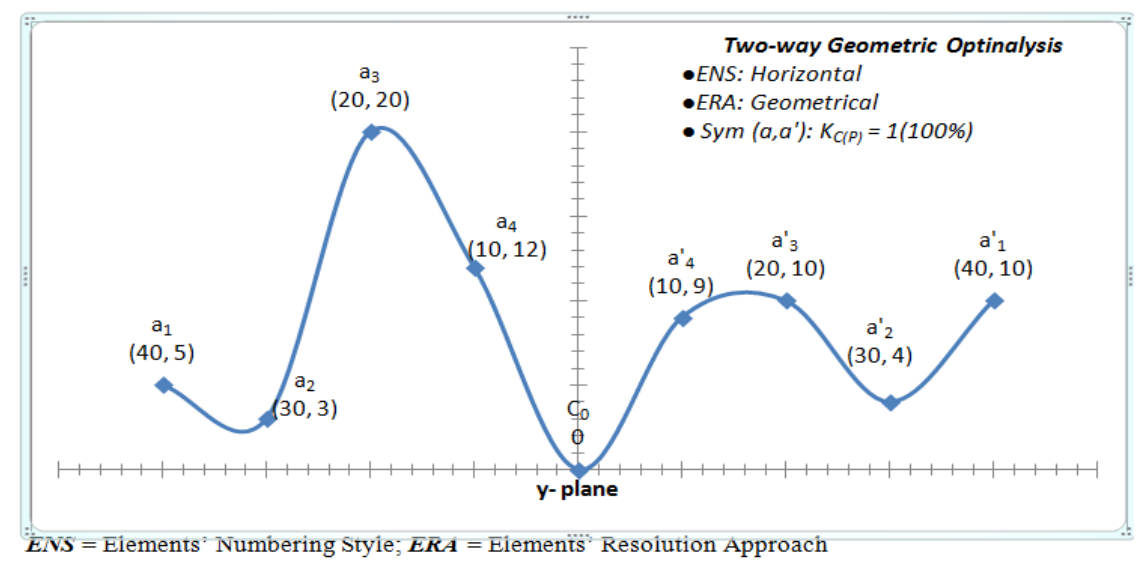

Figure 15: A pseudo-symmetrical distribution with a spherically reflected elements

\subsection{Planes/Axis of Symmetry and Reflection}

Elements of sequences can be reflective momentarily on $\mathrm{x}, \mathrm{y}$, and z planes.Mono-axial, bi-axial and tri-axial symmetry. On the basis of the number of planes a sequences elements can be symmetrically quantifies, three types of symmetry are recognized.

I. Mono-axial or mono-planal symmetry: An entity or structure is said to be mono-axial when it can only be quantified on one plane of symmetry. This symmetry characterizes bi-lateral objects.

II. Bi-axial or bi-planal symmetry: An entity or structure is said to be bi-axial when it can be quantified on two planes of symmetry. This symmetry characterizes radially symmetrical objects.

III. Tri-axial or tri-planal symmetry: An entity or structure is said to be tri-axial when it can be quantified on all the three planes of symmetry. This symmetry confirms the characterization of radially symmetrical objects.

\subsection{Rotation and stability (Rotational invariance)}

Rotational stability described the geometrically and geostatistically symmetric stability of a pattern or distribution of elements as the elements rotates $180^{\circ}$ around the central node (called the central or C-rotation) or the pericentral node (called the pericentral rotations).

Suppose we have a geometrical distribution in Figure 16, we shall see how it changes as a result of different kind of rotations about a symmetrical plane. 


\section{OPTINALYSIS}

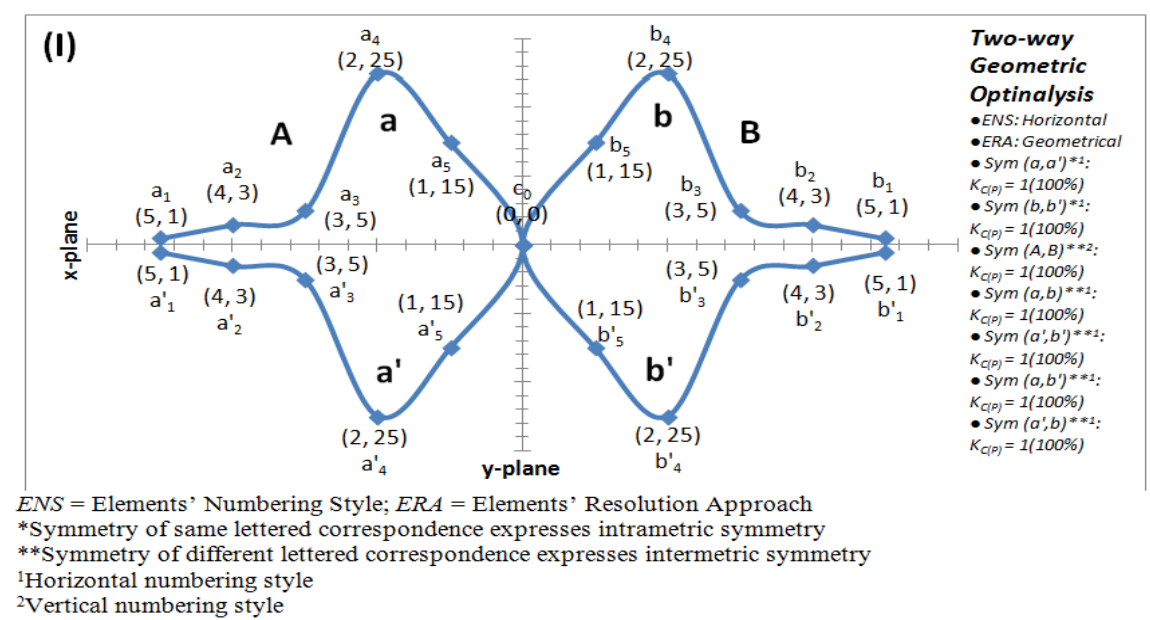

Figure 16: A symmetrical distribution of intermetric distribution

12.1 Central rotation: (called the C-rotation) refers to the rotation of the sequence elements around the central node of that distribution. Central rotation is a character that checks and proves the rotational equivalence of a distribution on a quantitative scale. Hence, the central rotation gives different Kabirian coefficients of similarity representing the same significance probability level. Central C-rotation (rotation through $180^{\circ}$ ) turns the patterns of the distribution in figure 16 to a pattern in figure 17.

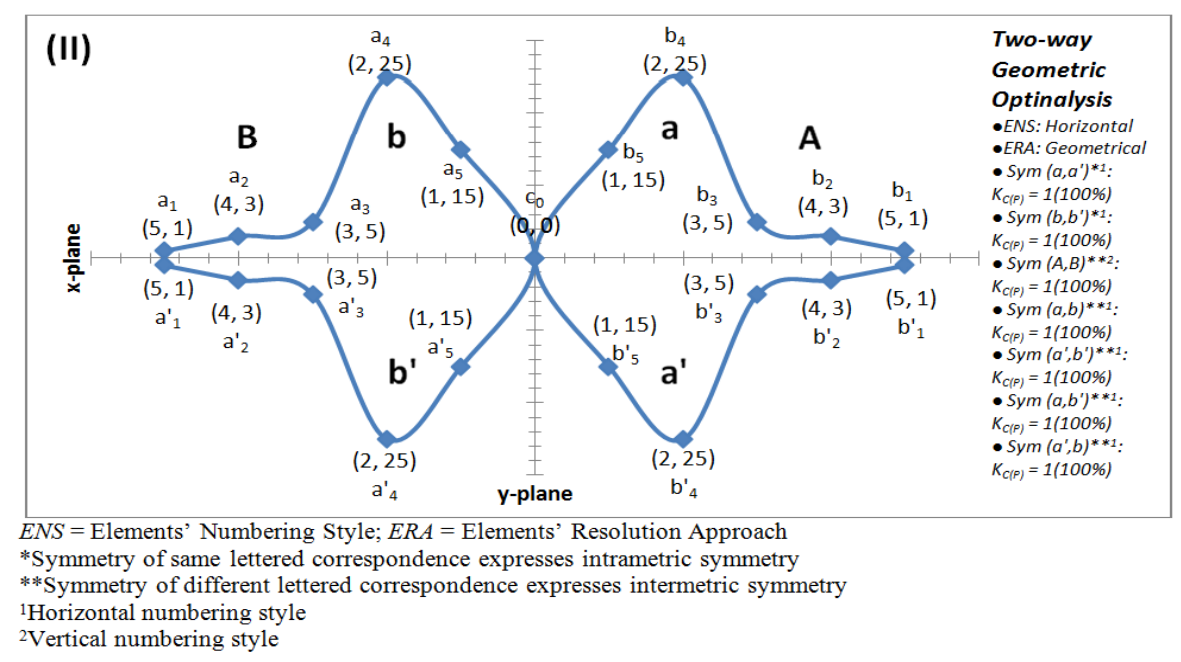

Figure 17: C-rotation about y-plane of intermetrically and radially symmetrical distributions.

12.2 Pericentral rotation: refers to the rotation of geometrical or geostatistical elements around the pericentres of that distribution.

Patterns of pericentral rotation

12.2.1 Pericentral E-rotation: refers to the rotation of elements around the pericentre of a given distribution. It is the test of symmetric stability or instability of a given geometrical or geostatistical distribution of sequence elements about a symmetric plane. Following pericentral E-rotation, head-to-head pairing turns into a tail-to-tail pairing and reverse is the case. Pericentral E-rotation is used to check the geometrically symmetric behavior of a given distribution. Elements of intrametric or intermetric distributions can be symmetrically stable or instable to 


\section{OPTINALYSIS}

pericentral E-rotation. Maintaining a geometrically symmetric stability following E-rotation is exclusive to eu-symmetric distribution. While geometrically symmetric instability (lost or gain in symmetry) following pericentral E-rotation is exclusive to pseudo-symmetric distribution. Pericentral E-rotation (rotation through $180^{\circ}$ ) turns the patterns of the distribution in figure 16 to a pattern in figure 18 .

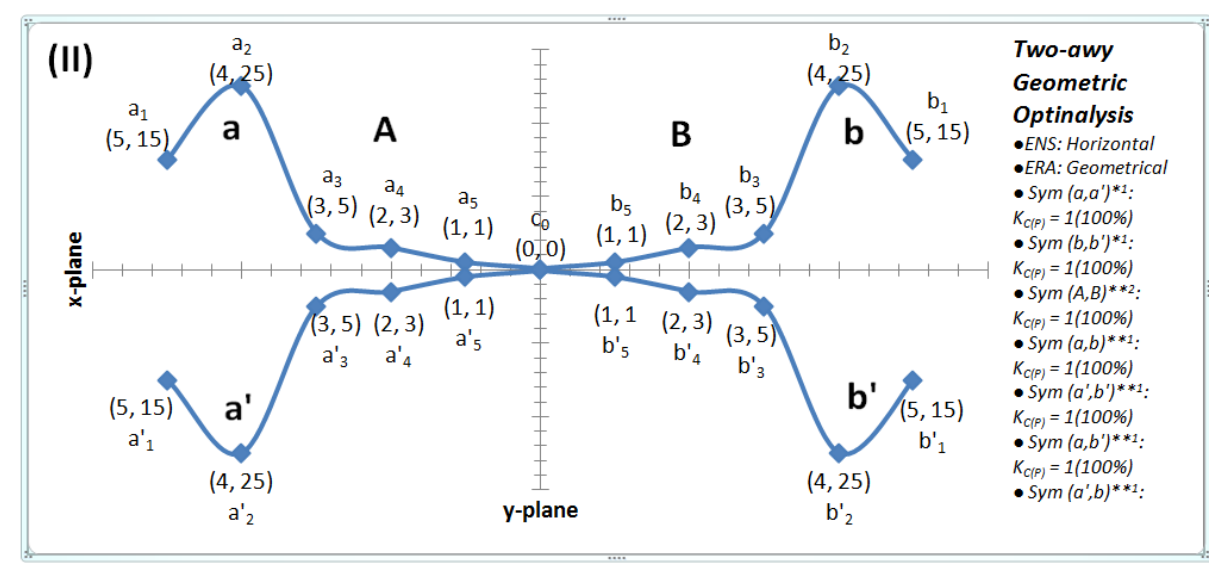

$E N S=$ Elements' Numbering Style; $E R A=$ Elements' Resolution Approach

*Symmetry of same lettered correspondence expresses intrametric symmetry

**Symmetry of different lettered correspondence expresses intermetric symmetry

${ }^{1}$ Horizontal numbering style

${ }^{2}$ Vertical numbering style

Figure 18: Pericentral E-rotation about y-plane of intermetrically and radially symmetrical distributions.

12.2.2 Pericental S-rotation: refers to the rotation of elements around the pericentre of that distribution. The S-rotation produces head-to-tail or tail-to-head pairing. If elements of a geometrically symmetric distribution S-rotates, it is more likely (except polyaxially or radially symmetric structures) to losses its geometric symmetry. Pericentral S-rotation (rotation through $180^{\circ}$ ) turns the pattern of the distribution in Figure 16 and 21 to a pattern in Figure 17-18 and 2021 respectively. In some cases, geometrically asymmetric pattern, following S-rotation may gain a geometrical symmetry about a certain symmetry plane (Figure 22-23).

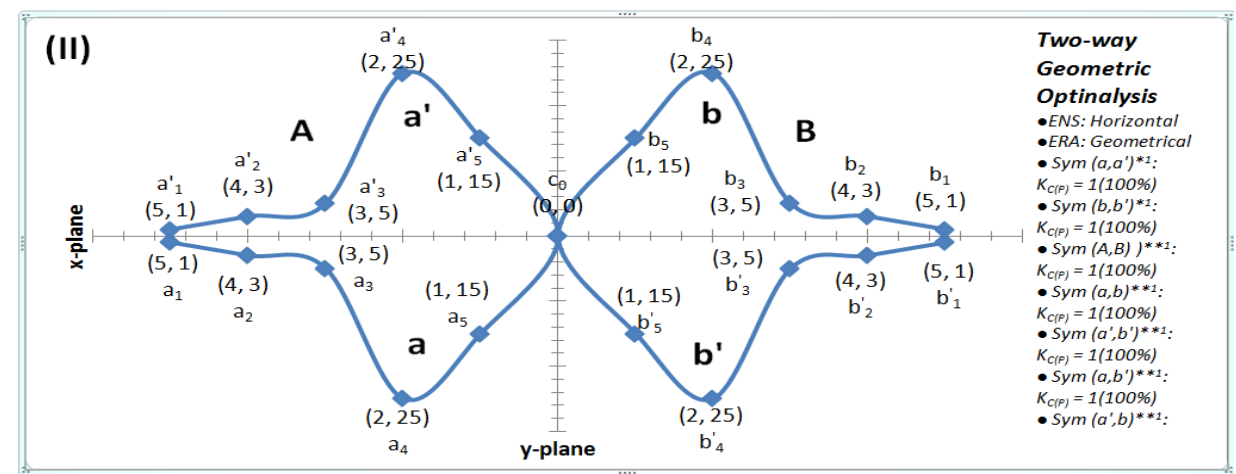

$E N S=$ Elements' Numbering Style; $E R A=$ Elements' Resolution Approach

*Symmetry of same lettered correspondence expresses intrametric symmetry

$* *$ Symmetry of different lettered correspondence expresses intermetric symmetry

${ }^{1}$ Horizontal numbering style

${ }^{2}$ Vertical numbering style

Figure 19: Pericentral S-rotation about x-plane of intermetrically and radially symmetrical distributions. 


\section{OPTINALYSIS}

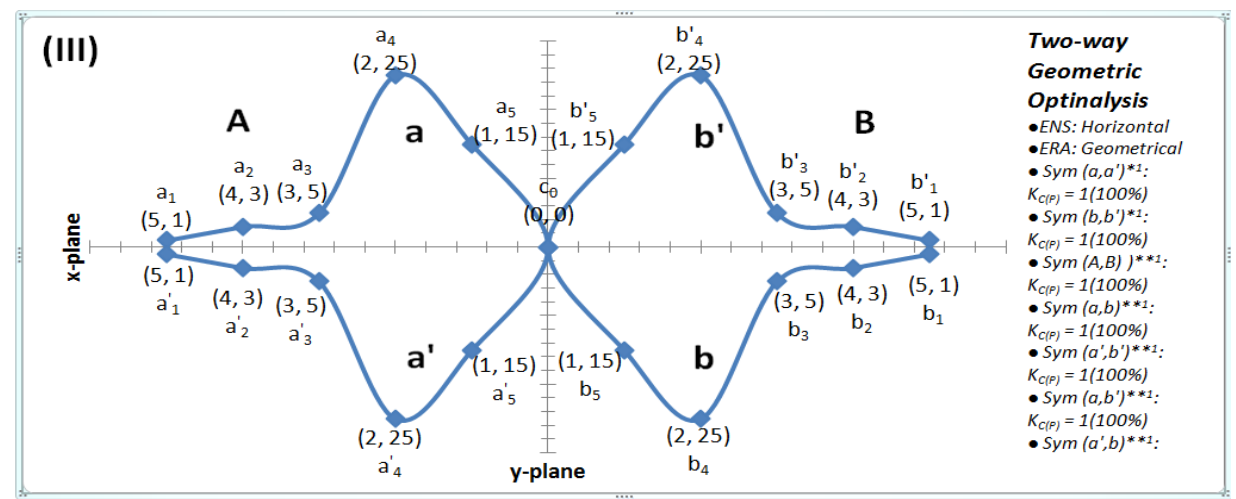

$E N S=$ Elements' Numbering Style; $E R A=$ Elements' Resolution Approach

*Symmetry of same lettered correspondence expresses intrametric symmetry

**Symmetry of different lettered correspondence expresses intermetric symmetry

${ }^{1}$ Horizontal numbering style

${ }^{2}$ Vertical numbering style

Figure 20: Pericentral S-rotation about $x$-plane of intermetrically and radially symmetrical distributions.

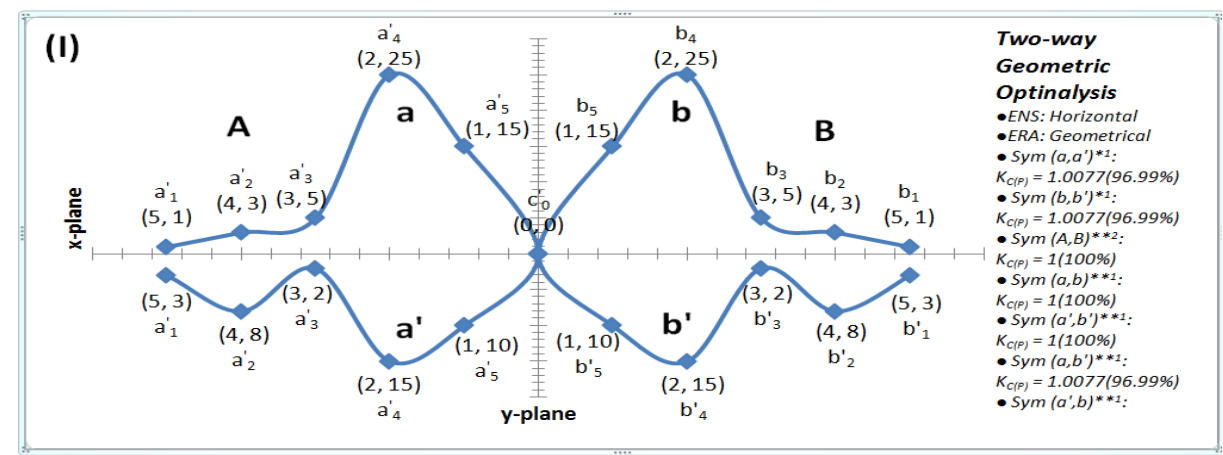

ENS = Elements' Numbering Style; $E R A=$ Elements' Resolution Approach

*Symmetry of same lettered correspondence expresses intrametric symmetry

**Symmetry of different lettered correspondence expresses intermetric symmetry

${ }^{1}$ Horizontal numbering style

${ }^{2}$ Vertical numbering style

Figure 21: Intermetrically and bilaterally symmetrical distributions.

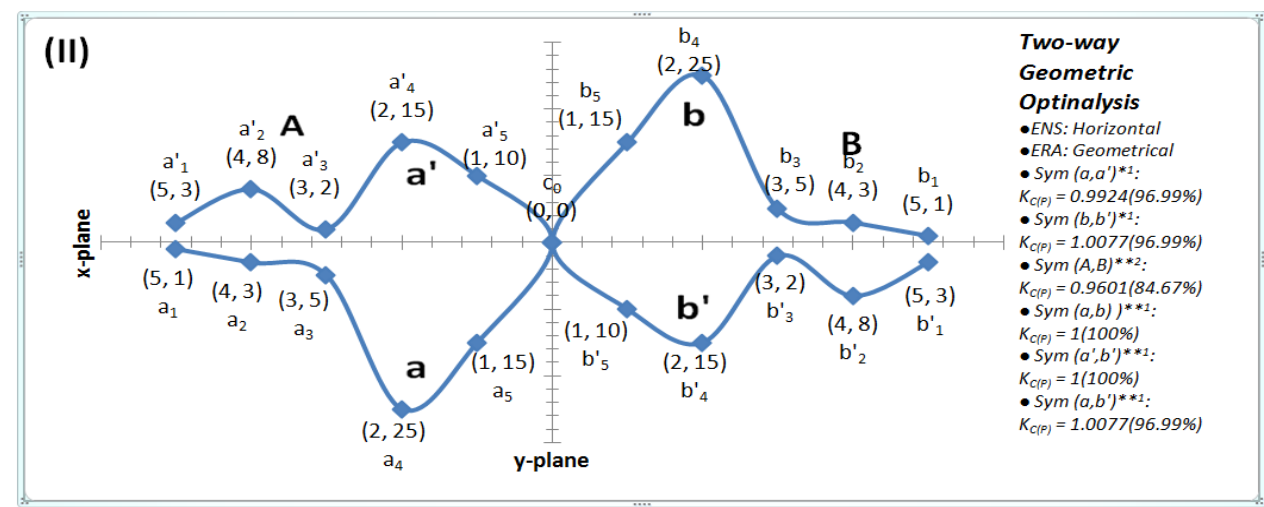

$E N S=$ Elements' Numbering Style; ERA = Elements' Resolution Approach

*Symmetry of same lettered correspondence expresses intrametric symmetry

**Symmetry of different lettered correspondence expresses intermetric symmetry

${ }^{1}$ Horizontal numbering style

${ }^{2}$ Vertical numbering style

Figure 22: Pericentral S-rotation about x-plane of intermetrically and bilaterally symmetrical distributions 


\section{OPTINALYSIS}

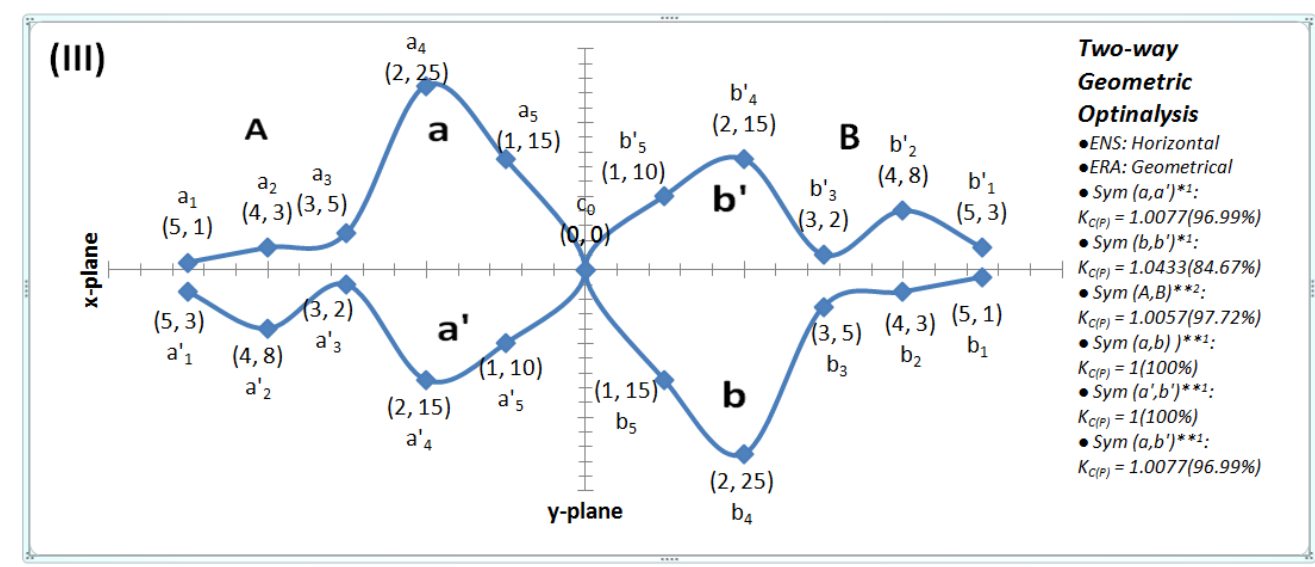

ENS = Elements' Numbering Style; $E R A=$ Elements' Resolution Approach

*Symmetry of same lettered correspondence expresses intrametric symmetry

**Symmetry of different lettered correspondence expresses intermetric symmetry

${ }^{1}$ Horizontal numbering style

${ }^{2}$ Vertical numbering style

Figure 23: Pericentral S-rotation about x-plane of intermetrically and bilaterally symmetrical distributions.

\subsection{Quantitative scale}

Denoted by ' $r_{n}$ ' are numbers arbitrarily assigned to rank every point, called the node, of a sequence in a very logical manner in such a way that every node has its own unique characteristic sensitivity to a changing magnitude. Note that, quantitative scale is different with geometric scale. The symmetric status of a given sequence remains invariant under any quantitative scaling provided a uniform difference (common difference) is maintained between each scale point to its proceeding point.

\subsection{Computations/Calculations}

To begin describing how the symmetry detection formulae were driven, we need to be familiar with these used terms.

Elements: Denoted by ' $p_{n}$ ' are main components of a set of sequence.

Co-elements: Denoted by ' $d_{n}$ ', ' $e_{n}$ ' are any supporting and accompanying element(s) represented both in magnitude and/or direction that dependently or proportionately determine or change the function of the main element of a set of a sequence. For instance, in geometry, any of the $x, y, x$ coordinates can be a main element, and the others as coelements.

Resultant Elements: Denoted by ' $a_{n}$ ', ' $a_{n}^{\prime}$,' ' $b_{n}$ ', and ' $b^{\prime}{ }_{n}$ ' are the outcomes of an established function which can summarize, harmonize and integrate the main element with its associated co-elements into a single value. Resultant elements are essential for two-way or three-away Optinalysis which can be achieve by several standard functions appropriate to the subject matter. Such standard functions include geometrical functions (e.g area, volume, centroid size), vector functions (e.g resultant magnitude), mathematical functions (e.g cumulative score of an observation and its frequency), or a theoretical functions (e.g a product relationship between a specific value score and its relative population activists). These resolutions of elements are refer to a elements resolution approaches (ERA). Table 8 expresses some examples of functional resolution of elements of a symmetry group. 


\section{OPTINALYSIS}

Table 8: Elements, co-elements and their resultant functional interactions.

\begin{tabular}{|c|c|c|c|c|}
\hline $\begin{array}{l}\text { Element } \\
\left(\boldsymbol{d}_{\boldsymbol{n}}\right)\end{array}$ & $\begin{array}{l}\text { Co-element } 1 \\
\left(\boldsymbol{d}_{\boldsymbol{n}}\right)\end{array}$ & $\begin{array}{l}\text { Co-element } 2 \\
\left(\boldsymbol{e}_{\boldsymbol{n}}\right)\end{array}$ & $\begin{array}{c}\text { Resultant Magnitude } \\
\text { By Geometrical Approach } \\
a_{n}=\left(p_{n} \times \Delta d_{n} \times \Delta e_{n}\right.\end{array}$ & $\begin{array}{l}\text { Resultant Magnitude } \\
\text { By Vector Approach } \\
a_{n}=\sqrt{p_{n}^{2}+d_{n}^{2}+e_{n}^{2}} \\
\end{array}$ \\
\hline$p_{1}$ & $d_{1}$ & $e_{1}$ & $a_{1}=\left(p_{1} \times \Delta d_{1} \times \Delta e_{1}\right)$ & $a_{1}=\sqrt{p_{1}^{2}+d_{1}^{2}+e_{1}^{2}}$ \\
\hline$p_{2}$ & $d_{2}$ & $e_{2}$ & $a_{2}=\left(p_{2} \times \Delta d_{2} \times \Delta e_{1}\right)$ & $a_{2}=\sqrt{p_{2}^{2}+d_{2}^{2}+e_{2}^{2}}$ \\
\hline$p_{3}$ & $d_{3}$ & $e_{3}$ & $a_{3}=\left(p_{3} \times \Delta d_{3} \times \Delta e_{1}\right)$ & $a_{3}=\sqrt{p_{3}^{2}+d_{3}^{2}+e_{3}^{2}}$ \\
\hline$p_{4}$ & $d_{4}$ & $e_{4}$ & $a_{4}=\left(p_{4} \times \Delta d_{4} \times \Delta e_{1}\right)$ & $a_{4}=\sqrt{p_{4}^{2}+d_{4}^{2}+e_{4}^{2}}$ \\
\hline$p_{5}$ & $d_{5}$ & $e_{5}$ & $a_{5}=\left(p_{5} \times \Delta d_{5} \times \Delta e_{1}\right)$ & $a_{5}=\sqrt{p_{5}^{2}+d_{5}^{2}+e_{5}^{2}}$ \\
\hline$p_{0}^{*}$ & $d_{0}^{*}$ & $e_{0}^{*}$ & $a_{0}^{*}$ or $c_{0}=\left(p_{0}^{*} \times \Delta d_{0}^{*} \times \Delta e_{0}^{*}\right)$ & $a_{0}^{*}$ or $b_{0}=\sqrt{p_{0}^{* 2}+d_{0}^{* 2}+e_{0}^{* 2}}$ \\
\hline$p^{\prime}{ }_{5}$ & $d^{\prime}{ }_{5}$ & $e_{5}^{\prime}$ & $a_{5}^{\prime}$ or $b_{5}=\left(p_{5} \times \Delta d^{\prime}{ }_{5} \times \Delta e^{\prime}{ }_{1}\right)$ & $a_{5}^{\prime}$ or $b_{5}=\sqrt{p_{5}^{\prime 2}+d_{5}^{\prime 2}+e^{\prime 2}}$ \\
\hline$p_{4}^{\prime}$ & $d_{4}^{\prime}$ & $e_{4}^{\prime}$ & $a_{4}^{\prime}$ or $b_{4}=\left(p_{4} \times \Delta d^{\prime}{ }_{4} \times \Delta e^{\prime}{ }_{1}\right)$ & $a_{4}^{\prime}$ or $b_{4}=\sqrt{p_{4}^{\prime 2}+d_{4}^{\prime 2}+e^{\prime 2}}$ \\
\hline$p_{3}^{\prime}$ & $d_{3}^{\prime}$ & $e_{3}^{\prime}$ & $a_{3}^{\prime}$ or $b_{3}=\left(p_{3} \times \Delta d^{\prime}{ }_{3} \times \Delta e^{\prime}{ }_{1}\right)$ & $a_{3}^{\prime}$ or $b_{3}=\sqrt{p_{3}^{\prime 2}+d_{3}^{\prime 2}+e_{3}^{\prime 2}}$ \\
\hline$p_{2}^{\prime}$ & $d_{2}^{\prime}$ & $e_{2}^{\prime}$ & $a_{2}^{\prime}$ or $b_{2}=\left(p_{2} \times \Delta d^{\prime}{ }_{2} \times \Delta e^{\prime}{ }_{1}\right)$ & $a_{2}^{\prime}$ or $b_{2}=\sqrt{p_{2}^{\prime 2}+d_{2}^{\prime 2}+e_{2}^{\prime 2}}$ \\
\hline$p_{1}^{\prime}$ & $d_{1}^{\prime}$ & $e_{1}^{\prime}$ & $a_{1}^{\prime}$ or $b_{1}=\left(p_{1} \times \Delta d_{1}^{\prime} \times \Delta e_{1}^{\prime}\right)$ & $a_{1}^{\prime}$ or $b_{1}=\sqrt{p_{1}^{\prime 2}+d_{1}^{\prime 2}+e_{1}^{\prime 2}}$ \\
\hline
\end{tabular}

Scalements: Denoted by ' $S_{m}$ ' it is expressed as the product of elements, co-element(s) and its bearing quantitative scale.

Node: Denoted by ' $n$ '. A node comprised of any specific quantitative scale's units, its bearing element and co-elements.

Query and Reflector Nodes/Query and Reflector Sequences: Query and reflector nodes describe respectively the nodes on which the elements of a query and reflector sequences are organized. Reversely, Query and reflector sequences describe respectively the sequence on which the components of a query and reflector nodes are organized. A query and reflector node may be mononodal (comprising of only one node, specifically with a univariate sequence) or polynodal (comprising of more than one node, specifically with a multivariate sequence).

Pericentral Node: Denoted by ' $P C_{n}$ '. It describes one of the query or reflector nodes that divide each of the components (the query and the reflector sequence) into two equal halves. Pericentral node exists only if and only two sequences are paired intermetrically. It is a point for pericentral E- rotation and F-rotation. See table 9 and 10.

The Central Node: Denoted by ' $C_{n}$ '. It describes that point of the symmetrical plane or axis. It is the midpoint that divides a sequence or two paired sequences into two equal halves. It is the node and point for central rotation. The nodal point may be monocentric (as found with odd-totaled nodality) or dicentric (as found in even-totaled nodality). See Table 9 and 10.

Nodality: Denoted by ' $N$ ' is the total number of existing nodes in a given distribution. Nodality directly correlates with the number of elements. Respect to the central limit theorem, the high nodality promotes the dimension of similarity scores within or between entities. See Table 9 and 10. 


\section{OPTINALYSIS}

\subsection{Symmetry coefficient}

The Kabirian coefficients of symmetry and similarity $\left(K_{c}\right)$ are values that quantify the magnitude and direction of balances or imbalances in the geometrical, geostatistical and statistical distribution of sequence elements and its co-elements about a symmetric plane. It may exist in two value outcomes (from to central rotation) which translate the same significance level. It is calculated by intrametrically or intermetrically associating the quantitative scale's unit $\left(r_{n}\right)$ with the variables/elements $\left(a_{n}\right)$, or $\left(b_{n}\right)$ and $\left(c_{n}\right)$ to generate a sequence of function called scalements that moves discretely or continuously in a space with or without influence of coelements $\left(d_{n}\right)$ and/or $\left(e_{n}\right)$ with the main elements $\left(p_{n}\right)$, from a mid-point(s) or symmetrical line or origin, called the central node as described in Table 1 below:

Table 9: Scalement generated function of elements intrametrically

\begin{tabular}{|c|c|c|c|c|}
\hline $\begin{array}{c}\text { QS-Unit } \\
\left(\boldsymbol{r}_{\boldsymbol{n}}\right)\end{array}$ & $\begin{array}{c}\text { Element } \\
\left(\boldsymbol{a}_{\boldsymbol{n}}\right)\end{array}$ & $\begin{array}{c}\text { Scalement Function } \\
r_{n}\left(a_{n}+a_{0}^{*}+a_{n}^{\prime}\right)\end{array}$ & $\begin{array}{c}\text { Node } \\
\left(\boldsymbol{N}_{\boldsymbol{n}}\right)\end{array}$ & Remarks \\
\hline $\boldsymbol{r}_{\mathbf{1}}$ & $a_{1}$ & $\left(r_{1} \times a_{1}\right)$ & $N_{1}$ & \\
\hline $\boldsymbol{r}_{\mathbf{2}}$ & $a_{2}$ & $\left(r_{2} \times a_{2}\right)$ & $N_{2}$ & \\
\hline $\boldsymbol{r}_{\mathbf{3}}$ & $a_{3}$ & $\left(r_{3} \times a_{3}\right)$ & $N_{3}$ & Pericentral node \\
\hline $\boldsymbol{r}_{\mathbf{4}}$ & $a_{4}$ & $\left(r_{4} \times a_{4}\right)$ & $N_{4}$ & \\
\hline $\boldsymbol{r}_{\mathbf{5}}$ & $a_{5}$ & $\left(r_{5} \times a_{5}\right)$ & $N_{5}$ & \\
\hline $\boldsymbol{r}_{\mathbf{6}}$ & $a_{0}^{*}$ & $\left(r_{6} \times a_{0}^{*}\right)$ & $N_{6}$ & Central node \\
\hline $\boldsymbol{r}_{\mathbf{7}}$ & $a_{5}^{\prime}$ & $\left(r_{7} \times a_{5}^{\prime}\right)$ & $N_{7}$ & \\
\hline $\boldsymbol{r}_{\mathbf{8}}$ & $a^{\prime}{ }_{4}$ & $\left(r_{8} \times a_{4}^{\prime}\right)$ & $N_{8}$ & \\
\hline $\boldsymbol{r}_{\mathbf{9}}$ & $a^{\prime}{ }_{3}$ & $\left(r_{9} \times a^{\prime}{ }_{3}\right)$ & $N_{9}$ & Pericentral node \\
\hline $\boldsymbol{r}_{\mathbf{1 0}}$ & $a_{2}^{\prime}$ & $\left(r_{10} \times a_{2}^{\prime}\right)$ & $N_{10}$ & \\
\hline $\boldsymbol{r}_{\mathbf{1 1}}$ & $a_{1}^{\prime}$ & $\left(r_{11} \times a_{1}^{\prime}\right)$ & $N_{11}$ & \\
\hline$\sum(r$ \\
$\left.{ }_{n}\right)$ & $\sum\left(a_{n}+a_{0}^{*}+a_{n}^{\prime}\right)$ & $\sum r_{n}\left(a_{n}+a_{0}^{*}+a_{n}^{\prime}\right)$ & & \\
\hline
\end{tabular}

Then, the Kabirian coefficient of similarity/symmetry that exists within the distribution of $a$ elements is given by the eq. (1) below. This is what quantifies intrametric symmetry/similarity.

$$
\begin{gathered}
K_{c}=\frac{\sum\left(r_{n}\right)}{N} \times \frac{\sum\left(a_{n}+a_{0}^{*}+a_{n}^{\prime}\right)}{1} \times \frac{1}{\sum r_{n}\left(a_{n}+a_{0}^{*}+a_{n}^{\prime}\right)} \\
K_{c}=\frac{\sum\left(r_{n}\right)}{N} \times \frac{\sum\left(a_{n}+a_{0}^{*}+a_{n}^{\prime}\right)}{\sum r_{n}\left(a_{n}+a_{0}^{*}+a_{n}^{\prime}\right)}
\end{gathered}
$$




\section{OPTINALYSIS}

Table 10: Scalement generated function of elements intermetrically

\begin{tabular}{|c|c|c|c|c|}
\hline $\begin{array}{c}\text { QS-Unit } \\
\left(\boldsymbol{r}_{\boldsymbol{n}}\right)\end{array}$ & $\begin{array}{c}\text { Elements } \\
\left(\boldsymbol{a}_{\boldsymbol{n}}\right)\end{array}$ & $\begin{array}{c}\text { Scalement Function } \\
r_{n}\left(a_{n}+c_{0}^{*}+b_{n}\right)\end{array}$ & $\begin{array}{c}\text { Node } \\
\left(\boldsymbol{N}_{\boldsymbol{n}}\right)\end{array}$ & Remarks \\
\hline$r_{1}$ & $a_{1}$ & $\left(r_{1} \times a_{1}\right)$ & $N_{1}$ & \\
\hline$r_{2}$ & $a_{2}$ & $\left(r_{2} \times a_{2}\right)$ & $N_{2}$ & \\
\hline$r_{3}$ & $a_{3}$ & $\left(r_{3} \times a_{3}\right)$ & $N_{3}$ & Pericentral node \\
\hline$r_{4}$ & $a_{4}$ & $\left(r_{4} \times a_{4}\right)$ & $N_{4}$ & \\
\hline$r_{5}$ & $\left.a_{5} \times a_{5}\right)$ & $N_{6}$ & Central node \\
\hline$r_{6}$ & $c_{0}^{*}$ & $\left(r_{6} \times c_{0}^{*}\right)$ & $N_{7}$ & \\
\hline$r_{7}$ & $b_{5}$ & $\left(r_{7} \times b_{5}\right)$ & $N_{8}$ & \\
\hline$r_{8}$ & $b_{4}$ & $\left(r_{8} \times b_{4}\right)$ & $N_{9}$ & Pericentral node \\
\hline$r_{9}$ & $b_{3}$ & $\left(r_{9} \times b_{3}\right)$ & $N_{10}$ & \\
\hline$r_{10}$ & $b_{2}$ & $\left(r_{10} \times b_{2}\right)$ & $N_{11}$ & \\
\hline$r_{11}$ & $b_{1}$ & $\left(r_{11} \times b_{1}\right)$ & & \\
\hline$\sum(r)$ & $\sum\left(a_{n}+c_{0}^{*}+b_{n}\right)$ & $\sum r_{n}\left(a_{n}+a_{0}^{*}+a_{n}^{\prime}\right)$ & & \\
\hline$n_{n}$ & & & & \\
\hline
\end{tabular}

Then, the Kabirian coefficient of similarity/symmetry that exists between the two paired sequences, $a_{n}$ and $b_{n}$ is given by eq. (2) below. This is what quantifies intermetric symmetry/similarity.

$$
\begin{gathered}
K_{c}=\frac{\sum\left(r_{n}\right)}{N} \times \frac{\sum\left(a_{n}+c_{0}^{*}+b_{n}\right)}{1} \times \frac{1}{\sum r_{n}\left(a_{n}+a_{0}^{*}+a_{n}^{\prime}\right)} \\
K_{c}=\frac{\sum\left(r_{n}\right)}{N} \times \frac{\sum\left(a_{n}+c_{0}^{*}+b_{n}\right)}{\sum r_{n}\left(a_{n}+a_{0}^{*}+a_{n}^{\prime}\right)}
\end{gathered}
$$

\section{What symmetry coefficient informs About}

i. Tells whether a distribution is geometrically, geostatistically, and statistically symmetrical or asymmetrical.

ii. Shows the level, nature and direction of distribution imbalances.

iii. Allows for the calculation of unknown variable.

iv. Allows for the calculation of probability of similarity/symmetry.

v. Allows for the calculation of probability dissimilarity/asymmetry.

\subsection{Confidence level (Probability value) of similarity}

The probability level of similarity or symmetry that exists between the two comparing intrametric or intermetric elements can be calculated by the general formula below:

Suppose $\mathrm{r}_{\mathrm{n}}=1,2,3 ; \quad \mathrm{p}_{2}\left(\mathrm{~b}_{1}\right)=1$ or $100 ; \mathrm{N}_{\mathrm{v}}=0 ; \mathrm{d}_{\mathrm{p} 1}, \mathrm{p} 2=1 ; \mathrm{e}_{\mathrm{p} 1, \mathrm{p} 2}=1 ;$ and $\mathrm{p}_{1}\left(\mathrm{a}_{1}\right)=$ unknown; for a simple dinodic and bivariate Optinalysis (Table 11). These parameters are uniform for all multivariate probabilities. 


\section{OPTINALYSIS}

Table 11: Bivariate Optinalysis under some constant parameters

\begin{tabular}{|c|c|c|c|c|c|}
\hline $\begin{array}{l}\text { QS-Unit } \\
\left(\boldsymbol{r}_{n}\right)\end{array}$ & $\begin{array}{l}\text { Elements } \\
\left(\boldsymbol{p}_{\boldsymbol{n}}\right)\end{array}$ & $\begin{array}{l}\text { Co-elements } \\
\left(\boldsymbol{d}_{\boldsymbol{n}}\right)\end{array}$ & $\begin{array}{l}\text { Co-elements } \\
\qquad\left(\boldsymbol{e}_{n}\right)\end{array}$ & $\begin{array}{l}\text { Resultant Element by Geometrical } \\
\text { Approach } \\
\quad a_{n}=\left(p_{n} \times \Delta d_{n} \times \Delta e_{n}\right)\end{array}$ & $\begin{array}{l}\text { Scalement Function } \\
\quad r_{n}\left(a_{n}+c_{0}^{*}+b_{n}\right)\end{array}$ \\
\hline 1 & $x$ & 1 & 1 & $a_{1}=(x \times 1 \times 1)$ & $(x \times 1)$ \\
\hline 2 & 0 & 0 & 0 & $c_{0}^{*}=(0)$ & $(2 \times 0)$ \\
\hline 3 & $\begin{array}{c}1 \\
\text { or } \\
100\end{array}$ & 1 & 1 & $\begin{array}{c}b_{1}=(1 \times 1 \times 1) \\
\text { or } \\
b_{1}=(100 \times 1 \times 1)\end{array}$ & $\begin{array}{c}(1 \times 1) \\
\text { or } \\
(1 \times 100) \\
\end{array}$ \\
\hline$\sum\left(r_{n}\right)$ & & & & $\sum\left(a_{n}+c_{0}^{*}+b_{n}\right)$ & $\sum r_{n}\left(a_{n}+c_{0}^{*}+b_{n}\right)$ \\
\hline$=(6)$ & & & & $\begin{array}{c}=(1+0+x) \\
\text { or } \\
(100+0+x)\end{array}$ & $\begin{array}{c}=(x+0+1) \\
\text { or } \\
(x+0+100)\end{array}$ \\
\hline
\end{tabular}

By substituting these variables into equation 2

$$
K_{c}=\frac{2(x+1)}{x+3} \text { or } K_{c}=\frac{2(x+100)}{x+300}
$$

By making $x$ the subject of the formula, we now have

$$
\begin{gathered}
P_{\text {Sim. }}-\text { value }=\frac{(2 \times 1)-\left(3 \times 1 \times S_{c}\right)}{K_{c}-2} \\
\% \text { Dsim. }=\frac{(2 \times 100)-\left(3 \times 100 \times S_{c}\right)}{K_{c}-2}
\end{gathered}
$$

Equation (3) is appropriate if $K_{c}$ is between 1 and tend to 0.66667

In the other turn, suppose $r_{n}=1,2,3 ; p_{1}\left(a_{1}\right)=1$ or $100 ; N_{v}=0 ; d_{p 1}, p 2=1 ;$ $\mathrm{e}_{\mathrm{p} 1, \mathrm{p} 2}=1$; and $\mathrm{p}_{2}\left(\mathrm{~b}_{1}\right)=$ unknown; for a simple dinodic and bivariate Optinalysis (Table 12).

\begin{tabular}{|c|c|c|c|c|c|}
\hline $\begin{array}{l}\text { QS-Unit } \\
\left(\boldsymbol{r}_{n}\right)\end{array}$ & $\begin{array}{l}\text { Elements } \\
\left(\boldsymbol{p}_{\boldsymbol{n}}\right)\end{array}$ & $\begin{array}{l}\text { Co-elements } \\
\left(\boldsymbol{d}_{n}\right)\end{array}$ & $\begin{array}{l}\text { Co-elements } \\
\left(\boldsymbol{e}_{\boldsymbol{n}}\right)\end{array}$ & $\begin{array}{l}\text { Resultant Element by Geometrical } \\
\text { Approach } \\
\quad a_{n}=\left(p_{n} \times \Delta d_{n} \times \Delta e_{n}\right)\end{array}$ & $\begin{array}{l}\text { Scalement Function } \\
\quad r_{n}\left(a_{n}+c_{0}^{*}+b_{n}\right)\end{array}$ \\
\hline 1 & $\begin{array}{c}1 \\
\text { or } \\
100\end{array}$ & 1 & 1 & $\begin{array}{c}a_{1}=(1 \times 1 \times 1) \\
\text { or } \\
a_{1}=(100 \times 1 \times 1)\end{array}$ & $\begin{array}{c}(1 \times 1) \\
\quad \text { or } \\
(1 \times 100)\end{array}$ \\
\hline 2 & 0 & 0 & 0 & $c_{0}^{*}=(0)$ & $(2 \times 0)$ \\
\hline 3 & $x$ & 1 & 1 & $b_{1}=(x \times 1 \times 1)$ & $(3 \times x)$ \\
\hline$\sum\left(r{ }_{n}\right)$ & & & & $\sum\left(a_{n}+c_{0}^{*}+b_{n}\right)$ & $\sum r_{n}\left(a_{n}+c_{0}^{*}+b_{n}\right)$ \\
\hline$=(6)$ & & & & $\begin{array}{c}=(1+0+x) \\
(\text { or } \\
100+0+x)\end{array}$ & $\begin{array}{c}=(1+0+3 x) \\
\text { or } \\
(100+0+3 x)\end{array}$ \\
\hline
\end{tabular}
These parameters are uniform for all multivariate probabilities.

Table 12: Bivariate Optinalysis under some constant parameters

By substituting these variables into equation 2

$$
K_{c}=\frac{2(1+x)}{3 x} \text { or } K_{c}=\frac{2(100+x)}{300 x}
$$


OPTINALYSIS

$$
\begin{gathered}
P_{\text {Sim. } .}-\text { value }=\frac{(2 \times 1)-\left(1 \times S_{c}\right)}{\left(3 \times K_{c}-2\right)} \\
\% \text { Sim. -value }=\frac{(2 \times 100)-\left(100 \times S_{c}\right)}{\left(3 \times K_{c}-2\right)}
\end{gathered}
$$

Equation (3) is appropriate if $K_{c}$ is between 1 and tend to 2

14.3 Confidence level (Probability value) of dissimilarity

$$
\begin{aligned}
& P_{\text {Dsim. }}-\text { value }=\left(1-P_{\text {Sim. }}-\text { value }\right) \\
& \% \text { Dsim. }- \text { value }=(100-\% \text { Sim. }- \text { value })
\end{aligned}
$$

\subsection{The Role of Co-elements in Harmonizing Size Variations and Dimensional Symmetry Detection}

Co-elements directly and dependently affect the geometric, geostatistical, and as well as the statistical characteristics and distribution of elements of a sequence.

Suppose we have two geometrical structures (shown in Figures 24-25) with same ycoordinates but differs by two folds in their x-coordinates. Logically, we can say that shape A is two times (x2) bigger in size than shape B with an expected probability P-value) equals to 0.5 $(50 \%)$. Following two-way geometric Optinalysis, the two structures are similar by $54 \%$ using the horizontal numbering style and also $50 \%$ using the vertical numbering style, as both cases shown on Figures 24 and 25 respectively. Therefore, from these two cases, we can conclude that the best and appropriate numbering style is the one that establishes a clearer pericental orientation about a symmetrical plane.

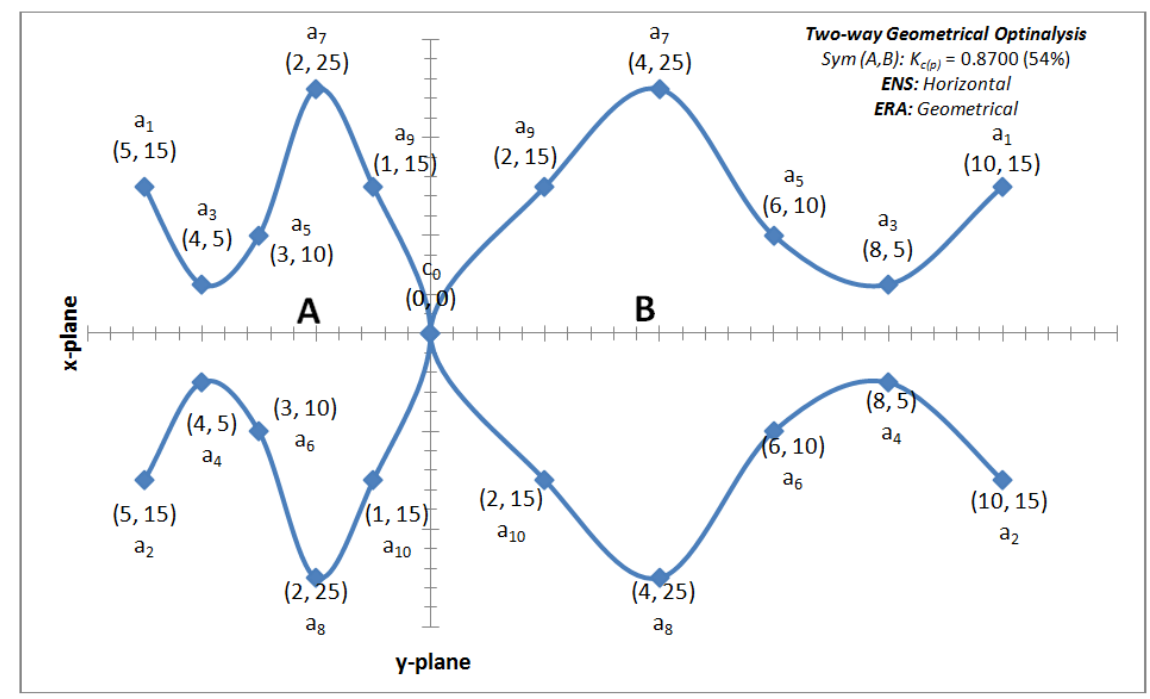

ENS = Elements' Numbering Style; ERA = Elements' Resolution Approach

Figure 24: The geometrical Optinalysis of two different sized structures 
OPTINALYSIS

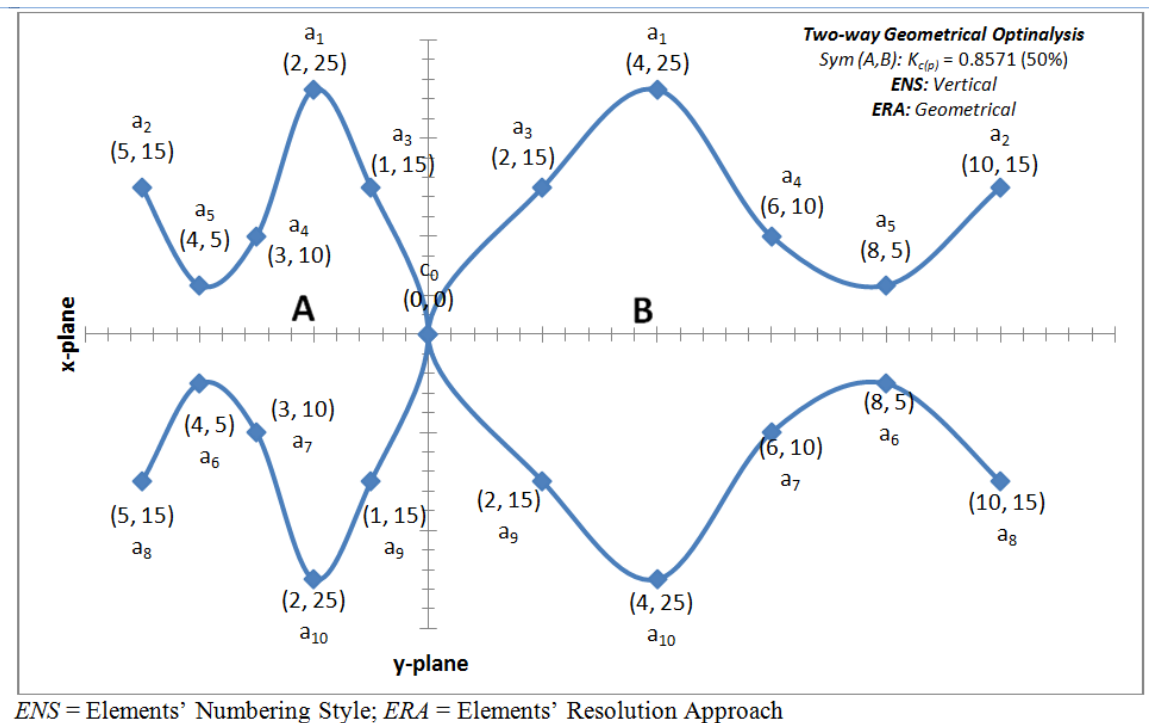

Figure 25: The geometrical Optinalysis of two different sized structures

\subsection{Types of Symmetry Detection by Optinalysis}

Intrametric symmetry detection: It describes the object symmetry explained by Mardia et.al., (2000) which demonstrates symmetry within elements (points) of same structure or entity.

Intermetric symmetry detection: It describes the matching symmetry explained by Mardia et.al., (2000) which demonstrates symmetry between elements (points) of different structures or entities.

\subsection{N-way Symmetry Detection by Optinalysis}

One-way Optinalysis: Quantify symmetry of set of elements (e.g set of magnitudes) only without the contribution of any co-element. A typical example is the symmetry of a random distribution of elements of a set.

Two-way Optinalysis: Quantify symmetry of set of elements (e.g set of magnitudes) and in association with any one of their co-elements. A typical example is the two dimensional symmetry of a vector (e.g shape symmetry in two dimensions).

Three-way Optinalysis: Quantify symmetry of set of elements (e.g set of magnitudes) in association with any two of their co-elements. A typical example is the three dimensional symmetry of a vectors (e.g shape symmetry in three dimensions).

\subsection{Types of Optinalysis}

Geometrical Optinalysis: Is the analysis that preserves the inherent geometric positions of all elements of a data set. This approach is more likely to be useful for geometric shape/pattern analysis.

Intrametric Geometric Optinalysis requires no pairing style to be chosen, because only one sequence is involved. But the Intermetric Geometric Optinalysis requires a suitable selection of a pairing style between the two sequences. In this case, selecting the most sensitive region toward the head (head-to-head pairing style) may not give same result if also considered toward the tail (tail-to-tail pairing style) except for geometrically eu-symmetrical distributions which are stable under any pairing style (i.e, under E-rotation). Where elements (observations) are in replicate measurements, the sequence order within the replicates must be disregarded by re-arranging the elements into a define sequence order (ascending or descending order). It is called type (I) 


\section{OPTINALYSIS}

geometrical Optinalysis if ascending order of replicates is used, while it is called type (II) geometrical Optinalysis if descending order of replicates is chosen. Some typical examples of geometric Optinalysis are in Figure 1-11 and 12-23.

Geostatistical Optinalysis: Is the analysis that preserves the inherent geometric positions of all elements of a data sequence and in respect to a statistical tendency of the distribution mean or median or mode. The geometric pattern of the sequence distribution is reflected with/by a headless and tailless sequence of its representing mean, median, mode or any other value of interest, as shown in figure 26-29.

Similar with Geometric Optinalysis, Intrametric Geostatistical Optinalysis requires no pairing style, because only one sequence is involved. But the Intermetric Geostatistical Optinalysis requires a suitable selection of pairing style between two sequences. In this case, selecting the most sensitive region toward the head (head-to-head pairing style) may not give same result if also considered toward the tail (tail-to-tail pairing style) except for geometrically eu-symmetric distributions which are stable under any pairing style (i.e, under E-rotation). Where elements (observations) are in replicate measurements, the sequence order within the replicates must be disregarded by re-arranging the elements into a define sequence order (ascending or descending order). It is called type (I) geostatistical Optinalysis if ascending order of replicates is chosen, while it is called type (II) geostatistical Optinalysis if descending order of replicates is used.

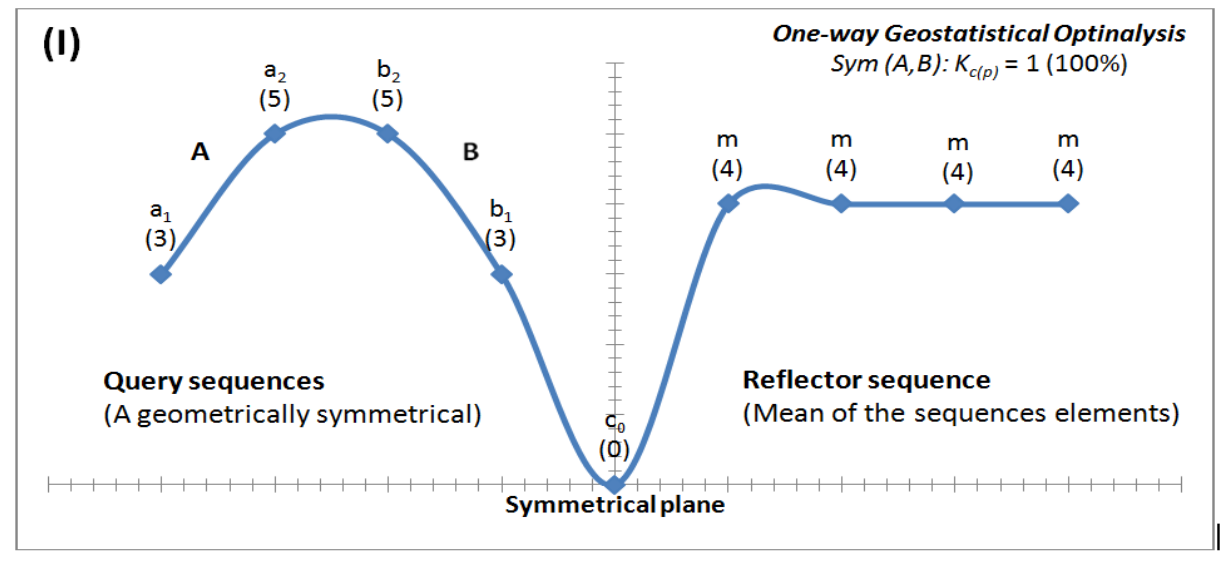

Figure 26: One-way Geostatistical Optinalysis (Paired Head-to-head Intermetrically)

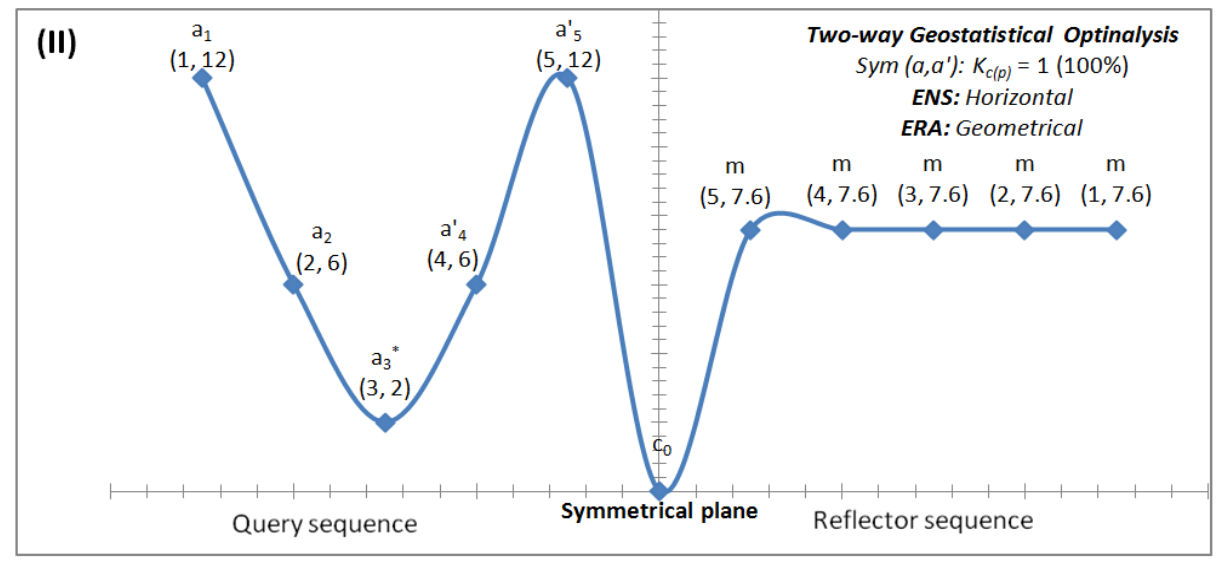

$E N S=$ Elements' Numbering Style; $E R A=$ Elements' Resolution Approach

Figure 27: Two-way Geostatistical Optinalysis (Unpaired elements intrametrically) 


\section{OPTINALYSIS}

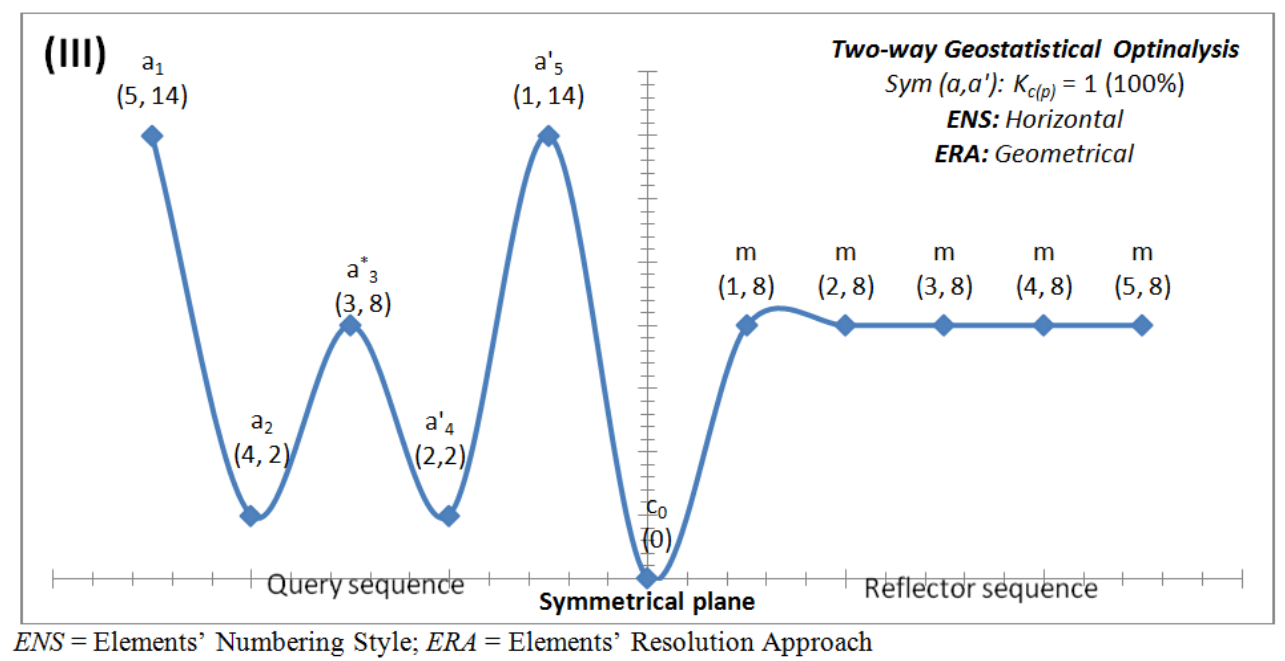

Figure 28: Two-way Geostatistical Optinalysis (Unpaired elements intrametrically)

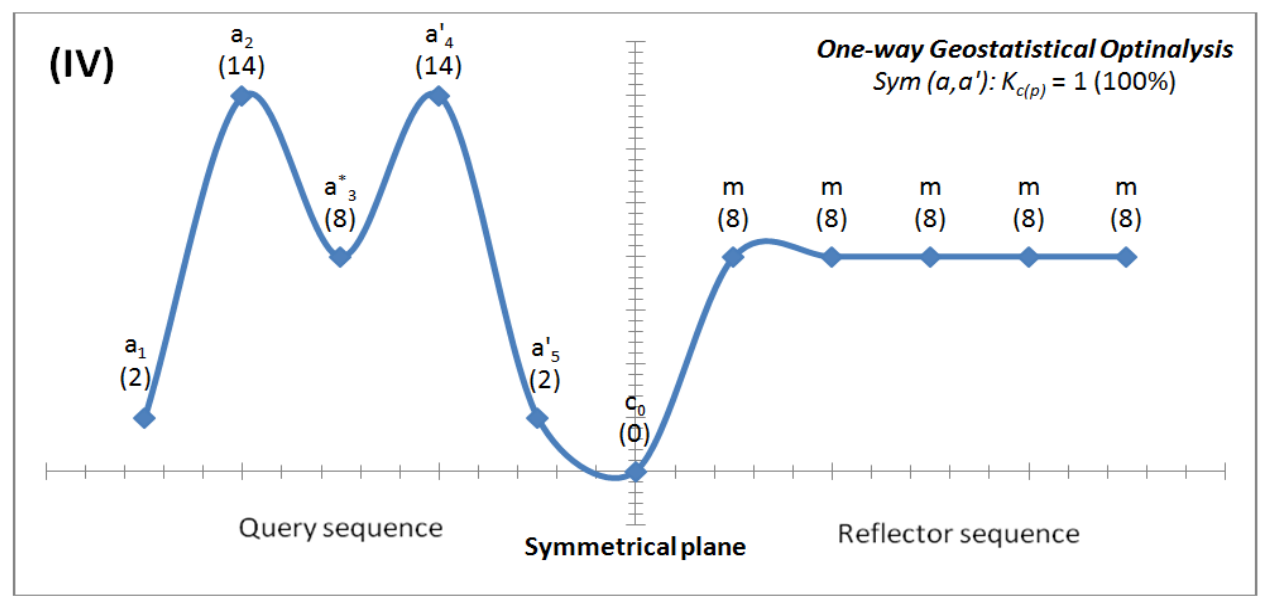

Figure 29: One-way Geostatistical Optinalysis (Unpaired elements intrametrically)

Statistical Optinalysis: Is the analysis that disregards the inherent geometric positions of all elements of a data sequence, but assume it own logical sequence. This approach is more likely to be used for the analysis of experimental data.

Unlike with Geometric and Geostatistical Optinalysis, both the Intrametric and Intermetric Statistical Optinalysis requires no pairing style, but all the elements of the sequence(s) are reorganized in ascending or descending order. Both the ascending and descending order of reorganization give different results. It is called type (I) statistical Optinalysis if ascending order of all the elements is chosen, while it is called type (II) statistical Optinalysis if descending order of all the elements is used.

Note that, a sequence with uniformly distributed elements, either in magnitude only (i.e, one-way Optinalysis) or both in magnitude and directions (i.e, two-way or three-way Optinalysis) is geometrically, geostatistically and statistically symmetrical absolutely. See Figure 30 . 


\section{OPTINALYSIS}

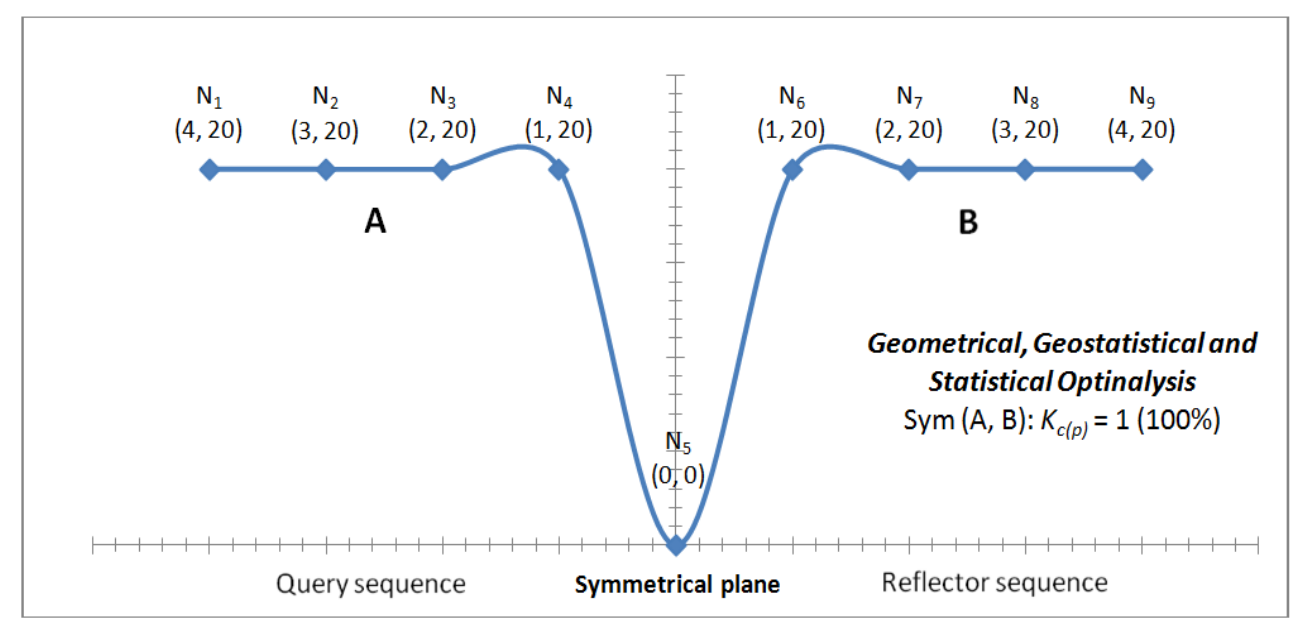

Figure 30: Optinalysis of uniformly distributed elements

\subsection{Geometrical Measure of Skewness by Optinalysis $\backslash$}

Skewness measure is one of the very important aspects of statistics. In this subsection, a new method is presented on some step-by-step approach to skewness detection using the principles of Optinalysis.

Step 1: Identify or obtain the data to be analyzed.

Step 2: Re-organize or sort the data into ascending or descending sequence order.

Step 3: Calculate the mean of the distribution.

Step 4: Compute the squared mean difference of each element of the data set and use it as the resultant element for geometrical Optinalysis. The sequence order must be maintained geometrically.

Step 5: Using geometrical Optinalysis method, calculate the Kabirian coefficient of symmetry (similarity), and the probabilities or percentages.

\subsection{Interpreting the Result of Skewness Measure}

Obtaining Kabirian coefficient equals to $1,>1,<1$ indicates zero skewness, negative skewness (more heaviness below the mean of the distribution), positive skewness (more heaviness above the mean of the distribution) respectively. The probabilities or percentages obtained are the significance level at which the distribution of the elements or the deviation of elements is symmetrical about a mean. Figure 31 is an illustration of a distribution of integers $(1,2,3,4,5$, $6,7,8,9,10,11$ ) with a zero skewness, look symmetrical about the mean value of 6 . The geometrically optinalytic approach of skewness detection described here gives a similar result with the standard method with zero skewness. 
OPTINALYSIS

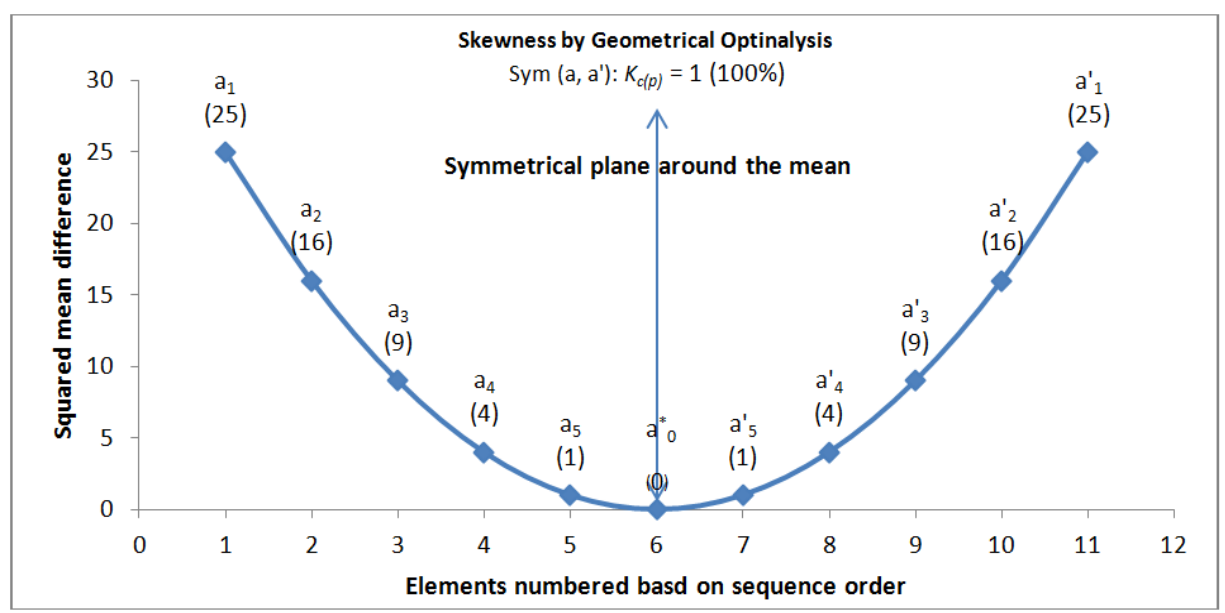

Figure 31: A normally distributed data

\subsection{Some Features of a Geometrical and Geostatistical Distributions}

Geometrical and geostatistical distribution exhibit these characteristics, as follows:

\subsection{Central modulation and Normalization}

Central modulation is refers to a deliberate positive or negative increase in magnitude of the central node's element of a given geometrical or geostatistical distribution. A geometrically or geostatistically symmetrical distribution remains symmetrically stable under any magnitude of central modulation. This explain that a geometrically or geostatistically symmetrical distribution is very flexible and stable to any limit of central modulation.

Asymmetrical distribution of elements can be transformed symmetrical if the central node is positively or negatively modulated to a certain minimum magnitude called a normalization value. The minimum value that is required to normalize asymmetrical distribution symmetrical is refers to as normalization value $( \pm N v)$. Therefore, central modulation promotes unimodality, minimizes the skewness of a data, and thus promotes unification of Kabirian coefficient similarity/symmetry. See Figure 32-34 for visually illustrative examples.

$$
\begin{gathered}
\bigwedge_{w}^{( \pm N v=0)}: \int_{\in\left(A^{\prime}\right)}^{\in(A)}=0.847(47 \%) \\
\bigwedge_{w}: \int_{C\left(A^{\prime}\right)}^{\in N v=3000)}=\sim 1(\sim 100 \%)
\end{gathered}
$$




\section{OPTINALYSIS}

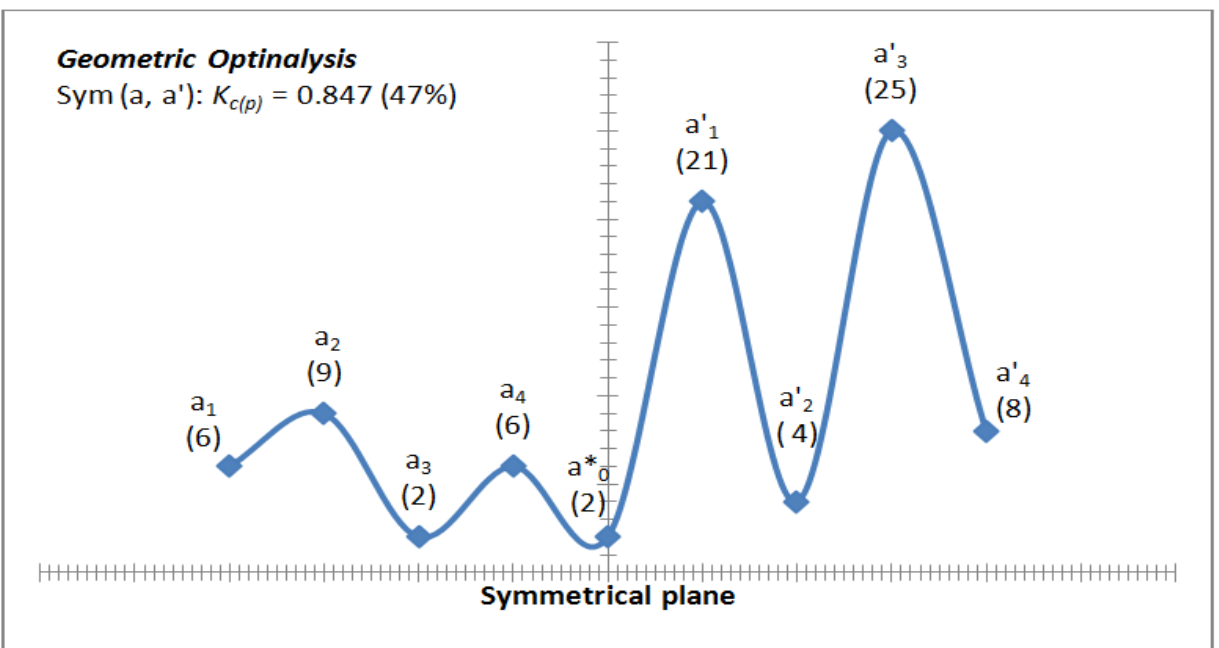

Figure 32: Asymmetrical distribution

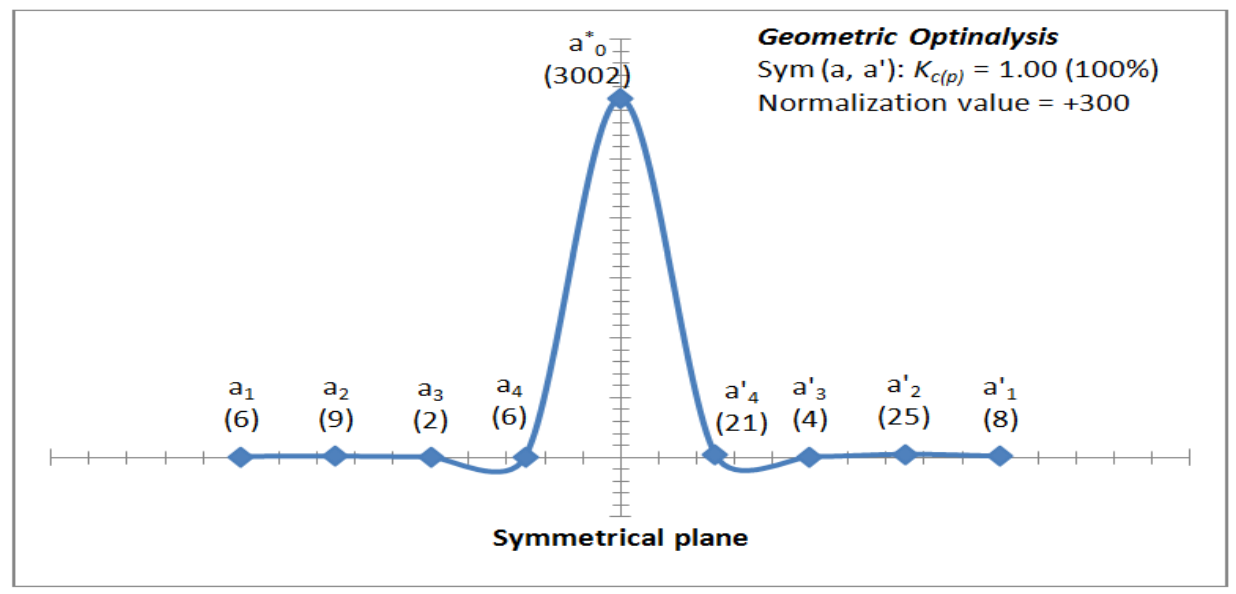

Figure 9: Transformed normalized distribution (By positive modulation) Figure 33: Transformed normalized distribution (By positive modulation)

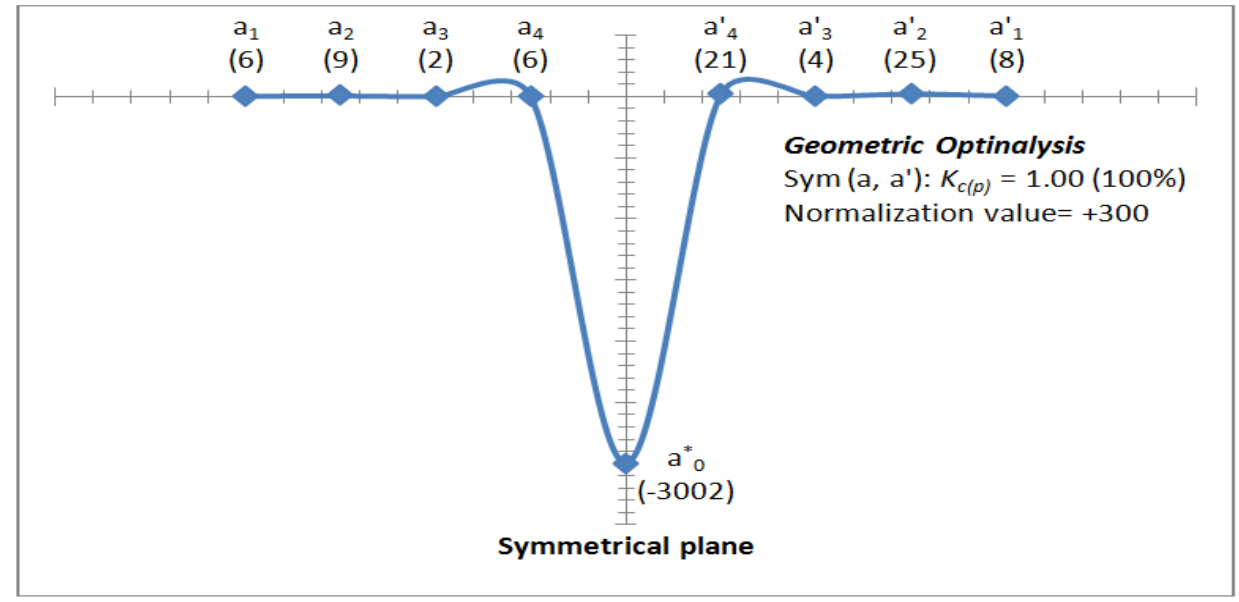

Figure 34: Transformed normalized distribution (By negative modulation) 
OPTINALYSIS

\subsection{Critical switch points:}

A geometrically or geostatistically symmetrical distribution is said to be absolutely nullified if the sum of all sequence elements is equal to zero. It is notated by the expression below.

$$
\bigwedge_{W \text { or } B}^{( \pm N v=0)}: \in\left(A+A^{\prime}\right)=0 \int_{\in\left(A^{\prime}\right)}^{\in(A)}=0( \pm 100 \%)
$$

The absolutely nullified symmetrical distribution can be absolutely activated if central node's element is modulated by any fraction of natural number $(\mathbb{N})$. It is notated by the expression below:

$$
\bigwedge_{W o r}^{( \pm N v a=\mathbb{N})}: \in\left(A+A^{\prime}\right)=0 \int_{\in\left(A^{\prime}\right)}^{\in(A)}=1(100 \%)
$$

The value required to nullify or activate a nullified symmetrical distribution is what define a nullification $\left(N v_{n}\right)$ and normalized activation $\left(N v_{a}\right)$ value respectively. The target site effective for nullification is the central node.

Therefore, if a the Kabirian coefficient of symmetry/similarity of a given distribution of elements is equal zero, then, further cross check is necessary to confirm whether the distribution is nullified symmetrical or is asymmetrical by the following approaches: a) normalized activation, b) visualization of pattern orientation, c) summation checking. Note that graphic visualization approach is not sufficient to make a conclusion, because pseudo-symmetrical distributions resemble the asymmetrical once visually. For a nullified symmetrical distributions, the zero Kabirian coefficient resume to unity (1) by a simple normalized activation at the central node, graphically look symmetrical and the total sum of all elements is equal to zero. See Figure 25-38.

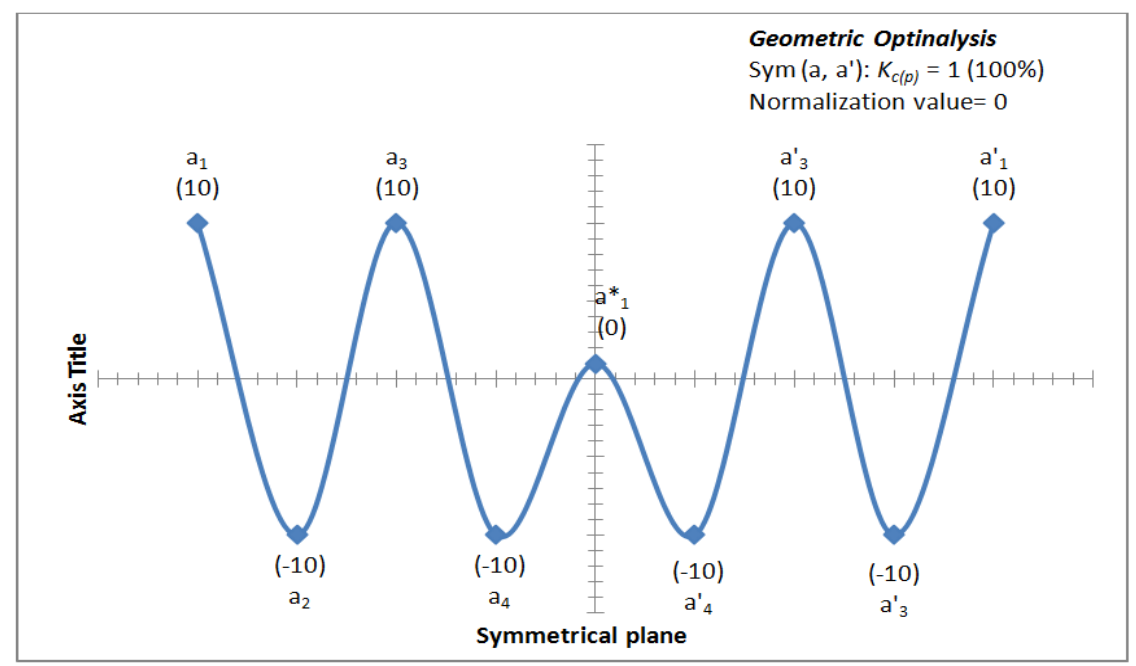

Figure 35: Showing a nullified symmetrical distribution with zero coefficients 


\section{OPTINALYSIS}

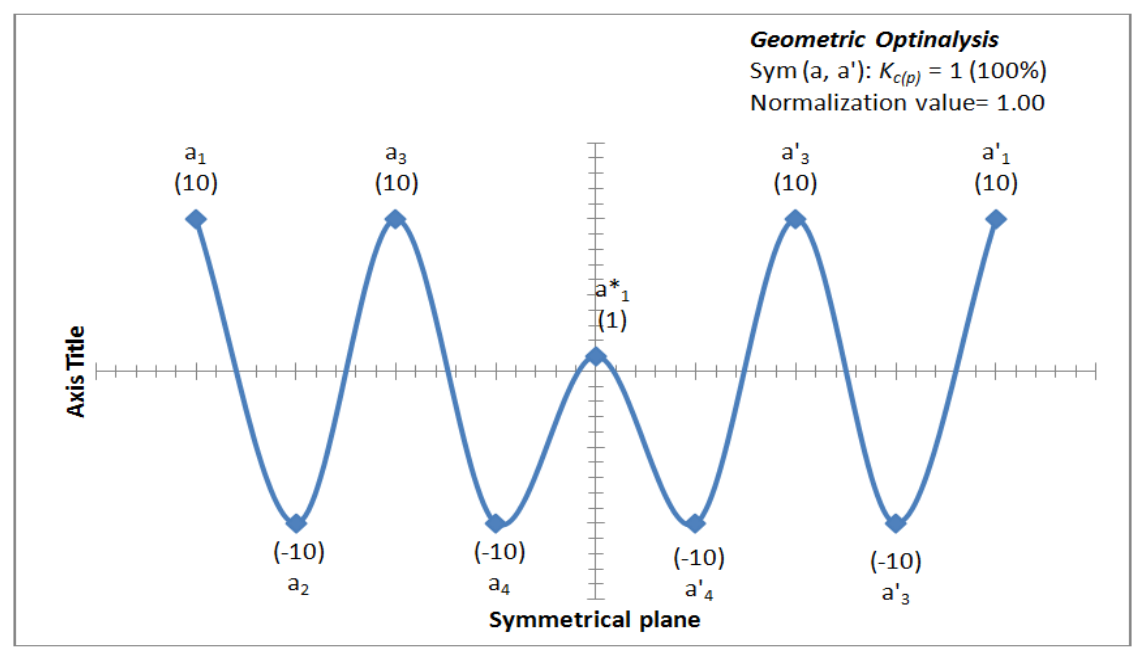

Figure 36: Showing the effect of normalized activation on a nullified symmetrical distribution

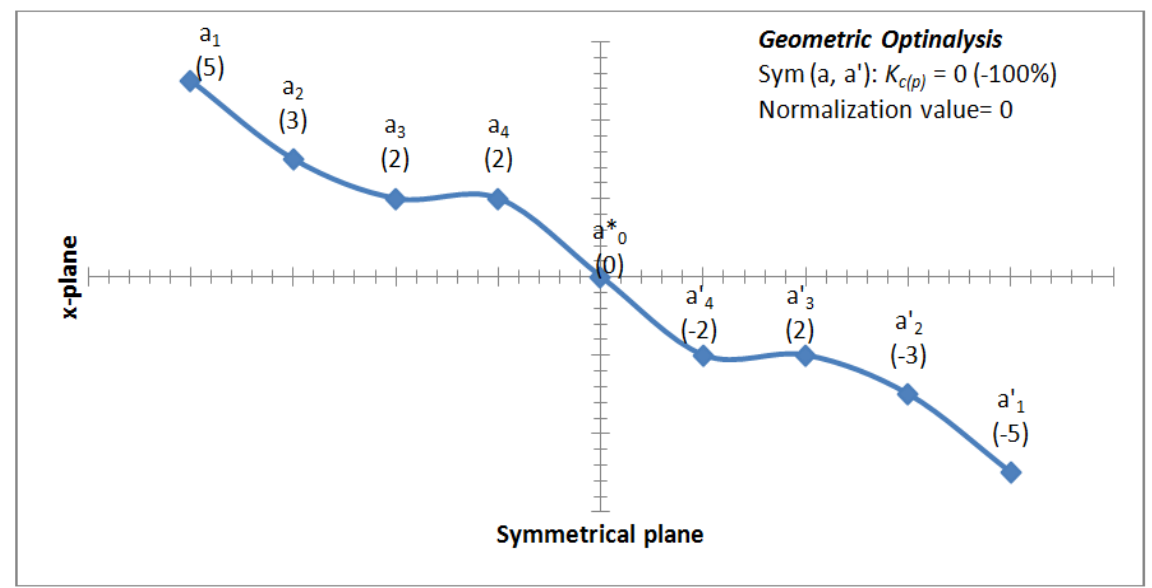

Figure 37: Showing an asymmetrical distribution with a zero coefficient

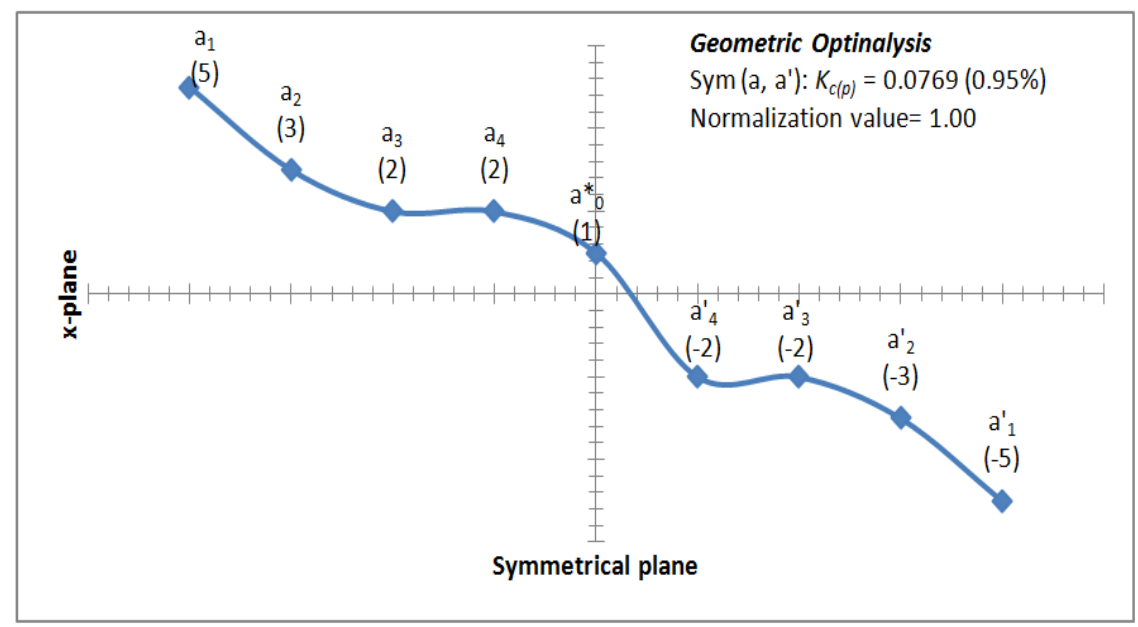

Figure 38: Showing the effect of normalized activation on asymmetrical distribution 
OPTINALYSIS

\subsection{Application, Simulation and Discussions}

This section will provide a practical example of how Optinalysis is suitable for analysis of socio-demographic data, demographic, social, and psychometric data.

\subsection{Example 1: Socio-demographic Data (I)}

Table 13 Presented the calculated socio-demographic positions and frequencies of the sampled 1,000 individuals from a given population of feminine socio-demographic kingdom of the third socio-demographic clades, within the upper socio-demographic group of class 1 sociodemographic status (Abdullahi, 2019b).

The data distibution was first tested for the level and direction of skewness using a Graphad Prism software of 8.0.2 version, and then by the geometrical Optinalysis. The results in Table 14 shows that Optinalysis is a more advance approach over the method used in the software, because it provide further detail about the significance level of skewness. Both the two methods shows the same direction of skewness.

The results of Optinalysis in Table 14 shows that all the frquency of individuals in each of the seven populations A-G are significantly dissimilar $(\mathrm{P}>0.95)$ statistically, geostatistically and geometrically except population $\mathrm{E}$ which is significantly similar ( $\mathrm{P}>0.95)$ geostatistically. Optinalysis, paired T-test, and Tukey's multiple comparions were used to separate the means. The result of the multiple comparison in Table 15-18 shows that Optinalysis is more sensitive and detected a significant dissimilarity $(\mathrm{P}>0.95)$ statistically, geostatistically and geometrically, which otherwise T-test and Turkey's multiple comparions has not detected any differences at $(\mathrm{P}<0.05)$ equivalence.

Table 13: Frequency distribution of a socio-demographic positions of individuals

\begin{tabular}{llllllll}
\hline \multicolumn{7}{c}{ Frequency (No. of individuals): } & $\mathbf{N}=\mathbf{1 , 0 0 0}$ \\
\hline SDp & A & B & C & D & E & F & G \\
\hline$($ H) 0.99999 & 113 & 147 & 5 & 99 & 89 & 56 & 79 \\
0.99996 & 97 & 125 & 9 & 87 & 115 & 85 & 89 \\
0.99993 & 87 & 98 & 18 & 54 & 73 & 67 & 69 \\
0.99990 & 82 & 79 & 27 & 98 & 28 & 36 & 75 \\
0.99969 & 61 & 80 & 38 & 90 & 30 & 87 & 46 \\
0.99966 & 46 & 69 & 45 & 76 & 21 & 123 & 92 \\
0.99963 & 99 & 75 & 43 & 44 & 10 & 35 & 34 \\
0.99960 & 19 & 56 & 110 & 89 & 67 & 76 & 65 \\
0.99939 & 37 & 60 & 78 & 34 & 46 & 36 & 56 \\
0.99936 & 29 & 48 & 69 & 89 & 98 & 105 & 85 \\
0.99933 & 59 & 48 & 79 & 45 & 34 & 55 & 67 \\
0.99930 & 70 & 30 & 90 & 9 & 65 & 34 & 36 \\
0.99909 & 52 & 36 & 98 & 34 & 57 & 45 & 87 \\
0.99906 & 80 & 25 & 96 & 23 & 111 & 23 & 67 \\
0.99903 & 22 & 15 & 96 & 93 & 58 & 89 & 23 \\
$0.99900^{(\mathbf{T})}$ & 47 & 9 & 99 & 36 & 98 & 48 & 30 \\
\hline
\end{tabular}


OPTINALYSIS

Table 14: Result of Analysis of a Socio-demographic data

\begin{tabular}{|c|c|c|c|c|c|c|c|}
\hline \multicolumn{8}{|c|}{ Analysis Results } \\
\hline & \multicolumn{7}{|c|}{ Populations } \\
\hline & A & B & C & $\mathbf{D}$ & $\mathbf{E}$ & $\mathbf{F}$ & $\mathbf{G}$ \\
\hline \multicolumn{8}{|c|}{ Skewness Measure ( Using Graphad Prism, Version 8.0.2) } \\
\hline & 0.1097 & 0.7297 & -0.3330 & -0.2557 & 0.1033 & 0.6039 & -0.4319 \\
\hline \multicolumn{8}{|c|}{ Skewness Measure (Optinalytic Method) } \\
\hline Kc-value & 0.967407 & 0.83483 & 1.137191 & 1.108889 & 0.968014 & 0.841813 & 1.164688 \\
\hline$P_{\text {Sim.-value }}$ & 0.87374 & 0.43298 & 0.61124 & 0.67169 & 0.87602 & 0.45367 & 0.55909 \\
\hline$P_{\text {Dsim.-value }}$ & 0.12626 & 0.56702 & 0.38876 & 0.32831 & 0.12398 & 0.54633 & 0.44091 \\
\hline \multicolumn{8}{|c|}{ One-way Type (I) Statistical Optinalysis } \\
\hline Kc-value & 0.94337 & 0.92825 & 0.93153 & 0.94154 & 0.93556 & 0.94402 & 0.95554 \\
\hline $\mathrm{P}_{\text {Sim.-value }}$ & 0.78562 & 0.73222 & 0.74368 & 0.77908 & 0.75783 & 0.78797 & 0.82973 \\
\hline$P_{\text {Dsim.-value }}$ & 0.21438 & 0.26778 & 0.25632 & 0.22092 & 0.24217 & 0.21203 & 0.17027 \\
\hline \multicolumn{8}{|c|}{ One-way Geostatistical Optinalysis } \\
\hline Kc-value & 1.03621 & 1.08318 & 0.93641 & 1.03700 & 0.99088 & 1.01511 & 1.02345 \\
\hline $\mathrm{P}_{\text {Sim.-value }}$ & 0.86936 & 0.73372 & 0.76084 & 0.86680 & 0.96384 & 0.94219 & 0.91237 \\
\hline$P_{\text {Dsim.-value }}$ & 0.13064 & 0.26628 & 0.23916 & 0.13320 & 0.03616 & 0.05781 & 0.08763 \\
\hline \multicolumn{8}{|c|}{ One-way Geometrical Optinalysis } \\
\hline Kc-value & 0.80638 & 0.76384 & 0.77280 & 0.80106 & 0.78399 & 0.80829 & 0.84309 \\
\hline$P_{\text {Sim.-value }}$ & 0.35114 & 0.23582 & 0.25945 & 0.33627 & 0.28944 & 0.35653 & 0.45748 \\
\hline $\mathrm{P}_{\text {Dsim.-value }}$ & 0.64886 & 0.76418 & 0.74055 & 0.66373 & 0.71056 & 0.64347 & 0.54252 \\
\hline
\end{tabular}




\section{OPTINALYSIS}

Table 15: Pairewise comparisons among the populations A-G by stanadard analysis (Paired ttest, Turkey;s multiple comparison test, and Pearson correlation) of the Socio-demographic data

\begin{tabular}{llccccccc}
\hline & \multicolumn{7}{c}{ Standard Statistical Methods } \\
\hline \multirow{4}{*}{ A } & Paired t-test & $\mathbf{A}$ & $\mathbf{B}$ & $\mathbf{C}$ & $\mathbf{D}$ & $\mathbf{E}$ & $\mathbf{F}$ & $\mathbf{G}$ \\
& TMCT & $>0.9999$ & $>0.9999$ & $>0.9999$ & $>0.9999$ & $>0.9999$ & $>0.9999$ & $>0.9999$ \\
& Correlation & $1-000$ & 0.667 & -0.726 & -0.049 & 0.088 & -0.390 & 0.171 \\
\hline B & Paired t-test & $>0.9999$ & $>0.9999$ & $>0.9999$ & $>0.9999$ & $>0.9999$ & $>0.9999$ & $>0.9999$ \\
& TMCT & $>0.9999$ & $>0.9999$ & $>0.9999$ & $>0.9999$ & $>0.9999$ & $>0.9999$ & $>0.9999$ \\
& Correlation & 0.667 & 10.000 & -0.904 & 0.513 & 0.016 & 0.176 & 0.488 \\
\hline C & Paired t-test & $>0.9999$ & $>0.9999$ & $>0.9999$ & $>0.9999$ & $>0.9999$ & $>0.9999$ & $>0.9999$ \\
& TMCT & $>0.9999$ & $>0.9999$ & $>0.9999$ & $>0.9999$ & $>0.9999$ & $>0.9999$ & $>0.9999$ \\
& Correlation & -0.726 & -0.904 & 1.000 & -0.484 & 0.075 & $-0 . .206$ & -0.384 \\
\hline D & Paired t-test & $>0.9999$ & $>0.9999$ & $>0.9999$ & $>0.9999$ & $>0.9999$ & $>0.9999$ & $>0.9999$ \\
& TMCT & $>0.9999$ & $>0.9999$ & $>0.9999$ & $>0.9999$ & $>0.9999$ & $>0.9999$ & $>0.9999$ \\
& Correlation & -0.049 & 0.513 & -0.484 & 1.000 & -0.032 & 0.639 & 0.298 \\
\hline E & Paired t-test & $>0.9999$ & $>0.9999$ & $>0.9999$ & $>0.9999$ & $>0.9999$ & $>0.9999$ & $>0.9999$ \\
& TMCT & $>0.9999$ & $>0.9999$ & $>0.9999$ & $>0.9999$ & $>0.9999$ & $>0.9999$ & $>0.9999$ \\
& Correlation & 0.088 & 0.016 & 0.075 & -0.032 & 10.000 & 0.014 & 0.188 \\
\hline F & Paired t-test & $>0.9999$ & $>0.9999$ & $>0.9999$ & $>0.9999$ & $>0.9999$ & $>0.9999$ & $>0.9999$ \\
& TMCT & $>0.9999$ & $>0.9999$ & $>0.9999$ & $>0.9999$ & $>0.9999$ & $>0.9999$ & $>0.9999$ \\
& Correlation & -0.390 & 0.176 & -0.206 & 0.639 & -0.014 & 1.000 & 0.311 \\
\hline G & Paired t-test & $>0.9999$ & $>0.9999$ & $>0.9999$ & $>0.9999$ & $>0.9999$ & $>0.9999$ & $>0.9999$ \\
& TMCT & $>0.9999$ & $>0.9999$ & $>0.9999$ & $>0.9999$ & $>0.9999$ & $>0.9999$ & $>0.9999$ \\
& Correlation & 0.171 & 0.488 & -0.384 & 0.298 & 0.188 & 0.301 & 1.000 \\
\hline
\end{tabular}

TMCT $=$ Turkey's multiple comparison test 
OPTINALYSIS

Table 16: Pairewise comparisons among the populations A-G by Type (I) Statistical Two-way Optinalysis of the Socio-demographic data

\begin{tabular}{|c|c|c|c|c|c|c|c|c|}
\hline & & \multicolumn{7}{|c|}{ Type (I) Statistical One-way Optinalysis } \\
\hline & & $\mathbf{A}$ & B & $\mathbf{C}$ & $\mathbf{D}$ & $\mathbf{E}$ & $\mathbf{F}$ & $\mathbf{G}$ \\
\hline \multirow[t]{3}{*}{$\mathbf{A}$} & Kc-value $(\mathrm{HH})$ & 0.95719 & 0.95470 & 0.94702 & 0.95183 & 0.95429 & 0.95901 & 0.95953 \\
\hline & $\mathrm{P}_{\text {Sim. }}$-value & 0.83578 & 0.82664 & 0.79876 & 0.81618 & 0.82515 & 0.84249 & 0.84440 \\
\hline & $P_{\text {Dsim.-value }}$ & 0.16422 & 0.17336 & 0.20124 & 0.18382 & 0.17485 & 0.15751 & 0.15560 \\
\hline \multirow[t]{3}{*}{ B } & Kc-value $(\mathrm{HH})$ & 0.95470 & 0.95186 & 508 & 0.94991 & 0.95192 & 0.95667 & 0.95681 \\
\hline & $\mathrm{P}_{\text {Sim.-value }}$ & 0.82664 & 0.81628 & 0.79 & 919 & 651 & 0.83387 & 438 \\
\hline & $P_{\text {Dsim.-value }}$ & 0.17336 & 0.18372 & 0.20825 & 0.19081 & 0.18349 & 0.16613 & 0.16562 \\
\hline \multirow[t]{3}{*}{$\mathbf{C}$} & Kc-value $(\mathrm{HH})$ & 0.94702 & 0.94508 & 0.93881 & 0.94236 & 0.94476 & 0.94869 & 0.95092 \\
\hline & $\mathrm{P}_{\text {Sim.-value }}$ & 0.79876 & 0.79175 & 0.76934 & 0.78200 & 0.79061 & 0.80478 & 0.81286 \\
\hline & $\mathrm{P}_{\text {Dsim.-value }}$ & 0.20124 & 0.20825 & 0.23066 & 0.21800 & 0.20939 & 0.19522 & 0.18714 \\
\hline \multirow[t]{3}{*}{ D } & Kc-value $(\mathrm{HH})$ & 0.95183 & 0.94991 & 0.94236 & 0.94605 & 0.94911 & 0.95425 & 0.95476 \\
\hline & $\mathrm{P}_{\text {Sim. }}$-value & & & & & & 0.82499 & \\
\hline & $P_{\text {Dsim.-value }}$ & & 0.19081 & 0.21800 & 0.20477 & 0.19369 & 0.17501 & 0.17311 \\
\hline \multirow[t]{3}{*}{$\mathbf{E}$} & Kc-value $(\mathrm{HH})$ & 0.95 & 0.95192 & 0.9 & 0.94911 & 0.95 & 0.95615 & 0.95733 \\
\hline & $\mathrm{P}_{\text {Sim. }}$-value & 0.82 & 0.81651 & 0.79061 & 0.80631 & 438 & 0.83196 & 0.83632 \\
\hline & $P_{\text {Dsim.-value }}$ & 0.17485 & 0.18349 & 0.20939 & 0.19369 & 0.18562 & 0.16804 & 0.16368 \\
\hline \multirow[t]{3}{*}{$\mathbf{F}$} & Kc-value $(\mathrm{HH})$ & 0.95901 & 0.95667 & 0.94869 & 0.95425 & 0.95615 & 0.96165 & 0.96108 \\
\hline & $\mathrm{P}_{\text {Sim. }}$-value & & 0.83387 & 0.80478 & 0.82499 & 0.83196 & 0.85227 & 0.85014 \\
\hline & $\mathrm{P}_{\text {Dsim. }}$-value & 0.15751 & 0.16613 & 0.19522 & 0.17501 & 0.16804 & 0.14773 & 0.14986 \\
\hline \multirow[t]{3}{*}{$\mathbf{G}$} & Kc-value $(\mathrm{HH})$ & 0.95953 & 0.95681 & 0.95092 & 0.95476 & 0.95733 & 0.96108 & 0.96308 \\
\hline & $\mathrm{P}_{\text {Sim.-value }}$ & & 0.83438 & 0.81286 & 0.82689 & 0.83632 & 0.85014 & 0.85759 \\
\hline & $P_{\text {Dsim.-value }}$ & 0.15560 & 0.16562 & 0.18714 & 0.17311 & 0.16368 & 0.14986 & 0.14241 \\
\hline
\end{tabular}




\section{OPTINALYSIS}

Table 17: Pairewise comparisons among the populations A-G by Geostatistical Optinalysis of the Socio-demographic data

\begin{tabular}{lllllllll}
\hline & & \multicolumn{7}{c}{ Geostatistical One-way Optinalysis } \\
\hline & & $\mathrm{A}$ & $\mathrm{B}$ & $\mathrm{C}$ & $\mathrm{D}$ & $\mathrm{E}$ & $\mathrm{F}$ & $\mathrm{G}$ \\
\hline $\mathbf{A}$ & Kc-value $(\mathrm{HH})$ & 1.00000 & 0.98933 & 1.02721 & 0.99981 & 1.01150 & 1.00519 & 1.00311 \\
& $\mathrm{P}_{\text {Sim.-value }}$ & 1.00000 & 0.95779 & 0.89936 & 0.99924 & 0.95553 & 0.97954 & 0.98768 \\
& $\mathrm{P}_{\text {Dsim-value }}$ & 0.00000 & 0.04221 & 0.10064 & 0.00076 & 0.04447 & 0.02046 & 0.01232 \\
\hline $\mathbf{B}$ & Kc-value $(\mathrm{HH})$ & 1.01090 & 1.00000 & 1.03872 & 1.01070 & 1.02265 & 1.01621 & 1.01407 \\
& $\mathrm{P}_{\text {Sim.-value }}$ & 0.95779 & 1.00000 & 0.86125 & 0.95852 & 0.91515 & 0.93818 & 0.94598 \\
& $\mathrm{P}_{\text {Dsim-value }}$ & 0.04221 & 0.00000 & 0.13875 & 0.04148 & 0.08485 & 0.06182 & 0.05402 \\
\hline $\mathbf{C}$ & Kc-value $(\mathrm{HH})$ & 0.97419 & 0.96407 & 1.00000 & 0.97401 & 0.98510 & 0.97912 & 0.97714 \\
& $\mathrm{P}_{\text {Sim.-value }}$ & 0.89936 & 0.86125 & 1.00000 & 0.89868 & 0.94129 & 0.91819 & 0.91061 \\
& $\mathrm{P}_{\text {Dsim-value }}$ & 0.10064 & 0.13875 & 0.00000 & 0.10132 & 0.05871 & 0.08181 & 0.08939 \\
\hline $\mathbf{D}$ & Kc-value $(\mathrm{HH})$ & 1.00019 & 0.98952 & 1.02741 & 1.00000 & 1.01170 & 1.00538 & 1.00330 \\
& $\mathrm{P}_{\text {Sim.-value }}$ & 0.99924 & 0.95852 & 0.89868 & 1.00000 & 0.95480 & 0.97880 & 0.98693 \\
& $\mathrm{P}_{\text {Dsim-value }}$ & 0.00076 & 0.04148 & 0.10132 & 0.00000 & 0.04520 & 0.02120 & 0.01307 \\
\hline $\mathbf{E}$ & Kc-value $(\mathrm{HH})$ & 0.98876 & 0.97833 & 1.01535 & 0.98857 & 1.00000 & 0.99383 & 0.99180 \\
& $\mathrm{P}_{\text {Sim.-value }}$ & 0.95553 & 0.91515 & 0.94129 & 0.95480 & 1.00000 & 0.97549 & 0.96745 \\
& $\mathrm{P}_{\text {Dsim.-value }}$ & 0.04447 & 0.08485 & 0.05871 & 0.04520 & 0.00000 & 0.02451 & 0.03255 \\
\hline F & Kc-value $(\mathrm{HH})$ & 0.99486 & 0.98430 & 1.02179 & 0.99467 & 1.00624 & 1.00000 & 0.99794 \\
& $\mathrm{P}_{\text {Sim.-value }}$ & 0.97954 & 0.93818 & 0.91819 & 0.97880 & 0.97549 & 1.00000 & 0.99176 \\
& $\mathrm{P}_{\text {Dsim.-value }}$ & 0.02046 & 0.06182 & 0.08181 & 0.02120 & 0.02451 & 0.00000 & 0.00824 \\
\hline $\mathbf{G}$ & Kc-value $(\mathrm{HH})$ & 0.99691 & 0.98631 & 1.02395 & 0.99672 & 1.00834 & 1.00207 & 1.00000 \\
& $\mathrm{P}_{\text {Sim.-value }}$ & 0.98768 & 0.94598 & 0.91061 & 0.98693 & 0.96745 & 0.99176 & 1.00000 \\
& $\mathrm{P}_{\text {Dsim.-value }}$ & 0.01232 & 0.05402 & 0.08939 & 0.01307 & 0.03255 & 0.00824 & 0.00000 \\
\hline & & & & & & &
\end{tabular}


OPTINALYSIS

Table 18: Pairewise comparisons among the populations A-G by Geometrical Optinalysis of the Socio-demographic data

\begin{tabular}{|c|c|c|c|c|c|c|c|c|}
\hline & & \multicolumn{7}{|c|}{ One-way Geometrical Optinalysis } \\
\hline & & $\mathbf{A}$ & $\mathbf{B}$ & $\mathbf{C}$ & D & $\mathbf{E}$ & $\mathbf{F}$ & $\mathbf{G}$ \\
\hline \multirow[t]{3}{*}{$\mathbf{A}$} & Kc-value $(\mathrm{HH})$ & 1.00000 & 0.95983 & 1.11464 & 0.99927 & 1.04619 & 1.02047 & 1.01218 \\
\hline & $\mathrm{P}_{\text {Sim. }}$-value & 1.00000 & 0.84552 & 0.65878 & 0.99706 & 0.83774 & 0.92286 & 0.95301 \\
\hline & $\mathrm{P}_{\text {Dsim. }}$-value & 0.00000 & 0.15448 & 0.34122 & 0.00294 & 0.16226 & 0.07714 & 0.04699 \\
\hline \multirow[t]{3}{*}{$\mathbf{B}$} & Kc-value $(\mathrm{HH})$ & 0.84552 & 1.00000 & 0.55109 & 0.84803 & 0.70648 & 0.77964 & 0.80544 \\
\hline & $\mathrm{P}_{\text {Sim. }}$-value & 0.15448 & 0.00000 & 0.44891 & 0.15197 & 0.29352 & 0.22036 & 0.19456 \\
\hline & $\mathrm{P}_{\text {Dsim.-value }}$ & 0.84552 & 1.00000 & 0.55109 & 0.84803 & 0.70648 & 0.77964 & 0.80544 \\
\hline \multirow[t]{3}{*}{$\mathrm{C}$} & Kc-value $(\mathrm{HH})$ & 0.90674 & 0.87359 & 1.00000 & 0.90614 & 0.94455 & 0.92354 & 0.91674 \\
\hline & $\mathrm{P}_{\text {Sim. }}$-value & 0.65878 & 0.55109 & 1.00000 & 0.65676 & 0.78985 & 0.71587 & 0.69255 \\
\hline & $\mathrm{P}_{\text {Dsim.-value }}$ & 0.34122 & 0.44891 & 0.00000 & 0.34324 & 0.21015 & 0.28413 & 0.30745 \\
\hline \multirow[t]{3}{*}{ D } & Kc-value $(\mathrm{HH})$ & 1.00074 & 0.96051 & 1.11556 & 1.00000 & 1.04699 & 1.02124 & 1.01293 \\
\hline & & & & 0.656 & & 3526 & & 021 \\
\hline & $P_{\text {Dsim.-value }}$ & 0.00294 & 0.15197 & 0.34324 & 0.00000 & 0.16474 & 0.07986 & 0.04979 \\
\hline \multirow[t]{3}{*}{$\mathbf{E}$} & Kc-value $(\mathrm{HH})$ & 0.95772 & 0.92081 & 1.06237 & 0.95705 & 1.00000 & 0.97648 & 0.96888 \\
\hline & $\mathrm{P}_{\text {Sim. }}$-value & 0.83774 & 0.70648 & 0.78985 & 0.83526 & 1.00000 & 0.90808 & 0.87928 \\
\hline & $\mathrm{P}_{\text {Dsim. }}$-value & 0.16226 & 0.29352 & 0.21015 & 0.16474 & 0.00000 & 0.09192 & 0.12072 \\
\hline \multirow[t]{3}{*}{$\mathbf{F}$} & Kc-value $(\mathrm{HH})$ & 0.98034 & 0.94170 & 1.09027 & 0.97963 & 1.02468 & 1.00000 & 0.99203 \\
\hline & $\mathrm{P}_{\text {Sim. }}$-value & 0.92286 & 0.77964 & 0.71587 & 0.92014 & 0.90808 & 1.00000 & 0.96839 \\
\hline & $\mathrm{P}_{\text {Dsim. }}$-value & 0.07714 & 0.22036 & 0.28413 & 0.07986 & 0.09192 & 0.00000 & 0.03161 \\
\hline \multirow[t]{3}{*}{$\overline{\mathbf{G}}$} & Kc-value $(\mathrm{HH})$ & 0.98811 & 0.94887 & 1.09990 & 0.98740 & 1.03318 & 1.00809 & 1.00000 \\
\hline & $\mathrm{P}_{\text {Sim.-value }}$ & 0.95301 & 0.80544 & 0.69255 & 0.95021 & 0.87928 & 0.96839 & 1.00000 \\
\hline & $\mathrm{P}_{\text {Dsim.-value }}$ & 0.04699 & 0.19456 & 0.30745 & 0.04979 & 0.12072 & 0.03161 & 0.00000 \\
\hline
\end{tabular}

\section{2 Example 2: Socio-demographic Data (II)}

Table 19 presented the composition of socio-demographic attributes of two populations from the sample 500 individuals. The oder and sequence of the attributes is based on the thoery of Abdullahi (2019b). Geostatistical Optinalysis was used to compare the frequency distribution against the pupulation mean frequency. The result of Optinalysis shows that the frequency distribution between the two populations $\mathrm{A}$ and $\mathrm{B}$ is significant dissimilar $(\mathrm{P}>0.95)$ geostatistically. 
OPTINALYSIS

Table 19: Frequency Composition of Populations and their Geostatistical Significance

\begin{tabular}{|c|c|c|}
\hline & Population A & Population B \\
\hline \multicolumn{3}{|l|}{ (H)Gender } \\
\hline Female & $2,153,943$ & $3,333,252$ \\
\hline Male & $1,267,026$ & $3,508,686$ \\
\hline Age & $3,420,969$ & $6,841,938$ \\
\hline \multicolumn{3}{|l|}{ Childhood } \\
\hline $0-3$ & 245,587 & 491,174 \\
\hline $4-6$ & 274,724 & 519,448 \\
\hline $7-9$ & 324,567 & 679,134 \\
\hline \multicolumn{3}{|l|}{ Adolescence } \\
\hline 10- 15 & 478,234 & 956,468 \\
\hline $16-20$ & 486,345 & 972,690 \\
\hline $21-25$ & 487,468 & 974,936 \\
\hline \multicolumn{3}{|l|}{ Adulthood } \\
\hline 26-40 & 356,234 & 752,468 \\
\hline $41-55$ & 373,787 & 707,574 \\
\hline Above 56 & 394,023 & 788,046 \\
\hline \multicolumn{3}{|l|}{ Education } \\
\hline None & $2,443,870$ & $1,872,740$ \\
\hline Student & 935,764 & $4,871,528$ \\
\hline Teacher & 27,879 & 70,758 \\
\hline Researcher & 13,456 & 26,912 \\
\hline \multicolumn{3}{|l|}{ Occupation } \\
\hline Unemployed & $2,473,049$ & $4,006,098$ \\
\hline Lower scale & 675,345 & $1,850,690$ \\
\hline Middle scale & 256,898 & 913,796 \\
\hline Higher scale & 15,677 & 71,354 \\
\hline \multicolumn{3}{|c|}{ (T)Marital status } \\
\hline Bachelor & $2,638,687$ & $5,277,374$ \\
\hline Divorced & 16,468 & 52,936 \\
\hline Widow(er) & 2,346 & 9,692 \\
\hline Married & 763,468 & $1,501,936$ \\
\hline
\end{tabular}

$\begin{array}{ll}\text { Kc-value } & 0.91838 \\ \mathrm{P}_{\text {Sim. }} \text {-value } & 0.69817 \\ \mathrm{P}_{\text {Dsim. }} \text {-value } & 0.30183\end{array}$

Number of individuals in each population A and B are 3,420,969 and 6,841,938 respectively. 


\section{OPTINALYSIS}

\subsection{Example 3: Psychometric Data (I)}

Table 20 Presented the calculated Value Priority Scores by Kab's Value Survey (KVS) and the frequency of individuals from a given socially dynamic population with different value orientation toward a particular value attribute. (Abdullahi, 2019a). Two-way Optinalysis (using $\operatorname{vps}^{-1} i$ as the element, and the indivduals' relative frequqncy as the co-element) was used to account for the significance of the variation in value practice in the populations. The results of two-way Optinalysis in Table 21 shows that the distribution of Value priority scores (VPS) in all the seven populations A-G are significantly dissimilar (P>0.95) statistically, geostatistically and geometrically.

One sample t-test and Optinalysis was also used to test if the populations' distribution of value priority scores was significantly similar with (represent) the reference standard code of value practice (theoretical mean) of $72 \mathrm{vps}^{-1} \mathrm{p}\left(0.72 \mathrm{vps}^{-1} \mathrm{i} \times 1,500\right.$ individuals $=$ 1080/15 = 72). The results presented in Table 22 shows that Optinalysis and one sample t-test provided almost same conclusion, but Optinalysis with the highest sensitivity.

Table 20: Populations' Value Priority Scores Using Kab's Value Survey

\begin{tabular}{|c|c|c|c|c|c|c|c|c|c|c|c|c|c|c|c|}
\hline & \multicolumn{15}{|c|}{ Kab's Value Survey (KVS) } \\
\hline & \multicolumn{3}{|c|}{5 (Every D \& N) } & \multicolumn{3}{|c|}{4 (Every DL or DN) } & \multicolumn{3}{|c|}{$3($ Every W $)$} & \multicolumn{3}{|c|}{2 (Every M) } & \multicolumn{3}{|c|}{1 (Every Y) } \\
\hline & $\begin{array}{c}3-4 \\
\text { times }\end{array}$ & $\begin{array}{c}2-3 \\
\text { times }\end{array}$ & $\begin{array}{c}1-2 \\
\text { times }\end{array}$ & $\begin{array}{c}3-4 \\
\text { times }\end{array}$ & $\begin{array}{c}2-3 \\
\text { times }\end{array}$ & $\begin{array}{c}1-2 \\
\text { times }\end{array}$ & $\begin{array}{c}3-4 \\
\text { times }\end{array}$ & $\begin{array}{c}2-3 \\
\text { times }\end{array}$ & $\begin{array}{c}1-2 \\
\text { times }\end{array}$ & $\begin{array}{c}3-4 \\
\text { times }\end{array}$ & $\begin{array}{c}2-3 \\
\text { times }\end{array}$ & $\begin{array}{c}1-2 \\
\text { times }\end{array}$ & $\begin{array}{c}3-4 \\
\text { times }\end{array}$ & $\begin{array}{c}2-3 \\
\text { times }\end{array}$ & $\begin{array}{c}1-2 \\
\text { times }\end{array}$ \\
\hline ERN & 4.9 & 4.6 & 4.3 & 3.9 & 3.6 & 3.3 & 2.9 & 2.6 & 2.3 & 1.9 & 1.6 & 1.3 & 0.9 & 0.6 & 0.3 \\
\hline VPS $^{-1} I$ & ${ }^{(\mathrm{H})} 0.98$ & 0.92 & 0.86 & 0.78 & 0.72 & 0.66 & 0.58 & 0.52 & 0.46 & 0.38 & 0.32 & 0.26 & 0.18 & 0.12 & $0.06^{(\mathrm{T})}$ \\
\hline Popn. & \multicolumn{15}{|c|}{ Frequency of respondents } \\
\hline $\mathbf{A}$ & 113 & 147 & 5 & 99 & 89 & 56 & 79 & 113 & 147 & 39 & 113 & 173 & 135 & 79 & 113 \\
\hline B & 97 & 125 & 163 & 122 & 115 & 85 & 89 & 97 & 125 & 9 & 87 & 115 & 85 & 89 & 97 \\
\hline $\mathbf{C}$ & 87 & 98 & 18 & 54 & 72 & 95 & 143 & 127 & 179 & 136 & 195 & 73 & 67 & 69 & 87 \\
\hline D & 257 & 198 & 179 & 111 & 96 & 77 & 75 & 82 & 79 & 27 & 98 & 28 & 36 & 75 & 82 \\
\hline $\mathbf{E}$ & 61 & 80 & 38 & 90 & 30 & 87 & 46 & 61 & 87 & 38 & 90 & 157 & 202 & 212 & 221 \\
\hline $\mathbf{F}$ & 154 & 133 & 169 & 126 & 99 & 123 & 92 & 46 & 69 & 45 & 76 & 21 & 123 & 106 & 118 \\
\hline $\mathbf{G}$ & 232 & 200 & 96 & 44 & 67 & 58 & 67 & 99 & 75 & 86 & 87 & 96 & 99 & 95 & 99 \\
\hline
\end{tabular}

ERN = Event's rank number; D = Day; $\mathrm{N}=$ Night; $\mathrm{DL}=$ Daylight; $\mathrm{DN}=$ Day-night; $\mathrm{W}=$ Week; $\mathrm{M}=$ Month;

$\mathrm{Y}=$ Year; $\mathrm{Np}=1,500=$ Population sample; $\mathrm{VPS}^{-1} \mathrm{I}=$ Value Priority Score Per Individual. 


\section{OPTINALYSIS}

Table 21: Result of Analysis of Populations' Value Priority Scores Using Kab's Value Survey

\begin{tabular}{llcl}
\hline Analysis & Kc-value & P $_{\text {Sim. }}$-value & P $_{\text {Dsim.-value }}$ \\
\hline A & \multicolumn{1}{c}{ Two-way Type (I) Statistical Optinalysis } \\
B & 0.91245 & 0.67800 & 0.32200 \\
C & 0.91213 & 0.67692 & 0.32308 \\
D & 0.92653 & 0.72624 & 0.27376 \\
E & 0.88630 & 0.59162 & 0.40838 \\
F & 0.94119 & 0.77784 & 0.22216 \\
G & 0.90181 & 0.64235 & 0.35765 \\
\hline & 0.63304 & 0.36696 \\
A & 0.89899 & Two-way Geostatistical Optinalysis \\
B & 1.07361 & 0.75883 & 0.24117 \\
C & 0.69595 & 0.30405 \\
D & 1.09847 & 0.82209 & 0.17791 \\
E & 1.05133 & 0.59365 & 0.40635 \\
F & 1.14612 & 0.84597 & 0.15403 \\
G & 1.04354 & 0.65006 & 0.34994 \\
\hline & 1.11862 & 0.63979 & 0.36021 \\
A & 1.12338 & Two-way Geometrical Optinalysis \\
B & 1.37786 & 0.29159 & 0.70841 \\
C & 1.55899 & 0.16474 & 0.83526 \\
D & 1.24268 & 0.43826 & 0.56174 \\
E & 2.04064 & -0.00986 & 1.00986 \\
F & 1.20031 & 0.49952 & 0.50048 \\
G & 1.73660 & 0.08206 & 0.91794 \\
\hline
\end{tabular}


OPTINALYSIS

Table 22: Result of Analysis of Populations' Value Priority Scores Using Kab's Value Survey

\begin{tabular}{lccc}
\hline Analysis & Kc-value & P $_{\text {Sim.-value }}$ & P $_{\text {Dsim.-value }}$ \\
\hline A & & One Sample T-test \\
B & & 0.0352 \\
C & & 0.1584 \\
D & & 0.0115 \\
E & & 0.7484 \\
F & & $<0.0001$ \\
G & & & 0.2976 \\
& & & 0.3860 \\
A & Two-way Type (I) Statistical Optinalysis (By the reference value score) \\
B & 0.85313 & 0.48776 & 0.51224 \\
C & 0.87143 & 0.54430 & 0.45570 \\
D & 0.86313 & 0.51843 & 0.48157 \\
E & 0.87324 & 0.55001 & 0.44999 \\
F & 0.83561 & 0.43526 & 0.56474 \\
G & 0.86834 & 0.53462 & 0.46538 \\
\hline
\end{tabular}

\subsection{Example 4: Psycometric Data (II)}

Table 23 Presented the response ratings and the frequency of individuals from a given socially dynamic population with different percived importance toward a particular value attribute. The result of Optinalysis attached wit Table 23 shows that the individuals' percived importance in the population is significantly dissimilar $(\mathrm{P}>0.95)$ statistically, geostatistically and geometrically.

Table 23: Psychometric Data and the the Results of the Analysis

\begin{tabular}{llll}
\hline Response scale & Ranking & Frequency & \\
\hline${ }^{(\mathrm{H})}$ Extremely important & 5 & 204 & \\
Very important & 4 & 351 & \\
Important & 3 & 463 & \\
Less important & 2 & 110 & \\
Very less important $^{(\mathrm{T})}$ & 1 & 26 & $\mathrm{P}_{\text {Dsim.-value }}$ \\
\hline & Results of One-way & Optinalysis & 0.2774 \\
Type (I) Statistical & Kc-value & P $_{\text {Sim.-value }}$ & 0.1588 \\
Geostatistical & 0.9255 & 0.7226 & 0.5129 \\
Geometrical & 1.0451 & 0.8412 & \\
\hline
\end{tabular}

\subsection{Example 5: Demographic Data}

Table 24 presented the age distribution and individuals' frequency from a given demographically surviving population of diabetic patients. The result of Optinalysis attached with Table 24 shows that the individuals' frequencies are significantly not similar $(\mathrm{P}>0.95)$ statistically, geostatistically and geometrically. 
OPTINALYSIS

Table 24: Psychometric Data and the the Results of the Analysis

\begin{tabular}{llll}
\hline Group & Age range (in Yrs.) & Frequency \\
\hline (H) Group A & $0-3$ & 25 \\
Group B & $4-6$ & 37 & \\
Group C & $7-9$ & 41 \\
Group D & $10-15$ & 34 \\
Group E & $16-20$ & 76 & \\
Group F & $21-25$ & 34 & \\
Group G & $26-40$ & 32 & \\
Group H & $41-55$ & 19 & \\
Group I ${ }^{(T)}$ & $56-$ Above & 21 & $\mathrm{P}_{\text {Dsim.-value }}$ \\
& \multicolumn{4}{c}{ Results of One-way } & Optinalysis \\
& Kc-value & $\mathrm{P}_{\text {Sim. }}$-value & 0.1792 \\
Type (I) Statistical & 0.9531 & 0.8208 & 0.0537 \\
Geostatistical & 1.0140 & 0.9463 & 0.5650 \\
Geometrical & 0.8355 & 0.4350 & \\
\hline
\end{tabular}

\subsection{Example 6: Words Semantics}

Spell checking is one of the important measure of students semantic performane. The word "Psychology" was differently written by students and the results were qualitatively compared with the correct word for similarity measure. The word sequence is numerically transformed by Kabirian (A) and Kabirian (B) Algorithmic transformation appraoach. For Kabirian (A) Algorithmic transformation appraoach, typ II resolution rule was used to for each polymorphic clusters. Geometric Optinalysis and cosine similarity designed online at https://glench.github.io/fuzzyset.js/ was used to calculate the percentage similarity and the similarity scores respectively. The results in Table 25-27 show that Optinalysis is the best approach over cosine similarity measure because it express a broad range of arguments, methodologies and results, more probablistic in conclusion, specific and sensitive to mismatchness. 


\section{OPTINALYSIS}

Table 25: Kabirian Algorithmic Transformations of a Word Strings

\begin{tabular}{|c|c|c|c|c|c|}
\hline & RMMGA & RCMMGA & RCM-(io) FA & RCMm-(io) FA & RCG-(io) FA \\
\hline Query Word & Query Sequence & $\begin{array}{l}\text { Query } \\
\text { Sequence }\end{array}$ & $\begin{array}{l}\text { Query } \\
\text { Sequence }\end{array}$ & & \\
\hline${ }^{(\mathrm{H})}$ Psy*cho*lo\#*gy ${ }^{(\mathrm{T})}$ & $(1,1,1,1,1,1,1,1,1,1)$ & $(1,1,1,1)$ & $(3,3,3,3)$ & $(3,3,3,3)$ & $(3,3,3,3)$ \\
\hline Reflector Word & Reflector Sequence & $\begin{array}{l}\text { Reflector } \\
\text { Sequence }\end{array}$ & $\begin{array}{l}\text { Reflector } \\
\text { Sequence }\end{array}$ & $\begin{array}{l}\text { Reflector } \\
\text { Sequence }\end{array}$ & $\begin{array}{l}\text { Reflector } \\
\text { Sequence }\end{array}$ \\
\hline${ }^{(\mathrm{H})}$ Psy*cho*lo\#*gy\# ${ }^{(\mathrm{T})}$ & $(1,1,1,1,1,1,1,1,1,1)$ & $(1,1,1,1)$ & $(3,3,3,3)$ & $(0,0,0,0)$ & $(0,0,0,0)$ \\
\hline$(\mathrm{H})$ - cy*cho*lo\#* gy $\#^{(\mathrm{T})}$ & $(-1,0,1,1,1,1,1,1,1,1)$ & $(0,1,1,1)$ & $(1,3,3,3)$ & $(1,0,0,0)$ & $(1,0,0,0)$ \\
\hline$(\mathrm{H})-\mathrm{sy}^{*} \mathrm{cho}{ }^{*} \mathrm{lo} \#^{*} \mathrm{gy} \#^{(\mathrm{T})}$ & $(-1,1,1,1,1,1,1,1,1,1)$ & $(0,1,1,1)$ & $(2,3,3,3)$ & $(0,0,0,0)$ & $(1,0,0,0)$ \\
\hline${ }^{(\mathrm{H})}$ Say*cho*lo\#*gy\# ${ }^{(\mathrm{T})}$ & $(0,0,1,1,1,1,1,1,1,1)$ & $(0,1,1,1)$ & $(1,3,3,3)$ & $(2,0,0,0)$ & $(0,0,0,0)$ \\
\hline${ }^{(\mathrm{H})} \mathrm{Psy}{ }^{*} \mathrm{c}-\mathrm{o}^{*} \mathrm{lo}{ }^{*} \mathrm{gy} \#^{(\mathrm{T})}$ & $(1,1,1,1,-1,1,1,1,1,1)$ & $(1,0,1,1)$ & $(3,2,3,3)$ & $(0,0,0,0)$ & $(0,1,0,0)$ \\
\hline${ }^{(\mathrm{H})} \mathrm{Psy}{ }^{*} \mathrm{k}-\mathrm{o}^{*} \mathrm{lo}{ }^{*} \mathrm{gy}^{(\mathrm{T})}$ & $(1,1,1,-1,0,1,1,1,1,1)$ & $(1,0,1,1)$ & $(3,1,3,3)$ & $(0,1,0,0)$ & $(0,1,0,0)$ \\
\hline${ }^{(\mathrm{H})}-\mathrm{cy}{ }^{*} \mathrm{c}-\mathrm{o}^{*} \mathrm{lo} \#^{*} \mathrm{gy} \#^{(\mathrm{T})}$ & $(-1,0,1,1,-1,1,1,1,1,1)$ & $(0,0,1,1)$ & $(1,2,3,3)$ & $(1,0,0,0)$ & $(1,1,0,0)$ \\
\hline$(\mathrm{H})-$ sy*c $-\mathrm{o}^{*} \mathrm{lo} \# * \mathrm{gy} \#^{(\mathrm{T})}$ & $(-1,1,1,1,-1,1,1,1,1,1)$ & $(0,0,1,1)$ & $(2,2,3,3)$ & $(0,0,0,0)$ & $(1,1,0,0)$ \\
\hline${ }^{(\mathrm{H})}$ Say*c $-\mathrm{o}^{*} \mathrm{lo \# *} \mathrm{gy} \#^{(\mathrm{T})}$ & $(0,0,1,1,-1,1,1,1,1,1)$ & $(0,0,1,1)$ & $(1,2,3,3)$ & $(2,0,0,0)$ & $(0,1,0,0)$ \\
\hline$(\mathrm{H})-c{ }^{*} \mathrm{k}-\mathrm{o}^{*} \mathrm{lo} \# * \mathrm{gy} \#^{(\mathrm{T})}$ & $(-1,0,1,0,-1,1,1,1,1,1)$ & $(0,0,1,1)$ & $(1,1,3,3)$ & $(1,1,0,0)$ & $(1,1,0,0)$ \\
\hline${ }^{(\mathrm{H})}-\mathrm{sy} * \mathrm{k}-\mathrm{o}^{*} \mathrm{lo \#} * \mathrm{gy} \#^{(\mathrm{T})}$ & $(-1,1,1,0,-1,1,1,1,1,1)$ & $(0,0,1,1)$ & $(2,1,3,3)$ & $(0,1,0,0)$ & $(1,1,0,0)$ \\
\hline${ }^{(\mathrm{H})}$ Say*k - o*lo\#*gy\# ${ }^{(\mathrm{T})}$ & $(0,0,1,0,-1,1,1,1,1,1)$ & $(0,0,1,1)$ & $(1,1,3,3)$ & $(2,1,0,0)$ & $(0,1,0,0)$ \\
\hline$(\mathrm{H})-$ cy*cho*lu\#*gy\# ${ }^{(\mathrm{T})}$ & $(-1,0,1,1,1,1,1,0,1,1)$ & $(0,1,0,1)$ & $(1,3,2,3)$ & $(1,0,1,0)$ & $(1,0,0,0)$ \\
\hline${ }^{(\mathrm{H})}-$ sy*cho*lu\#*gy\# $^{(\mathrm{T})}$ & $(-1,1,1,1,1,1,1,0,1,1)$ & $(0,1,0,1)$ & $(2,3,2,3)$ & $(0,0,1,0)$ & $(1,0,0,0)$ \\
\hline${ }^{(\mathrm{H})}$ Say*cho*lu\#*gy\# ${ }^{(\mathrm{T})}$ & $(0,0,1,1,1,1,1,0,1,1)$ & $(0,1,0,1)$ & $(1,3,2,3)$ & $(2,0,1,0)$ & $(0,0,0,0)$ \\
\hline${ }^{(\mathrm{H})}$ Psy*c - o*lu\#*gy\# ${ }^{(\mathrm{T})}$ & $(1,1,1,1,-1,1,1,0,1,1)$ & $(1,0,0,1)$ & $(3,2,2,3)$ & $(0,0,1,0)$ & $(0,1,0,0)$ \\
\hline${ }^{(\mathrm{H})} \mathrm{Psy}^{*} \mathrm{k}-\mathrm{o}^{*} \mathrm{lu} \#^{*} \mathrm{gy}^{(\mathrm{T})}$ & $(1,1,1,0,-1,1,1,0,1,1)$ & $(1,0,0,1)$ & $(3,1,2,3)$ & $(0,1,1,0)$ & $(0,1,0,0)$ \\
\hline$(\mathrm{H})-c{ }^{*} \mathrm{c}-\mathrm{o}^{*} \mathrm{lu} \# * \mathrm{gy} \#^{(\mathrm{T})}$ & $(-1,0,1,1,-1,1,1,0,1,1)$ & $(0,0,0,1)$ & $(1,2,2,3)$ & $(1,0,1,0)$ & $(1,1,0,0)$ \\
\hline${ }^{(\mathrm{H})}-\mathrm{sy}^{*} \mathrm{c}-\mathrm{o}^{*} \mathrm{lu} \# * \mathrm{gy}^{(\mathrm{T})}$ & $(-1,1,1,1,-1,1,1,0,1,1)$ & $(0,0,0,1)$ & $(2,2,2,3)$ & $(0,0,1,0)$ & $(1,1,0,0)$ \\
\hline${ }^{(\mathrm{H})}$ Say*c - o*lu\#* $^{*} \mathrm{gy}^{(\mathrm{T})}$ & $(0,0,1,1,-1,1,1,0,1,1)$ & $(0,0,0,1)$ & $(1,2,2,3)$ & $(2,0,1,0)$ & $(0,1,0,0)$ \\
\hline${ }^{(\mathrm{H})}-\mathrm{cy} * \mathrm{k}-\mathrm{o}^{*} \mathrm{lu} \# * \mathrm{gy} \#^{(\mathrm{T})}$ & $(-1,0,1,0,-1,1,1,0,1,1)$ & $(0,0,0,1)$ & $(1,1,2,3)$ & $(1,1,1,0)$ & $(1,1,0,0)$ \\
\hline${ }^{(\mathrm{H})}-$ sy*k - o*la\#*gy\# ${ }^{(\mathrm{T})}$ & $(-1,1,1,0,-1,1,1,0,1,1)$ & $(0,0,0,1)$ & $(2,1,2,3)$ & $(0,1,1,0)$ & $(1,1,0,0)$ \\
\hline${ }^{(\mathrm{H})}$ Say*k - o*la\#*gy\# ${ }^{(\mathrm{T})}$ & $(0,0,1,0,-1,1,1,0,1,1)$ & $(0,0,0,1)$ & $(1,1,2,3)$ & $(2,1,1,0)$ & $(0,1,0,0)$ \\
\hline${ }^{(\mathrm{H})}$ Sai*k - o*la\#* gi $^{(\mathrm{T})}$ & $(0,0,0,0,-1,1,1,0,1,0)$ & $(0,0,0,0)$ & $(0,1,2,2)$ & $(3,1,1,1)$ & $(0,1,0,0)$ \\
\hline
\end{tabular}

RMMGA = Reflective Match-mismatch-gab Approach;

RCMMGA = Reflective Cluster Match-mismatch-gab Approach;

RCM-(io) FA = Reflective Match-(in order) Frequency Approach;

RCMm-(io) FA = Reflective Mismatch-(in order) Frequency Approach;

RCG-(io) FA = Reflective Gab-(in order) Frequency Approach

$*=$ Separate between the clusters;

- = Indictes the point of ommions or deletion

Note: Type II Resolution Rule is considered for each cluster. 


\section{OPTINALYSIS}

Table : Results of the Geometrical Optinalysis of the Word Strings

\begin{tabular}{|c|c|c|c|c|c|}
\hline & $\begin{array}{r}\text { Reflective Match-mi } \\
\text { (One-way }\end{array}$ & $\begin{array}{l}\text { match-gab Appraoch } \\
\text { Optinalysis) }\end{array}$ & $\begin{array}{r}\text { Reflective Cluster Match- } \\
\text { way } 0 \\
\end{array}$ & $\begin{array}{l}\text { imatch-gab Appraoch (One- } \\
\text { inalysis) }\end{array}$ & $\begin{array}{c}\text { Cosine } \\
\text { similarity }\end{array}$ \\
\hline Query Word & $\bigwedge_{B}^{( \pm N=0)}: \int_{\in(R)}^{\in(Q)}=?(? \%)$ & $\bigvee_{( \pm N=0)}^{B}: \int_{\in(R)}^{\in(Q)}=?(? \%)$ & $\bigwedge_{B}^{( \pm N=0)}: \int_{\in(R)}^{\in(Q)}=?(? \%)$ & $\bigvee_{( \pm N=0)}^{B}: \int_{c(R)}^{\epsilon(Q)}=?(? \%)$ & \\
\hline${ }^{(\mathrm{H})}$ Psy*cho*1o*gy ${ }^{(\mathrm{T})}$ & & & & & \\
\hline Reflector Word & & & & & \\
\hline${ }^{(\mathrm{H})}$ Psy*cho*1o* $\mathrm{gy}^{(\mathrm{T})}$ & $1.0000(100)$ & $1.0000(100)$ & $1.0000(100)$ & $1.0000(100)$ & 1 \\
\hline${ }^{(\mathrm{H})}-\mathrm{cy}^{*} \mathrm{cho}^{*} \mathrm{lo}^{*} \mathrm{gy}^{(\mathrm{T})}$ & $1.1835(52.65)$ & $1.0219(91.79)$ & $1.1290(62.79)$ & $1.0294(89.19)$ & 0.738 \\
\hline${ }^{(\mathrm{H})}-\mathrm{sy}^{*} \mathrm{cho}^{*} \mathrm{lo} * \mathrm{gy}^{(\mathrm{T})}$ & $1.1124(66.39)$ & $1.0102(96.04)$ & $1.1290(62.79)$ & $1.0294(89.19)$ & 0.843 \\
\hline${ }^{(\mathrm{H})}$ Say*cho*lo*gy ${ }^{(\mathrm{T})}$ & $1.1061(67.80)$ & $1.0154(94.12)$ & $1.1290(62.79)$ & $1.0294(89.19)$ & 0.700 \\
\hline${ }^{(\mathrm{H})}$ Psy*c - o* $\mathrm{o}^{*} \mathrm{gy}^{(\mathrm{T})}$ & $1.0645(78.38)$ & $1.0532(81.65)$ & $1.0938(70.73)$ & $1.0606(79.49)$ & 0.738 \\
\hline${ }^{(\mathrm{H})} \mathrm{Psy}^{*} \mathrm{k}-\mathrm{O}^{*} \mathrm{lo}^{*} \mathrm{gy}^{(\mathrm{T})}$ & $1.1198(64.76)$ & $1.0747(75.59)$ & $1.0938(70.73)$ & $1.0606(79.49)$ & 0.632 \\
\hline${ }^{(\mathrm{H})}-\mathrm{cy}{ }^{*} \mathrm{c}-\mathrm{o}^{*} \mathrm{lo}^{*} \mathrm{gy}{ }^{(\mathrm{T})}$ & $1.3306(33.60)$ & $1.0927(70.98)$ & $1.3043(36.36)$ & $1.1111(66.67)$ & 0.447 \\
\hline${ }^{(\mathrm{H})}-\mathrm{sy}^{*} \mathrm{c}-\mathrm{o}^{*} \mathrm{lo}^{*} \mathrm{gy} \mathrm{y}^{(\mathrm{T})}$ & $1.2222(46.67)$ & $1.0732(76.00)$ & $1.3043(36.36)$ & $1.1111(66.67)$ & 0.559 \\
\hline${ }^{(\mathrm{H})}$ Say*c - o*lo* $\mathrm{gy}^{(\mathrm{T})}$ & $1.2138(47.90)$ & $1.0798(74.26)$ & $1.3043(36.36)$ & $1.1111(66.67)$ & 0.422 \\
\hline (H) $-\mathrm{cy} * \mathrm{k}-\mathrm{o}^{*} \mathrm{lo}^{*} \mathrm{gy} \mathrm{y}^{(\mathrm{T})}$ & $1.4528(23.20)$ & $1.1324(62.11)$ & $1.3043(36.36)$ & $1.1111(66.67)$ & 0.447 \\
\hline${ }^{(\mathrm{H})}-\mathrm{sy} * \mathrm{k}-\mathrm{o}^{*} \mathrm{lo}^{*} \mathrm{gy}{ }^{(\mathrm{T})}$ & $1.3095(35.80)$ & $1.1074(67.51)$ & $1.3043(36.36)$ & $1.1111(66.67)$ & 0.447 \\
\hline${ }^{(\mathrm{H})}$ Say*k - o*lo*gy ${ }^{(\mathrm{T})}$ & $1.2992(36.93)$ & $1.1149(65.83)$ & $1.3043(36.36)$ & $1.1111(66.67)$ & 0.422 \\
\hline${ }^{(\mathrm{H})}-\mathrm{cy}^{*} \mathrm{cho} * \mathrm{lu}^{*} \mathrm{gy}^{(\mathrm{T})}$ & $1.2222(46.67)$ & $1.0732(76.00)$ & $1.2500(42.86)$ & $1.1538(57.89)$ & 0.422 \\
\hline${ }^{(\mathrm{H})}-$ sy*cho*lu*gy ${ }^{(\mathrm{T})}$ & $1.1402(60.52)$ & $1.0565(80.68)$ & $1.2500(42.86)$ & $1.1538(57.89)$ & 0.527 \\
\hline${ }^{(\mathrm{H})}$ Say*cho*lu*gy ${ }^{(\mathrm{T})}$ & $1.1333(61.90)$ & $1.0625(78.95)$ & $1.2500(42.86)$ & $1.1538(57.89)$ & 0.400 \\
\hline${ }^{(\mathrm{H})}$ Psy*c - o*lu*gy ${ }^{(\mathrm{T})}$ & $1.0872(72.35)$ & $1.1065(67.71)$ & $1.2000(50.00)$ & $1.2000(50.00)$ & 0.422 \\
\hline${ }^{(\mathrm{H})}$ Psy*k - o*lu* gy ${ }^{(\mathrm{T})}$ & $1.1429(60.00)$ & $1.1429(60.00)$ & $1.2000(50.00)$ & $1.2000(50.00)$ & 0.572 \\
\hline${ }^{(H)}-c^{*} c-o^{*} l u^{*} g y^{(T)}$ & $1.4000(27.27)$ & $1.1667(55.56)$ & $1.5625(16.28)$ & $1.3158(35.14)$ & 0.402 \\
\hline$(\mathrm{H})-\mathrm{sy} * \mathrm{c}-\mathrm{o}^{*} l \mathrm{u}^{*} \mathrm{gy}(\mathrm{T})$ & $1.2692(40.43)$ & $1.1379(60.98)$ & $1.5625(16.28)$ & $1.3158(35.14)$ & 0.503 \\
\hline${ }^{(\mathrm{H})} \mathrm{Say}^{*} \mathrm{c}-\mathrm{o}^{*} \mathrm{lu}{ }^{*} \mathrm{gy}^{(\mathrm{T})}$ & $1.2595(41.63)$ & $1.1458(59.42)$ & $1.5625(16.28)$ & $1.3158(35.14)$ & 0.381 \\
\hline${ }^{(\mathrm{H})}-\mathrm{cy} * \mathrm{k}-\mathrm{o}^{*} \mathrm{lu} \mathrm{u}^{*} \mathrm{gy}^{(\mathrm{T})}$ & $1.5543(16.73)$ & $1.2222(46.67)$ & $1.5625(16.28)$ & $1.3158(35.14)$ & 0 \\
\hline${ }^{(\mathrm{H})}-\mathrm{sy} * \mathrm{k}-\mathrm{o} * \mathrm{la} * \mathrm{gy}^{(\mathrm{T})}$ & $1.3750(29.41)$ & $1.1846(52.48)$ & $1.5625(16.28)$ & $1.3158(35.14)$ & 0.402 \\
\hline${ }^{(\mathrm{H})}$ Say*k - o*la* $\mathrm{gy}^{(\mathrm{T})}$ & $1.3628(30.51)$ & $1.1938(50.98)$ & $1.5625(16.28)$ & $1.3158(35.14)$ & 0 \\
\hline${ }^{(\mathrm{H})}$ Sai*k - o*la*gi ${ }^{(\mathrm{T})}$ & $1.6098(13.79)$ & $1.4043(26.92)$ & $2.0000(0.00)$ & $2.0000(0.00)$ & 0 \\
\hline
\end{tabular}

Note: Type II Resolution Rule is considered for each cluster. 


\section{OPTINALYSIS}

Table 27: Results of the Geometrical Optinalysis of the Word Strings

\begin{tabular}{|c|c|c|c|c|c|c|c|}
\hline \multirow[b]{2}{*}{ Query Word } & \multicolumn{2}{|c|}{$\begin{array}{l}\text { RCM-(io)FA } \\
\text { (Optinalysis) }\end{array}$} & \multicolumn{2}{|c|}{$\begin{array}{c}\text { RCMm-(io)FA } \\
\text { (Optinalysis) }\end{array}$} & \multicolumn{2}{|c|}{$\begin{array}{l}\text { RCG-(io)FA } \\
\text { (Optinalysis) }\end{array}$} & \multirow[t]{2}{*}{$\begin{array}{c}\text { Cosine } \\
\text { Similarity }\end{array}$} \\
\hline & H-H Pairing & T-T Pairing & H-H Pairing & T-T Pairing & H-H Pairing & T-T Pairing & \\
\hline \multicolumn{8}{|l|}{${ }^{(\mathrm{H})}$ Psy*cho*lo\#*gy\# ${ }^{(\mathrm{T})}$} \\
\hline \multicolumn{8}{|l|}{ Reflector Word } \\
\hline${ }^{(\mathrm{H})}$ Psy* $^{*}$ cho*lo\#* gy\# $^{(\mathrm{T})}$ & $1.0000(100)$ & $1.0000(100)$ & $2.0000(0.00)$ & $2.0000(0.00)$ & $2.0000(0.00)$ & $2.0000(0.00)$ & 1 \\
\hline 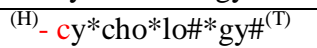 & $1.0784(74.60)$ & $1.0185(92.98)$ & $1.6667(11.11)$ & $1.8056(5.69)$ & $1.6667(11.11)$ & $1.8056(5.69)$ & 0.738 \\
\hline (H) - sy*cho*lo\#*gy\# ${ }^{(\mathrm{T})}$ & $1.0360(86.99)$ & $1.0088(96.58)$ & $2.0000(0.00)$ & $2.0000(0.00)$ & $1.6667(11.11)$ & $1.8056(5.69)$ & 0.843 \\
\hline${ }^{(\mathrm{H})}$ Say*cho*lo\#* gy\# ${ }^{(\mathrm{T})}$ & $1.0784(74.60)$ & $1.0185(92.98)$ & $1.4583(22.81)$ & $1.6667(11.11)$ & $2.0000(0.00)$ & $2.0000(0.00)$ & 0.700 \\
\hline${ }^{(\mathrm{H})} \mathrm{Psy}{ }^{*} \mathrm{c}-\mathrm{o}^{*} \mathrm{lo \#}{ }^{*} \mathrm{gy} \#^{(\mathrm{T})}$ & $1.0268(90.08)$ & $1.0177(93.28)$ & $2.0000(0.00)$ & $2.0000(0.00)$ & $1.7105(9.24)$ & $1.7568(7.44)$ & 0.738 \\
\hline${ }^{(\mathrm{H})}$ Psy*k - o*lo\#*gy\# ${ }^{(\mathrm{T})}$ & $1.0577(80.33)$ & $1.0377(86.44)$ & $1.7105(9.24)$ & $1.7568(7.44)$ & $1.7105(9.24)$ & $1.7568(7.44)$ & 0.632 \\
\hline${ }^{(\mathrm{H})}-\mathrm{cy}{ }^{*} \mathrm{c}-\mathrm{o}^{*} \mathrm{lo} \# *$ gy $\#^{(\mathrm{T})}$ & $1.1170(65.35)$ & $1.0396(85.84)$ & $1.6667(11.11)$ & $1.8056(5.69)$ & $1.4894(20.69)$ & $1.6279(12.90)$ & 0.447 \\
\hline$(\mathrm{H})-\mathrm{sy} * \mathrm{c}-\mathrm{o}^{*} \mathrm{lo} \#^{*} \mathrm{gy} \#^{(\mathrm{T})}$ & $1.0680(77.42)$ & $1.0280(89.66)$ & $2.0000(0.00)$ & $2.0000(0.00)$ & $1.4894(20.69)$ & $1.6279(12.90)$ & 0.559 \\
\hline${ }^{(\mathrm{H})}$ Say*c $-\mathrm{O}^{*}$ lo\#* gy\# $\#^{(\mathrm{T})}$ & $1.1170(65.35)$ & $1.0396(85.84)$ & $1.4583(22.81)$ & $1.6667(11.11)$ & $1.7105(9.24)$ & $1.7568(7.44)$ & 0.422 \\
\hline$(\mathrm{H})-c{ }^{*} \mathrm{k}-\mathrm{o}^{*} \mathrm{lo} \# * \mathrm{gy} \#^{(\mathrm{T})}$ & $1.1628(56.25)$ & $1.0638(78.57)$ & $1.4894(20.69)$ & $1.6279(12.90)$ & $1.4894(20.69)$ & $1.6279(12.90)$ & 0.447 \\
\hline${ }^{(\mathrm{H})}-\mathrm{sy} * \mathrm{k}-\mathrm{o}^{*} \mathrm{lo \#} * \mathrm{gy} \#^{(\mathrm{T})}$ & $1.1053(68.00)$ & $1.0500(82.61)$ & $1.7105(9.24)$ & $1.7568(7.44)$ & $1.4894(20.69)$ & $1.6279(12.90)$ & 0.447 \\
\hline${ }^{(\mathrm{H})}$ Say*k - o*lo\#* gy\# ${ }^{(\mathrm{T})}$ & $1.1628(56.25)$ & $1.0638(78.57)$ & $1.3393(32.74)$ & $1.5306(18.11)$ & $1.7105(9.24)$ & $1.7568(7.44)$ & 0.422 \\
\hline${ }^{(\mathrm{H})}-$ cy*$^{*}$ cho*lu\#* gy $^{(\mathrm{T})}$ & $1.1053(68.00)$ & $1.0500(82.61)$ & $1.5217(18.64)$ & $1.5909(14.75)$ & $1.6667(11.11)$ & $1.8056(5.69)$ & 0.422 \\
\hline$(\mathrm{H})-$ sy*cho*lu\#*gy\# $^{(\mathrm{T})}$ & $1.0577(80.33)$ & $1.0377(86.44)$ & $1.7568(7.44)$ & $1.7105(9.24)$ & $1.6667(11.11)$ & $1.8056(5.69)$ & 0.527 \\
\hline${ }^{(\mathrm{H})} \mathrm{Say}^{*} \mathrm{cho}^{*}$ lu\#*gy\#${ }^{(\mathrm{T})}$ & $1.1053(68.00)$ & $1.0500(82.61)$ & $1.3636(30.43)$ & $1.5000(20.00)$ & $2.0000(0.00)$ & $2.0000(0.00)$ & 0.400 \\
\hline${ }^{(\mathrm{H})}$ Psy*c - o*lu\#*gy\# ${ }^{(\mathrm{T})}$ & $1.0476(83.33)$ & $1.0476(83.33)$ & $1.7568(7.44)$ & $1.7105(9.24)$ & $1.7105(9.24)$ & $1.7568(7.44)$ & 0.422 \\
\hline${ }^{(\mathrm{H})}$ Psy*k - o*lu\#* gy\# ${ }^{(\mathrm{T})}$ & $1.0825(73.55)$ & $1.0714(76.47)$ & $1.5556(16.67)$ & $1.5556(16.67)$ & $1.7105(9.24)$ & $1.7568(7.44)$ & 0.572 \\
\hline${ }^{(\mathrm{H})}-\mathrm{cy} * \mathrm{c}-\mathrm{o}^{*} \mathrm{lu} \#^{*} \mathrm{gy} \#^{(\mathrm{T})}$ & $1.1494(58.73)$ & $1.0753(75.44)$ & $1.5217(18.64)$ & $1.5909(14.75)$ & $1.4894(20.69)$ & $1.6279(12.90)$ & 0.402 \\
\hline$(\mathrm{H})-\mathrm{sy} * \mathrm{c}-\mathrm{o}^{*} \mathrm{lu} \#^{*} \mathrm{gy} \#^{(\mathrm{T})}$ & $1.0938(70.73)$ & $1.0606(79.49)$ & $1.7568(7.44)$ & $1.7105(9.24)$ & $1.4894(20.69)$ & $1.6279(12.90)$ & 0.503 \\
\hline${ }^{(\mathrm{H})}$ Say*c - o*lu\#* gy\# ${ }^{(\mathrm{T})}$ & $1.1494(58.73)$ & $1.0753(75.44)$ & $1.3636(30.43)$ & $1.5000(20.00)$ & $1.7105(9.24)$ & $1.7568(7.44)$ & 0.381 \\
\hline$(\mathrm{H})-$ cy*k - o*lu\#*gy\# ${ }^{(\mathrm{T})}$ & $1.2025(49.61)$ & $1.1047(68.14)$ & $1.3889(28.21)$ & $1.4706(21.95)$ & $1.4894(20.69)$ & $1.6279(12.90)$ & 0 \\
\hline${ }^{(\mathrm{H})}-\mathrm{sy} * \mathrm{k}-\mathrm{o}^{*} \mathrm{la} \# * \mathrm{gy}^{(\mathrm{T})}$ & $1.1364(61.29)$ & $1.0870(72.41)$ & $1.5556(16.67)$ & $1.5556(16.67)$ & $1.4894(20.69)$ & $1.6279(12.90)$ & 0.402 \\
\hline${ }^{(\mathrm{H})}$ Say*k - o*la\#* gy\# ${ }^{(\mathrm{T})}$ & $1.2025(49.61)$ & $1.1047(68.14)$ & $1.2698(40.35)$ & $1.4035(26.98)$ & $1.7105(9.24)$ & $1.7568(7.44)$ & 0 \\
\hline${ }^{(\mathrm{H})}$ Sai*k - o*la\#* gi $\#^{(\mathrm{T})}$ & $1.3281(33.86)$ & $1.1972(50.44)$ & $1.1538(57.89)$ & $1.2500(42.86)$ & $1.7105(9.24)$ & $1.7568(7.44)$ & 0 \\
\hline
\end{tabular}

H-H = Head-to-head Pairing ; T-T = Tail-totail Pairing

RCM-(io) FA = Reflective Match-(in order) Frequency Approach;

RCMm-(io) FA = Reflective Mismatch-(in order) Frequency Approach;

RCG-(io) FA = Reflective Gab-(in order) Frequency Approach 
OPTINALYSIS

\subsection{Example 7: Genetics and Bioinformatics (Homology searches)}

Tables 28-32 presented are the set of problems regarding nucleotide base and protein sequences comparisions. The sequences were numerically transformed by Kabirian (A) and Kabirian (B) Algorithmic transformation appraoaches. For Kabirian (A) Algorithmic transformation appraoach, type I resolution rule was used to for each of the polymorphic clusters. Geometric Optinalysis was used to calculate the percentage similarities. Moreover, an online BLAST software at a link https://blast.ncbi.nlm.nih.gov/Blast.cgi was used to perform pairewise alignment and obtained the blasted results of percentage idenentity and similarity, and the Needleman-Wunsch score. The results show that Optinalysis is more advanced method, beecause it express a broad range of methodologies and results (See Tables 28-32 for the different results from different Kabirian transformation algorithms used). Optinalyis is more specific to the data sequence geometry (Seen Tables 28-32) and very sensitive to changes in magnitude and position, sequence rearrangements, sequence length, may combine the computation of match, mismatch and gab at same time, or each can be seperately quantified. The adopted methods of identity and similarity detection used in the software (the BLAST algorithm) considered the whole aligned sequences as a one cluster for match or gab frequency scores, and this lack of clustering distinguishes it from Kabirian (B) algorithmic transformation, in addition to Optinalysis compare among the sequences rather than by simple fraction.as use in BLAST.

Moreover, dispite the disregardness of the BLAST algorithms to the sequence geometry, even the Needleman-Wunsch algorithm is some times bias. Bias in the sanse that two distinctly different sequence may have same results as pairewisely compared to a same query sequence.

However, Optinalysis can be a good choice for numerical chromosomal abberations due to delection, duplication, translocation, and inversion. Optinalysis further revealed that organisms with short genomic sequence are more sensitive to mutation by even few nuclotide changes that those organisms with very lengthy genomic sequence. This explain why prokaryotic DNA/RNA are more sensitive to mutation and immensely used in mutation study, because the mutagenic effects are more express phenotypically even if the mutation rate is low. For general mutation detection, Kabirian (A) algorithmic transformations can be suitable, but for the case of deletion, duplication, inversion and translocation each seperately, Kabirian algorithmic transformations can be used.

In bioinformatics, lack of statistical confidence estimation, alignment errors, low specificity and sensitivity, are some of the problems associated with homogy search algorithms (Lunter et. al. 2008). Therefore, Optinalysis has solved the problem of lack of confidence estimates which other methods have failed to explain the result in a probalistic manner (Lunter et. al. 2008). Statistical confidence estimation, and geometric specicifity and sensitivity is one of the grand acheivement using Optinalysis to compare among a pairwise set of nuclotide and protein sequnces. Other algorithms such BLAST is not geomeric analytically. The accuracy of the result following Optinalysis depends on the correctiness and effectiveness of the sequence pairwise alignments. What among the homology search problems Optinalysis have failed to solve include an alignment errors. 


\section{OPTINALYSIS}

Table 28: Kabirian Algorithmic Transformations of a Nucleotide Base Sequences

\begin{tabular}{|c|c|c|c|}
\hline & & \multicolumn{2}{|c|}{ Kabirian Transformation Algorithm } \\
\hline & CASE A & $\begin{array}{l}\text { Reflective Match-mismatch-gab } \\
\text { Approach }\end{array}$ & Molecular Mass Score Approach \\
\hline Items & Query Sequence & Transformed Query Sequence & Transformed Query Sequence \\
\hline 1 & ${ }^{(\mathrm{H})}$ AGCTGGCATTATTTATGGCTG $^{(\mathrm{T})}$ & $(1,1,1,1,1,1,1,1,1,1,1,1,1,1,1,1,1,1,1,1,1)$ & $\begin{array}{c}135,151,111,126,151,151,111,135,126,126,135,126,126,126 \\
, 135,126,151,151,111,126,151,\end{array}$ \\
\hline & Reflector Sequence & Transformed Reflector Sequence & Transformed Reflector Sequence \\
\hline 2 & ${ }^{(\mathrm{H})}$ AGCTGGCATTATTTATGGCTG $^{(\mathrm{T})}$ & $(1,1,1,1,1,1,1,1,1,1,1,1,1,1,1,1,1,1,1,1,1)$ & $\begin{array}{c}135,151,111,126,151,151,111,135,126,126,135,126,126,126 \\
, 135,126,151,151,111,126,151,\end{array}$ \\
\hline 3 & ${ }^{(\mathrm{H})}$ CGCTGGCATTATTTATGGCTG ${ }^{(\mathrm{T})}$ & $(0,1,1,1,1,1,1,1,1,1,1,1,1,1,1,1,1,1,1,1,1)$ & $\begin{array}{c}111,151,111,126,151,151,111,135,126,126,135,126,126,126 \\
, 135,126,151,151,111,126,151,\end{array}$ \\
\hline 4 & ${ }^{(\mathrm{H})}$ AGCTGGCATTCTTTATGGCTG ${ }^{(\mathrm{T})}$ & $(1,1,1,1,1,1,1,1,1,1,0,1,1,1,1,1,1,1,1,1,1)$ & $\begin{array}{c}135,151,111,126,151,151,111,135,126,126,111,126,126,126 \\
, 135,126,151,151,111,126,151,\end{array}$ \\
\hline 5 & ${ }^{(\mathrm{H})}$ AGCTGGCATTATTTATGGCTT $^{(\mathrm{T})}$ & $(1,1,1,1,1,1,1,1,1,1,1,1,1,1,1,1,1,1,1,1,0)$ & $\begin{array}{c}135,151,111,126,151,151,111,135,126,126,135,126,126,126 \\
, 135,126,151,151,111,126,126,\end{array}$ \\
\hline 6 & ${ }^{(\mathrm{H})}$ AGCTGGCATTATTTATGGCAA ${ }^{(\mathrm{T})}$ & $(1,1,1,1,1,1,1,1,1,1,1,1,1,1,1,1,1,1,1,0,0)$ & $\begin{array}{c}135,151,111,126,151,151,111,135,126,126,135,126,126,126 \\
, 135,126,151,151,111,135,135\end{array}$ \\
\hline 7 & ${ }^{(\mathrm{H})}$ AGCTGGCATTGGTTATGGCTG $^{(\mathrm{T})}$ & $(1,1,1,1,1,1,1,1,1,1,0,0,1,1,1,1,1,1,1,1,1)$ & $\begin{array}{c}135,151,111,126,151,151,111,135,126,126,151,151,126,126 \\
, 135,126,151,151,111,126,151,\end{array}$ \\
\hline 8 & ${ }^{(\mathrm{H})}$ GACTGGCATTATTTATGGCTG ${ }^{(\mathrm{T})}$ & $(0,0,1,1,1,1,1,1,1,1,1,1,1,1,1,1,1,1,1,1,1)$ & $\begin{array}{c}151,135,111,126,151,151,111,135,126,126,135,126,126,126 \\
, 135,126,151,151,111,126,151,\end{array}$ \\
\hline 9 & ${ }^{(\mathrm{H})}$ TCGAGGCATTATTTATGGCTG $^{(\mathrm{T})}$ & $(0,0,0,0,1,1,1,1,1,1,1,1,1,1,1,1,1,1,1,1,1)$ & $\begin{array}{c}126,111,151,135,151,151,111,135,126,126,135,126,126,126 \\
, 135,126,151,151,111,126,151,\end{array}$ \\
\hline 10 & ${ }^{(\mathrm{H})}$ AGCTGGCAGCTGTTATGGCTG $^{(\mathrm{T})}$ & $(1,1,1,1,1,1,1,1,0,0,0,0,1,1,1,1,1,1,1,1,1)$ & $\begin{array}{c}135,151,111,126,151,151,111,135,151,111,126,151,126,126 \\
, 135,126,151,151,111,126,151,\end{array}$ \\
\hline 11 & ${ }^{(\mathrm{H})}$ AGCTGGCATTATTTATGTTAT ${ }^{(\mathrm{T})}$ & $(1,1,1,1,1,1,1,1,1,1,1,1,1,1,1,1,1,0,0,0,0)$ & $\begin{array}{c}135,151,111,126,151,151,111,135,126,126,135,126,126,126 \\
135,126,151,126,126,135,126,\end{array}$ \\
\hline 12 & ${ }^{(\mathrm{H})}$ TTATACTCGTCTTTATGGCTG $^{(\mathrm{T})}$ & $(0,0,0,0,0,0,0,0,0,0,0,1,1,1,1,1,1,1,1,1,1)$ & $\begin{array}{c}126,126 \\
135,126,135,111,126,111,151,126,111,126,126,126,135,126 \\
, 151,151,111,126,151,\end{array}$ \\
\hline 13 & ${ }^{(\mathrm{H})}$ CAGTGGCATGGCTTATGGTCA ${ }^{(\mathrm{T})}$ & $(0,0,0,1,1,1,1,1,1,0,0,0,1,1,1,1,1,1,0,0,0)$ & $\begin{array}{c}111,135,151,126,151,151,111,135,126,151,151,111,126,126 \\
, 135,126,151,151,126,111,135,\end{array}$ \\
\hline 14 & ${ }^{(\mathrm{H})}$ TGCAAGCATCGCTTACGGATG $^{(\mathrm{T})}$ & $(0,1,1,0,0,1,1,1,1,0,0,0,1,1,1,0,1,1,0,1,1)$ & $\begin{array}{c}126,151,111,135,135,151,111,135,126,111,151,111,126,126 \\
, 135,111,151,151,135,126,151,\end{array}$ \\
\hline & CASE B & & \\
\hline & Query Sequence & Transformed Query Sequence & Transformed Query Sequence \\
\hline 15 & ${ }^{(\mathrm{H})}$ AGCTGGCATTATTTATGGCTG ${ }^{(\mathrm{T})}$ & $(1,1,1,1,1,1,1,1,1,1,1,1,1,1,1,1,1,1,1,1,1)$ & $\begin{array}{c}135,151,111,126,151,151,111,135,126,126,135,126,126,126 \\
, 135,126,151,151,111,126,151,\end{array}$ \\
\hline & Reflector Sequence & Transformed Reflector Sequence & Transformed Reflector Sequence \\
\hline 16 & (H) $_{\text {- }}$ - TGGCATTATTTATGGCTG $^{(\mathrm{T})}$ & $(-1,-1,-$ & $0,0,0,126,151,151,111,135,126,126,135,126,126,126,135,12$ \\
\hline
\end{tabular}


OPTINALYSIS

\begin{tabular}{|c|c|c|c|}
\hline & & $1,1,1,1,1,1,1,1,1,1,1,1,1,1,1,1,1,1,1)$ & 6,151,151,111,126,151, \\
\hline 17 & ${ }^{(\mathrm{H})}$ AGCTGGCAT - - TTATGGCTG $^{(\mathrm{T})}$ & $\begin{array}{c}(1,1,1,1,1,1,1,1,1,1,-1,-1,- \\
1,1,1,1,1,1,1,1,1) \\
\end{array}$ & $\begin{array}{c}135,151,111,126,151,151,111,135,126,0,0,0,126,126,135,12 \\
6,151,151,111,126,151,\end{array}$ \\
\hline 18 & ${ }^{(\mathrm{H})}$ AGCTGGCATTATTTATGG - - ${ }^{(\mathrm{T})}$ & $\begin{array}{c}(1,1,1,1,1,1,1,1,1,1,1,1,1,1,1,1,1,1,-1,-1,- \\
1)\end{array}$ & $\begin{array}{c}135,151,111,126,151,151,111,135,126,126,135,126,126,126 \\
, 135,126,151,151,0,0,0,\end{array}$ \\
\hline 19 & ${ }^{(\mathrm{H})}$ AGC - GGCAT - - TTT - TGGCTG $^{(\mathrm{T})}$ & $\begin{array}{c}(1,1,1,-1,1,1,1,1,1,-1,-1,1,1,1,- \\
1,1,1,1,1,1,1)\end{array}$ & $\begin{array}{c}135,151,111,0,151,151,111,135,126,0,0,126,126,126,0,126 \\
151,151,111,126,151\end{array}$ \\
\hline 20 & $\left({ }^{(\mathrm{H})} \ldots \ldots-\ldots-\right.$ TTATGGCTG $^{(\mathrm{T})}$ & $\begin{array}{c}(-1,-1,-1,-1,-1,-1,-1,-1,-1,-1,-1,- \\
1,1,1,1,1,1,1,1,1,1)\end{array}$ & $\begin{array}{c}0,0,0,0,0,0,0,0,0,0,0,0,126,126,135,126,151,151,111,126,15 \\
1,\end{array}$ \\
\hline \multirow[t]{3}{*}{21} & (H) $\ldots-\cdots \cdots-\cdots$ CTG $^{(\mathrm{T})}$ & $\begin{array}{c}(-1,-1,-1,-1,-1,-1,-1,-1,-1,-1,-1,-1,-1,-1,-1,- \\
1,-1,-1,1,1,1)\end{array}$ & $0,0,0,0,0,0,0,0,0,0,0,0,0,0,0,0,0,0,111,126,151$ \\
\hline & CASE C & & \\
\hline & Query Sequence & Transformed Query Sequence & Transformed Query Sequence \\
\hline \multirow[t]{2}{*}{22} & ${ }^{(\mathrm{H})}$ A - CTGGCATTATTTATG - - TG ${ }^{(\mathrm{T})}$ & $\begin{array}{c}(1,-1,1,1,1,1,1,1,1,1,1,1,1,1,1,1,1,-1,- \\
1,1,1)\end{array}$ & $\begin{array}{c}135,0,111,126,151,151,111,135,126,126,135,126,126,126,1 \\
35,126,151,0,0,126,151,\end{array}$ \\
\hline & Reflector Sequence & Transformed Reflector Sequence & Transformed Reflector Sequence \\
\hline 23 & (H) - - TGGCATTATTTATGGCTG ${ }^{(\mathrm{T})}$ & $\begin{array}{c}(-1,-1,- \\
1,1,1,1,1,1,1,1,1,1,1,1,1,1,1,1,1,1,1)\end{array}$ & $\begin{array}{c}0,0,0,126,151,151,111,135,126,126,135,126,126,126,135,12 \\
6,151,151,111,126,151\end{array}$ \\
\hline 24 & ${ }^{(\mathrm{H})}$ AGCTGGCAT - - TTATGGCTG $^{(\mathrm{T})}$ & $\begin{array}{c}(1,1,1,1,1,1,1,1,1,1,-1,-1,- \\
1,1,1,1,1,1,1,1,1)\end{array}$ & $\begin{array}{c}135,151,111,126,151,151,111,135,126,0,0,0,126,126,135,12 \\
6,151,151,111,126,151,\end{array}$ \\
\hline 25 & ${ }^{(\mathrm{H})}$ AGCTGGCATTATTTATGG - - ${ }^{(\mathrm{T})}$ & $\begin{array}{c}(1,1,1,1,1,1,1,1,1,1,1,1,1,1,1,1,1,1,-1,-1,- \\
1)\end{array}$ & $\begin{array}{c}135,151,111,126,151,151,111,135,126,126,135,126,126,126 \\
, 135,126,151,151,0,0,0,\end{array}$ \\
\hline \multirow[t]{3}{*}{26} & ${ }^{(\mathrm{H})}$ AGC - GGCAT - - TTT - TGGCTG ${ }^{(\mathrm{T})}$ & $\begin{array}{c}(1,1,1,-1,1,1,1,1,1,-1,-1,1,1,1,- \\
1,1,1,1,1,1,1)\end{array}$ & $\begin{array}{c}135,151,111,0,151,151,111,135,126,0,0,126,126,126,0,126 \\
151,151,111,126,151,\end{array}$ \\
\hline & CASE D & & \\
\hline & Query Sequence & Transformed Query Sequence & $\begin{array}{c}\text { Transformed Query Sequence } \\
\end{array}$ \\
\hline \multirow[t]{2}{*}{27} & ${ }^{(\mathrm{H})}$ AGCTGGCATTATTTATGGCTG $^{(\mathrm{T})}$ & $(1,1,1,1,1,1,1,1,1,1,1,1,1,1,1,1,1,1,1,1,1)$ & $\begin{array}{c}135,151,111,126,151,151,111,135,126,126,135,126,126,126 \\
, 135,126,151,151,111,126,151,\end{array}$ \\
\hline & Reflector Sequence & Transformed Reflector Sequence & Transformed Reflector Sequence \\
\hline 28 & ${ }^{(\mathrm{H})}{ }_{-}$- TGGCGGTATTTATAACTG $^{(\mathrm{T})}$ & $\begin{array}{c}(-1,-1,- \\
1,1,1,1,1,0,0,1,1,1,1,1,1,1,0,0,1,1,1)\end{array}$ & $\begin{array}{c}0,0,0,126,151,151,111,151,151,126,135,126,126,126,135,12 \\
6,135,135,111,126,151,\end{array}$ \\
\hline 29 & ${ }^{(\mathrm{H})}$ AGCTGGCAT - - TTATGTCTG ${ }^{(\mathrm{T})}$ & $\begin{array}{c}(1,1,0,1,1,1,1,1,1,1,-1,-1,- \\
1,1,1,1,1,0,1,1,1) \\
\end{array}$ & $\begin{array}{c}135,151,111,126,151,151,111,135,126,0,0,0,126,126,135,12 \\
6,151,126,111,126,151,\end{array}$ \\
\hline 30 & ${ }^{(\mathrm{H})}$ AGCTGGGTCGTCTTATGG - - ${ }^{(\mathrm{T})}$ & $\begin{array}{c}(1,1,1,1,1,1,0,0,0,0,0,0,1,1,1,1,1,1,-1,-1,- \\
1)\end{array}$ & $\begin{array}{c}135,151,111,126,151,151,151,126,111,151,126,111,126,126 \\
, 135,126,151,151,0,0,0,\end{array}$ \\
\hline \multirow[t]{3}{*}{31} & AGC - GGCAT - - TTT - TGGCAT ${ }^{(T)}$ & $\begin{array}{c}(1,1,1,-1,1,1,1,1,1,-1,-1,1,1,1,- \\
1,1,1,1,1,0,0)\end{array}$ & $\begin{array}{c}135,151,111,0,151,151,111,135,126,0,0,126,126,126,0,126, \\
151,151,111,135,126,\end{array}$ \\
\hline & CASE E & & \\
\hline & Query Sequence & Transformed Query Sequence & Transformed Query Sequence \\
\hline 32 & 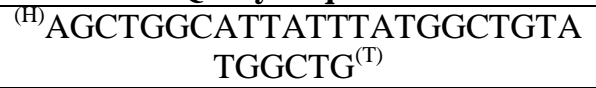 & $\begin{array}{c}(1,1,1,1,1,1,1,1,1,1,1,1,1,1,1,1,1,1,1,1,1,1 \\
1,1,1,1,1,1,1)\end{array}$ & $\begin{array}{l}135,151,111,126,151,151,111,135,126,126,135,126,126,126 \\
, 135,126,151,151,111,126,151,126,135,126,151,151,111,12\end{array}$ \\
\hline
\end{tabular}




\section{OPTINALYSIS}

\begin{tabular}{|c|c|c|c|}
\hline & & & 6,151, \\
\hline & Reflector Sequence & Transformed Reflector Sequence & Transformed Reflector Sequence \\
\hline \multirow[t]{3}{*}{33} & $\begin{array}{c}{ }^{(\mathrm{H})} \text { TTCTGGCATTATTTATGGCTGTA } \\
\text { TGGCTG }^{(\mathrm{T})}\end{array}$ & $\begin{array}{c}(0,0,1,1,1,1,1,1,1,1,1,1,1,1,1,1,1,1,1,1,1,1 \\
1,1,1,1,1,1,1)\end{array}$ & $\begin{array}{c}126,126,111,126,151,151,111,135,126,126,135,126,126,126 \\
, 135,126,151,151,111,126,151,126,135,126,151,151,111,12 \\
6,151,\end{array}$ \\
\hline & CASE F & & \\
\hline & Query Sequence & Transformed Query Sequence & Transformed Query Sequence \\
\hline \multirow[t]{2}{*}{34} & $\begin{array}{c}{ }^{(\mathrm{H})} \text { AGCTGGCATTATTTATGGCTGTA } \\
\text { TGGCTGTATGGCTG }^{(\mathrm{T})}\end{array}$ & $\begin{array}{c}(1,1,1,1,1,1,1,1,1,1,1,1,1,1,1,1,1,1,1,1,1,1, \\
1,1,1,1,1,1,1,1,1,1,1,1,1,1,1)\end{array}$ & $\begin{array}{c}135,151,111,126,151,151,111,135,126,126,135,126,126,126 \\
, 135,126,151,151,111,126,151,126,135,126,151,151,111,12 \\
6,151,126,135,126,151,151,111,126,151,\end{array}$ \\
\hline & Reflector Sequence & Transformed Reflector Sequence & Transformed Reflector Sequence \\
\hline \multirow[t]{3}{*}{35} & $\begin{array}{c}{ }^{(\mathrm{H})} \text { TTCTGGCATTATTTATGGCTGTA } \\
\text { TGGCTGTATGGCTG }^{(\mathrm{T})}\end{array}$ & $\begin{array}{c}(0,0,1,1,1,1,1,1,1,1,1,1,1,1,1,1,1,1,1,1,1,1, \\
1,1,1,1,1,1,1,1,1,1,1,1,1,1,1)\end{array}$ & $\begin{array}{c}126,126,111,126,151,151,111,135,126,126,135,126,126,126 \\
, 135,126,151,151,111,126,151,126,135,126,151,151,111,12 \\
6,151,126,135,126,151,151,111,126,151,\end{array}$ \\
\hline & CASE G & & \\
\hline & Query Sequence & Transformed Query Sequence & Transformed Query Sequence \\
\hline \multirow[t]{2}{*}{36} & $\begin{array}{l}{ }^{(\mathrm{H})} \text { AGCTGGCATTATTTATGGCTGTA } \\
\text { TGGCTGTATGGCTGTATGGCTG }^{(\mathrm{T})}\end{array}$ & $\begin{array}{c}(1,1,1,1,1,1,1,1,1,1,1,1,1,1,1,1,1,1,1,1,1,1 \\
1,1,1,1,1,1,1,1,1,1,1,1,1,1,1,1,1,1,1,1,1,1 \\
1)\end{array}$ & $\begin{array}{c}135,151,111,126,151,151,111,135,126,126,135,126,126,126 \\
135,126,151,151,111,126,151,126,135,126,151,151,111,12 \\
6,151,126,135,126,151,151,111,126,151,126,135,126,151,1 \\
51,111,126,151,\end{array}$ \\
\hline & Reflector Sequence & Transformed Reflector Sequence & $\begin{array}{c}\text { Transformed Reflector Sequence } \\
\end{array}$ \\
\hline \multirow[t]{3}{*}{37} & $\begin{array}{l}{ }^{(\mathrm{H})} \text { TTCTGGCATTATTTATGGCTGTA } \\
\text { TGGCTGTATGGCTGTATGGCTG }^{(\mathrm{T})}\end{array}$ & $\begin{array}{c}(0,0,1,1,1,1,1,1,1,1,1,1,1,1,1,1,1,1,1,1,1,1 \\
1,1,1,1,1,1,1,1,1,1,1,1,1,1,1,1,1,1,1,1,1,1 \\
1)\end{array}$ & $\begin{array}{c}126,126,111,126,151,151,111,135,126,126,135,126,126,126 \\
, 135,126,151,151,111,126,151,126,135,126,151,151,111,12 \\
6,151,126,135,126,151,151,111,126,151,126,135,126,151,1 \\
51,111,126,151,\end{array}$ \\
\hline & CASE H & & \\
\hline & Query Sequence & Transformed Query Sequence & $\begin{array}{c}\text { Transformed Query Sequence } \\
\end{array}$ \\
\hline \multirow[t]{2}{*}{38} & $\begin{array}{c}\text { (H) AGCTGGCATTATTTATGGCTGTA } \\
\text { TGGCTGTATGGCTGTATGGCTGTA } \\
\text { TGGCTG }^{(\mathrm{T})}\end{array}$ & $\begin{array}{c}(1,1,1,1,1,1,1,1,1,1,1,1,1,1,1,1,1,1,1,1,1,1 \\
1,1,1,1,1,1,1,1,1,1,1,1,1,1,1,1,1,1,1,1,1,1 \\
1,1,1,1,1,1,1,1,1)\end{array}$ & $\begin{array}{c}135,151,111,126,151,151,111,135,126,126,135,126,126,126 \\
, 135,126,151,151,111,126,151,126,135,126,151,151,111,12 \\
6,151,126,135,126,151,151,111,126,151,126,135,126,151,1 \\
51,111,126,151,126,135,126,151,151,111,126,151,\end{array}$ \\
\hline & Reflector Sequence & Transformed Reflector Sequence & $\begin{array}{c}\text { Transformed Reflector Sequence } \\
\end{array}$ \\
\hline 39 & $\begin{array}{l}{ }^{(\mathrm{H})} \text { TTCTGGCATTATTTATGGCTGTA } \\
\text { TGGCTGTATGGCTGTATGGCTGTA } \\
\text { TGGCTG }^{(\mathrm{T})}\end{array}$ & $\begin{array}{c}(0,0,1,1,1,1,1,1,1,1,1,1,1,1,1,1,1,1,1,1,1,1 \\
1,1,1,1,1,1,1,1,1,1,1,1,1,1,1,1,1,1,1,1,1,1 \\
1,1,1,1,1,1,1,1,1)\end{array}$ & $\begin{array}{c}126,126,111,126,151,151,111,135,126,126,135,126,126,126 \\
, 135,126,151,151,111,126,151,126,135,126,151,151,111,12 \\
6,151,126,135,126,151,151,111,126,151,126,135,126,151,1 \\
51,111,126,151,126,135,126,151,151,111,126,151,\end{array}$ \\
\hline
\end{tabular}




\section{OPTINALYSIS}

Table 29: Kabirian Algorithmic Transformations of a Nucleotide Base Sequences

\begin{tabular}{|c|c|c|c|c|c|}
\hline & & \multicolumn{4}{|c|}{ Kabirian Transformation Algorithm } \\
\hline & CASE A & RCMMGA & RCM-(io) FA & RCMm-(io) FA & RCG-(io) FA \\
\hline Items & Query Sequence & $\begin{array}{c}\text { Transformed Query } \\
\text { Sequence }\end{array}$ & $\begin{array}{c}\text { Transformed Query } \\
\text { Sequence }\end{array}$ & $\begin{array}{c}\text { Transformed Query } \\
\text { Sequence }\end{array}$ & $\begin{array}{c}\text { Transformed Query } \\
\text { Sequence }\end{array}$ \\
\hline \multirow[t]{2}{*}{1} & ${ }^{(\mathrm{H})} \mathrm{AGC}^{*} \mathrm{TGG}^{*} \mathrm{CAT}^{*} \mathrm{TAT}^{*} \mathrm{TTA}^{*} \mathrm{TGG}^{*} \mathrm{CTG}^{(\mathrm{T})}$ & $(1,1,1,1,1,1,1)$ & $(3,3,3,3,3,3,3)$ & $(0,0,0,0,0,0,0)$ & $(0,0,0,0,0,0,0)$ \\
\hline & Reflector Sequence & $\begin{array}{c}\text { Transformed } \\
\text { Reflector Sequence }\end{array}$ & $\begin{array}{c}\text { Transformed } \\
\text { Reflector Sequence }\end{array}$ & $\begin{array}{c}\text { Transformed } \\
\text { Reflector Sequence }\end{array}$ & $\begin{array}{c}\text { Transformed } \\
\text { Reflector Sequence }\end{array}$ \\
\hline 2 & ${ }^{(\mathrm{H})} \mathrm{AGC}^{*} \mathrm{TGG}^{*} \mathrm{CAT}^{*} \mathrm{TAT}^{*} \mathrm{TTA}^{*} \mathrm{TGG}^{*} \mathrm{CTG}^{(\mathrm{T})}$ & $(1,1,1,1,1,1,1)$ & $(3,3,3,3,3,3,3)$ & $(0,0,0,0,0,0,0)$ & $(0,0,0,0,0,0,0)$ \\
\hline 3 & ${ }^{(\mathrm{H})} \mathrm{CGC}^{*} * \mathrm{TGG}^{*} \mathrm{CAT}^{*} \mathrm{TAT}^{*} \mathrm{TTA}^{*} \mathrm{TGG}^{*} \mathrm{CTG}^{(\mathrm{T})}$ & $(0,1,1,1,1,1,1)$ & $(2,3,3,3,3,3,3)$ & $(1,0,0,0,0,0,0)$ & $(0,0,0,0,0,0,0)$ \\
\hline 4 & ${ }^{(\mathrm{H})} \mathrm{AGC}^{*} \mathrm{TGG}^{*} \mathrm{CAT} * \mathrm{TCT} * \mathrm{TTA} * \mathrm{TGG}^{*} \mathrm{CTG}^{(\mathrm{T})}$ & $(1,1,1,0,1,1,1)$ & $(3,3,3,2,3,3,3)$ & $(0,0,0,1,0,0,0)$ & $(0,0,0,0,0,0,0)$ \\
\hline 5 & ${ }^{(\mathrm{H})} \mathrm{AGC}^{*} \mathrm{TGG}^{*} \mathrm{CAT}^{*} \mathrm{TAT}^{*} \mathrm{TTA}^{*} \mathrm{TGG}^{*} \mathrm{CTT}^{(\mathrm{T})}$ & $(1,1,1,1,1,1,0)$ & $(3,3,3,3,3,3,2)$ & $(0,0,0,0,0,0,1)$ & $(0,0,0,0,0,0,0)$ \\
\hline 6 & ${ }^{(\mathrm{H})} \mathrm{AGC}^{*} \mathrm{TGG}^{*} \mathrm{CAT} * \mathrm{TAT}^{*} \mathrm{TTA}^{*} \mathrm{TGG}^{*} \mathrm{CAA}^{(\mathrm{T})}$ & $(1,1,1,1,1,1,0)$ & $(3,3,3,3,3,3,1)$ & $(0,0,0,0,0,0,2)$ & $(0,0,0,0,0,0,0)$ \\
\hline 7 & ${ }^{(\mathrm{HI})} \mathrm{AGC}^{*} \mathrm{TGG}^{*} \mathrm{CAT}^{*} \mathrm{TGG}^{*} \mathrm{TTA}^{*} \mathrm{TGG}^{*} \mathrm{CTG}^{(\mathrm{T})}$ & $(1,1,1,0,1,1,1)$ & $(3,3,3,1,3,3,3)$ & $(0,0,0,2,0,0,0)$ & $(0,0,0,0,0,0,0)$ \\
\hline 8 & ${ }^{(\mathrm{H})} \mathrm{GAC}^{*} \mathrm{TGG}^{*} \mathrm{CAT} * \mathrm{TAT}^{*} \mathrm{TTA}^{*} \mathrm{TGG}^{*} \mathrm{CTG}^{(\mathrm{T})}$ & $(0,1,1,1,1,1,1)$ & $(1,3,3,3,3,3,3)$ & $(2,0,0,0,0,0,0)$ & $(0,0,0,0,0,0,0)$ \\
\hline 9 & ${ }^{(\mathrm{H})} \mathrm{TCG}^{*} \mathrm{AGG}^{*} \mathrm{CAT}^{*} \mathrm{TAT}^{*} \mathrm{TTA}^{*} \mathrm{TGG}^{*} \mathrm{CTG}^{(\mathrm{T})}$ & $(0,0,1,1,1,1,1)$ & $(0,2,3,3,3,3,3)$ & $(3,1,0,0,0,0,0)$ & $(0,0,0,0,0,0,0)$ \\
\hline 10 & ${ }^{(\mathrm{H})} \mathrm{AGC}^{*} \mathrm{TGG}^{*} \mathrm{CAG}^{*} \mathrm{CTG}{ }^{*} \mathrm{TTA}^{*} \mathrm{TGG}^{*} \mathrm{CTG}^{(\mathrm{T})}$ & $(1,1,0,0,1,1,1)$ & $(3,3,2,0,3,3,3)$ & $(0,0,1,3,0,0,0)$ & $(0,0,0,0,0,0,0)$ \\
\hline 11 & ${ }^{(\mathrm{H})} \mathrm{AGC}^{*} \mathrm{TGG}^{*} \mathrm{CAT} * \mathrm{TAT} * \mathrm{TTA}^{*} \mathrm{TGT}^{*} \mathrm{TAT}^{(\mathrm{T})}$ & $(1,1,1,1,1,0,0)$ & $(3,3,3,3,3,2,0)$ & $(0,0,0,0,0,1,3)$ & $(0,0,0,0,0,0,0)$ \\
\hline 12 & ${ }^{(\mathrm{H})} \mathrm{TTA}^{*} \mathrm{TAC}^{*} \mathrm{TCG}^{*} \mathrm{TCT}^{*} \mathrm{TTA} * \mathrm{TGG}^{*} \mathrm{CTG}^{(\mathrm{T})}$ & $(0,0,0,0,1,1,1)$ & $(0,0,0,1,3,3,3)$ & $(3,3,3,2,0,0,0)$ & $(0,0,0,0,0,0,0)$ \\
\hline 13 & ${ }^{(\mathrm{H})} \mathrm{CAG}^{*} \mathrm{TGG}^{*} \mathrm{CAT}^{*} \mathrm{GGC}^{*} \mathrm{TTA}^{*} * \mathrm{TGG}^{*} \mathrm{TCA}^{(\mathrm{T})}$ & $(0,1,1,0,1,1,0)$ & $(0,3,3,0,3,3,0)$ & $(3,0,0,3,0,0,3)$ & $(0,0,0,0,0,0,0)$ \\
\hline \multirow[t]{3}{*}{14} & ${ }^{(\mathrm{H})} \mathrm{TGC}^{*} \mathrm{AAG}^{*} \mathrm{CAT}^{*} \mathrm{CGC}^{*} \mathrm{TTA}^{*} \mathrm{CGG}^{*} \mathrm{ATG}^{(\mathrm{T})}$ & $(0,0,1,0,1,0,0)$ & $(2,1,3,0,3,2,2)$ & $(1,2,0,3,0,1,1)$ & $(0,0,0,0,0,0,0)$ \\
\hline & CASE B & & & & \\
\hline & Query Sequence & $\begin{array}{c}\text { Transformed Query } \\
\text { Sequence }\end{array}$ & $\begin{array}{c}\text { Transformed Query } \\
\text { Sequence }\end{array}$ & $\begin{array}{c}\text { Transformed Query } \\
\text { Sequence }\end{array}$ & $\begin{array}{c}\text { Transformed Query } \\
\text { Sequence }\end{array}$ \\
\hline \multirow[t]{2}{*}{15} & ${ }^{(\mathrm{H})} \mathrm{AGC}^{*} \mathrm{TGG}^{*} \mathrm{CAT} * \mathrm{TAT}^{*} \mathrm{TTA} * \mathrm{TGG}^{*} \mathrm{CTG}^{(\mathrm{T})}$ & $(1,1,1,1,1,1,1)$ & $(3,3,3,3,3,3,3)$ & $(0,0,0,0,0,0,0)$ & $(0,0,0,0,0,0,0)$ \\
\hline & Reflector Sequence & $\begin{array}{c}\text { Transformed } \\
\text { Reflector Sequence }\end{array}$ & $\begin{array}{c}\text { Transformed } \\
\text { Reflector Sequence }\end{array}$ & $\begin{array}{c}\text { Transformed } \\
\text { Reflector Sequence }\end{array}$ & $\begin{array}{c}\text { Transformed } \\
\text { Reflector Sequence }\end{array}$ \\
\hline 16 & $(\mathrm{H})$ - - *TGG*CAT*TAT*TTA*TGG*CTG ${ }^{(\mathrm{T})}$ & $(-1,1,1,1,1,1,1)$ & $(0,3,3,3,3,3,3)$ & $(0,0,0,0,0,0,0)$ & $(3,0,0,0,0,0,0)$ \\
\hline 17 & ${ }^{(\mathrm{H})} \mathrm{AGC}^{*} \mathrm{TGG}^{*} \mathrm{CAT}^{*} \ldots \ldots$. $* \mathrm{TTA}^{*} \mathrm{TGG}^{*} \mathrm{CTG}^{(\mathrm{T})}$ & $(1,1,1,-1,1,1,1)$ & $(3,3,3,0,3,3,3)$ & $(0,0,0,0,0,0,0)$ & $(0,0,0,3,0,0,0)$ \\
\hline 18 & ${ }^{(\mathrm{H})} \mathrm{AGC} * \mathrm{TGG}^{*} \mathrm{CAT} * \mathrm{TAT} * \mathrm{TTA} * \mathrm{TGG}^{*}$ _ _ _ $^{(\mathrm{T})}$ & $(1,1,1,1,1,1,-1)$ & $(3,3,3,3,3,3,0)$ & $(0,0,0,0,0,0,0)$ & $(0,0,0,0,0,0,3)$ \\
\hline 19 & ${ }^{(\mathrm{H})} \mathrm{AGC}^{*}-\mathrm{GG}^{*} \mathrm{CAT} *_{-}-\mathrm{T}^{*} * \mathrm{TT}-* \mathrm{TGG}^{*} \mathrm{CTG}^{(\mathrm{T})}$ & $(1,-1,1,-1,-1,1,1)$ & $(3,2,3,1,2,3,3)$ & $(0,0,0,0,0,0,0)$ & $(0,1,0,2,1,0,0)$ \\
\hline 20 & 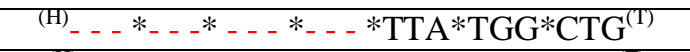 & $(-1,-1,-1,-1,1,1,1)$ & $(0,0,0,0,3,3,3)$ & $(0,0,0,0,0,0,0)$ & $(3,3,3,3,0,0,0)$ \\
\hline \multirow[t]{3}{*}{21} & $\left({ }^{(\mathrm{H})}\right)_{-} *_{-} \ldots *_{-} \ldots *_{-} \ldots *_{-} \ldots *_{-} \ldots * \mathrm{CTG}^{(\mathrm{T})}$ & $(-1,-1,-1,-1,-1,-1,1)$ & $(0,0,0,0,0,0,3)$ & $(0,0,0,0,0,0,0)$ & $(3,3,3,3,3,3,0)$ \\
\hline & CASE C & & & & \\
\hline & Query Sequence & $\begin{array}{c}\text { Transformed Query } \\
\text { Sequence }\end{array}$ & $\begin{array}{c}\text { Transformed Query } \\
\text { Sequence }\end{array}$ & $\begin{array}{c}\text { Transformed Query } \\
\text { Sequence }\end{array}$ & $\begin{array}{c}\text { Transformed Query } \\
\text { Sequence }\end{array}$ \\
\hline \multirow[t]{2}{*}{22} & ${ }^{(\mathrm{H})} \mathrm{A}-\mathrm{C}^{*} \mathrm{TGG} * \mathrm{CAT}^{*} \mathrm{TAT} * \mathrm{TTA} * \mathrm{TG}-*-\mathrm{TG}^{(\mathrm{T})}$ & $(-1,1,1,1,1,-1,-1)$ & $(3,3,3,3,3,3,3)$ & $(3,3,3,3,3,3,3)$ & $(3,3,3,3,3,3,3)$ \\
\hline & Reflector Sequence & $\begin{array}{c}\text { Transformed } \\
\text { Reflector Sequence }\end{array}$ & $\begin{array}{c}\text { Transformed } \\
\text { Reflector Sequence }\end{array}$ & $\begin{array}{c}\text { Transformed } \\
\text { Reflector Sequence }\end{array}$ & $\begin{array}{c}\text { Transformed } \\
\text { Reflector Sequence }\end{array}$ \\
\hline 23 & $(\mathrm{H}) \ldots$ _ $* \mathrm{TGG}^{*} \mathrm{CAT}^{*} \mathrm{TAT}^{*} \mathrm{TTA}^{*} \mathrm{TGG}^{*} \mathrm{CTG}^{(\mathrm{T})}$ & $(-1,1,1,1,1,1,1)$ & $(1,3,3,3,3,2,2)$ & $(0,0,0,0,0,1,1)$ & $(2,0,0,0,0,0,0)$ \\
\hline
\end{tabular}




\section{OPTINALYSIS}

\begin{tabular}{|c|c|c|c|c|c|}
\hline 24 & $\begin{array}{l}{ }^{(\mathrm{H})} \mathrm{AGC}^{*} \mathrm{TGG}^{*} \mathrm{CAT}^{*}--- \\
{ }^{*} \mathrm{TTA}^{*} \mathrm{TGG}^{*} \mathrm{CTG}^{(\mathrm{T})}\end{array}$ & $(1,1,1,-1,1,1,1)$ & $(2,3,3,0,3,2,2)$ & $(1,0,0,0,0,1,1)$ & $(0,0,0,3,0,0,0)$ \\
\hline 25 & ${ }^{(\mathrm{H})} \mathrm{AGC}^{*} \mathrm{TGG}^{*} \mathrm{CAT} * \mathrm{TAT}^{*} \mathrm{TTA}^{*} \mathrm{TGG}^{*}$ - _ $^{(\mathrm{T})}$ & $(1,1,1,1,1,1,-1)$ & $(2,3,3,3,3,2,1)$ & $(1,0,0,0,0,1,0)$ & $(0,0,0,0,0,0,2)$ \\
\hline \multirow[t]{3}{*}{26} & ${ }^{(\mathrm{H})} \mathrm{AGC}^{*}-\mathrm{GG}^{*} \mathrm{CAT}^{*}-\mathrm{T}^{*} \mathrm{TT}-* \mathrm{TGG}^{*} \mathrm{CTG}^{(\mathrm{T})}$ & $(1,-1,1,-1,-1,1,1)$ & $(2,2,3,1,2,2,2)$ & $(1,0,0,0,0,1,1)$ & $(0,1,0,2,1,0,0)$ \\
\hline & CASE D & & & & \\
\hline & Query Sequence & $\begin{array}{c}\text { Transformed Query } \\
\text { Sequence }\end{array}$ & $\begin{array}{c}\text { Transformed Query } \\
\text { Sequence }\end{array}$ & $\begin{array}{c}\text { Transformed Query } \\
\text { Sequence }\end{array}$ & $\begin{array}{c}\text { Transformed Query } \\
\text { Sequence }\end{array}$ \\
\hline \multirow[t]{2}{*}{27} & ${ }^{(\mathrm{H})} \mathrm{AGC}^{*} \mathrm{TGG}^{*} \mathrm{CAT}^{*}{ }^{\mathrm{T} A T} * \mathrm{TTA}^{*}$ TGG$^{*} \mathrm{CTG}^{(\mathrm{T})}$ & $(1,1,1,1,1,1,1)$ & $(3,3,3,3,3,3,3)$ & $(0,0,0,0,0,0,0)$ & $(0,0,0,0,0,0,0)$ \\
\hline & Reflector Sequence & $\begin{array}{c}\text { Transformed } \\
\text { Reflector Sequence }\end{array}$ & $\begin{array}{c}\text { Transformed } \\
\text { Reflector Sequence }\end{array}$ & $\begin{array}{c}\text { Transformed } \\
\text { Reflector Sequence }\end{array}$ & $\begin{array}{c}\text { Transformed } \\
\text { Reflector Sequence }\end{array}$ \\
\hline 28 & (H) $\ldots$ - * TGG*CGG*TAT*TTA*TAA*CTG ${ }^{(\mathrm{T})}$ & $(-1,1,0,1,1,0,1)$ & $(0,3,1,3,3,1,3)$ & $(0,0,2,0,0,2,0)$ & $(3,0,0,0,0,0,0)$ \\
\hline 29 & ${ }^{(\mathrm{H})} \mathrm{AGC}^{*} \mathrm{TGG}^{*} \mathrm{CAT}^{*} \ldots$. $*$ TTA $* \mathrm{TGT}^{*} \mathrm{CTG}^{(\mathrm{T})}$ & $(0,1,1,-1,1,0,1)$ & $(2,3,3,0,3,2,3)$ & $(1,0,0,0,0,1,0)$ & $(0,0,0,3,0,0,0)$ \\
\hline 30 & ${ }^{(\mathrm{H})} \mathrm{AGC}^{*} \mathrm{TGG} * \mathrm{GTC}^{*} \mathrm{GTC} * \mathrm{TTA}^{*} \mathrm{TGG}^{*}$ - _ $^{(\mathrm{T})}$ & $(1,1,0,0,1,1,-1)$ & $(3,3,0,0,3,3,0)$ & $(0,0,3,3,0,0,0)$ & $(0,0,0,0,0,0,3)$ \\
\hline 31 & ${ }^{(\mathrm{H})} \mathrm{AGC}^{*}-\mathrm{GG}^{*} \mathrm{CAT}^{*}-\mathrm{T}^{*} \mathrm{TT}-* \mathrm{TGG}^{*} \mathrm{CAT}^{(\mathrm{T})}$ & $(1,-1,1,-1,-1,1,0)$ & $(3,2,3,1,2,3,1)$ & $(0,0,0,0,0,0,2)$ & $(0,1,0,2,1,0,0)$ \\
\hline
\end{tabular}

RCMMGA = Reflective Cluster Match-mismatch-gab Approach; RCM-(io) FA = Reflective Match-(in order) Frequency Approach;

RCMm-(io) FA = Reflective Mismatch-(in order) Frequency Approach ; RCG-(io) FA = Reflective Gab-(in order) Frequency Approach

Note: Type I Resolution Rule is considered for the polymorphic cluster. 


\section{OPTINALYSIS}

Table 30: Results of the Geometrical Optinalysis of the Nucleotide Base Sequences and other Standard Methods

\begin{tabular}{|c|c|c|c|c|c|c|c|c|}
\hline & & \multicolumn{2}{|c|}{ RMMGA } & \multicolumn{2}{|c|}{ MMSA } & \multirow{2}{*}{$\begin{array}{l}\text { \% ID and } \\
\text { SIM. }\end{array}$} & \multirow{2}{*}{$\begin{array}{c}\text { NW } \\
\text { Score }\end{array}$} & \multirow{2}{*}{$\begin{array}{c}\text { \% Gab } \\
\text { Score }\end{array}$} \\
\hline & CASE A & H-H Pairing & T-T Pairing & H-H Pairing & T-T Pairing & & & \\
\hline Items & Query Sequence & & & & & & & \\
\hline \multirow[t]{2}{*}{1} & ${ }^{(\mathrm{H})}$ AGCTGGCATTATTTATGGCTG $^{(\mathrm{T})}$ & & & & & & & \\
\hline & Reflector Sequence & & & & & & & \\
\hline 2 & ${ }^{(\mathrm{H})}$ AGCTGGCATTATTTATGGCTG $^{(\mathrm{T})}$ & $1.0000(100)$ & $1.0000(100)$ & $1.0000(100)$ & $1.0000(100)$ & 100 & 42 & 0 \\
\hline 3 & ${ }^{(\mathrm{H})}$ CGCTGGCATTATTTATGGCTG $^{(\mathrm{T})}$ & $1.0238(91.10)$ & $1.0011(99.56)$ & $1.0041(98.36)$ & $1.0002(99.92)$ & 95 & 37 & 0 \\
\hline 4 & ${ }^{(\mathrm{H})}$ AGCTGGCATTCTTTATGGCTG $^{(\mathrm{T})}$ & $1.0123(95.24)$ & $1.0124(95.24)$ & $1.0022(99.14)$ & $1.0022(99.14)$ & 95 & 37 & 0 \\
\hline 5 & ${ }^{(\mathrm{H})}$ AGCTGGCATTATTTATGGCTT $^{(\mathrm{T})}$ & $1.0011(99.56)$ & $1.0238(91.10)$ & $1.0002(99.92)$ & $1.0043(98.29)$ & 95 & 37 & 0 \\
\hline 6 & ${ }^{(\mathrm{H})}$ AGCTGGCATTATTTATGGCAA $^{(\mathrm{T})}$ & $1.0034(98.65)$ & $1.0489(82.95)$ & $1.0000(100.00)$ & $1.0013(99.49)$ & 90 & 32 & 0 \\
\hline 7 & ${ }^{(\mathrm{H})}$ AGCTGGCATTGGTTATGGCTG $^{(\mathrm{T})}$ & $1.0244(90.89)$ & $1.0268(90.06)$ & $0.9966(98.65)$ & $0.9962(98.49)$ & 90 & 32 & 0 \\
\hline 8 & ${ }^{(\mathrm{H})}$ GACTGGCATTATTTATGGCTG ${ }^{(\mathrm{T})}$ & $1.0489(82.95)$ & $1.0034(98.65)$ & $0.9999(99.96)$ & $1.0001(99.95)$ & 90 & 32 & 0 \\
\hline 9 & ${ }^{(\mathrm{H})}$ TCGAGGCATTATTTATGGCTG $^{(\mathrm{T})}$ & $1.1029(68.55)$ & $1.0121(95.33)$ & $1.0005(99.78)$ & $0.9995(99.80)$ & 81 & 22 & 0 \\
\hline 10 & ${ }^{(\mathrm{H})}$ AGCTGGCAGCTGTTATGGCTG $^{(\mathrm{T})}$ & $1.0582(80.17)$ & $1.0529(81.74)$ & $0.9976(99.04)$ & $0.9978(99.12)$ & 81 & 22 & 0 \\
\hline 11 & ${ }^{(\mathrm{H})}$ AGCTGGCATTATTTATGTTAT ${ }^{(\mathrm{T})}$ & $1.0121(95.33)$ & $1.1029(68.55)$ & $1.0005(99.80)$ & $1.0042(98.34)$ & 81 & 22 & 0 \\
\hline 12 & ${ }^{(\mathrm{H})}$ TTATACTCGTCTTTATGGCTG $^{(\mathrm{T})}$ & $1.3478(31.91)$ & $1.1071(67.57)$ & $1.0100(96.13)$ & $1.0036(98.58)$ & 57 & -3 & 0 \\
\hline 13 & ${ }^{(\mathrm{H})}$ CAGTGGCATGGCTTATGGTCA ${ }^{(\mathrm{T})}$ & $1.1579(57.14)$ & $1.1579(57.14)$ & $0.9979(99.16)$ & $1.0003(99.87)$ & 57 & -3 & 0 \\
\hline \multirow[t]{3}{*}{14} & ${ }^{(\mathrm{H})}$ TGCAAGCATCGCTTACGGATG ${ }^{(\mathrm{T})}$ & $1.1508(58.47)$ & $1.1164(65.49)$ & $1.0039(98.47)$ & $0.9999(99.96)$ & 62 & 2 & 0 \\
\hline & CASE B & & & & & & & \\
\hline & Query Sequence & & & & & & & \\
\hline \multirow[t]{2}{*}{15} & ${ }^{(\mathrm{H})}$ AGCTGGCATTATTTATGGCTG $^{(\mathrm{T})}$ & & & & & & & \\
\hline & Reflector Sequence & & & & & & & \\
\hline 16 & (H) & $1.1786(53.49)$ & $1.0154(94.12)$ & $1.0068(97.33)$ & $1.0752(75.46)$ & 86 & 25 & 14 \\
\hline 17 & 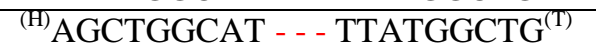 & $1.0820(73.68)$ & $1.1000(69.23)$ & $1.0388(86.11)$ & $1.0388(86.11)$ & 86 & 25 & 14 \\
\hline 18 & ${ }^{(\mathrm{H})}$ AGCTGGCATTATTTATGG $\ldots-^{(\mathrm{T})}$ & $1.0154(94.12)$ & $1.1786(53.49)$ & $1.0734(75.94)$ & $1.0065(97.45)$ & 86 & 25 & 14 \\
\hline 19 & ${ }^{(\mathrm{H})}$ AGC - GGCAT - - TTT - TGGCTG ${ }^{(\mathrm{T})}$ & $1.1472(49.15)$ & $1.1198(64.76)$ & $1.0498(82.66)$ & $1.0592(79.90)$ & 76 & 11 & 19 \\
\hline 20 & ${ }^{(\mathrm{H})} \ldots \ldots-\ldots-$ TTATGGCTG $^{(\mathrm{T})}$ & $16.500(-30)$ & $1.6500(11.86)$ & $1.1312(62.34)$ & $1.3908(28.04)$ & 43 & -11 & 57 \\
\hline \multirow[t]{3}{*}{21} & ${ }^{(\mathrm{H})} \ldots \ldots \ldots-\cdots \mathrm{CTG}^{(\mathrm{T})}$ & $\begin{array}{c}-0.4151(- \\
74.42)\end{array}$ & $\begin{array}{c}-0.6286(- \\
67.65)\end{array}$ & $1.4881(20.77)$ & $1.7470(7.81)$ & 14 & -35 & 85 \\
\hline & CASE C & & & & & & & \\
\hline & Query Sequence & & & & & & & \\
\hline \multirow[t]{2}{*}{22} & ${ }^{(\mathrm{H})}$ A - CTGGCATTATTTATG - - TG $^{(\mathrm{T})}$ & & & & & & & \\
\hline & Reflector Sequence & & & & & & & \\
\hline 23 & (H) - - TGGCATTATTTATGGCTG ${ }^{(\mathrm{T})}$ & $1.1111(66.67)$ & $0.9091(66.67)$ & $1.0398(85.79)$ & $0.9601(84.65)$ & 80 & 14 & 20 \\
\hline 24 & 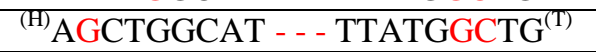 & $1.0092(96.43)$ & $0.9910(96.43)$ & $1.0029(98.86)$ & $0.9918(96.75)$ & 71 & 3 & 28 \\
\hline 25 & ${ }^{(\mathrm{H})}$ AGCTGGCATTATTTATGG - - ${ }^{(\mathrm{T})}$ & $0.9402(77.43)$ & $1.0679(77.43)$ & $0.9702(88.43)$ & $1.0261(90.32)$ & 89 & 20 & 10 \\
\hline 26 & ${ }^{(\mathrm{H})} \mathrm{AGC}-\mathrm{GGCAT}--\mathrm{TTT}-\mathrm{TGGCTG}^{(\mathrm{T})}$ & $1.0732(76.00)$ & $1.0033(98.71)$ & $1.0226(91.54)$ & $1.0014(99.43)$ & 67 & 2 & 5 \\
\hline
\end{tabular}




\section{OPTINALYSIS}

\begin{tabular}{|c|c|c|c|c|c|c|c|c|}
\hline & CASE D & & & & & & & \\
\hline & Query Sequence & & & & & & & \\
\hline \multirow[t]{2}{*}{27} & ${ }^{(\mathrm{H})}$ AGCTGGCATTATTTATGGCTG ${ }^{(\mathrm{T})}$ & & & & & & & \\
\hline & Reflector Sequence & & & & & & & \\
\hline 28 & $\left.{ }^{(\mathrm{H})}\right)_{-}$- TGGCGGTATTTATAACTG $^{(\mathrm{T})}$ & $1.2847(38.58)$ & $1.1000(69.23)$ & $1.0710(76.60)$ & $1.0086(96.63)$ & 67 & 5 & 14 \\
\hline 29 & ${ }^{(\mathrm{H})}$ AGCTGGCAT - - - TTATGTCTG ${ }^{(\mathrm{T})}$ & $1.1248(63.68)$ & $1.1420(60.17)$ & $1.0399(85.75)$ & $1.0432(84.69)$ & 81 & 20 & 14 \\
\hline 30 & ${ }^{(\mathrm{H})}$ AGCTGGGTCGTCTTATGG - _ ${ }^{(\mathrm{T})}$ & $1.1518(58.27)$ & $1.3665(30.18)$ & $1.0036(98.59)$ & $1.0727(76.13)$ & 57 & -5 & 14 \\
\hline \multirow[t]{3}{*}{31} & ${ }^{(\mathrm{H})}$ AGC - GGCAT - - TTT - TGGCAT ${ }^{(\mathrm{T})}$ & $1.1636(56.10)$ & $1.2075(48.84)$ & $1.0595(79.82)$ & $1.0534(81.58)$ & 67 & 1 & 19 \\
\hline & CASE E & & & & & & & \\
\hline & Query Sequence & & & & & & & \\
\hline \multirow[t]{2}{*}{32} & $\begin{array}{c}{ }^{(\mathrm{H})} \text { AGCTGGCATTATTTATGGCTGTA } \\
\text { TGGCTG }^{(\mathrm{T})}\end{array}$ & & & & & & & \\
\hline & Reflector Sequence & & & & & & & \\
\hline \multirow[t]{3}{*}{34} & $\begin{array}{c}{ }^{(\mathrm{H})} \text { TTCTGGCATTATTTATGGCTGTA } \\
\text { TGGCTG }^{(\mathrm{T})}\end{array}$ & $1.0351(87.29)$ & $1.0018(9929)$ & $1.0034(98.64)$ & $1.00022(99.91)$ & 93 & 48 & 0 \\
\hline & CASE F & & & & & & & \\
\hline & Query Sequence & & & & & & & \\
\hline \multirow[t]{2}{*}{35} & $\begin{array}{c}{ }^{(\mathrm{H})} \text { AGCTGGCATTATTTATGGCTGTA } \\
\text { TGGCTGTATGGCTG }^{(\mathrm{T})}\end{array}$ & & & & & & & \\
\hline & Reflector Sequence & & & & & & & \\
\hline \multirow[t]{3}{*}{36} & $\begin{array}{c}{ }^{(\mathrm{H})} \text { TTCTGGCATTATTTATGGCTGTA } \\
\text { TGGCTGTATGGCTG }^{(\mathrm{T})}\end{array}$ & $1.0274(89.67)$ & $1.0011(99.56)$ & $1.0033(98.69)$ & $1.00016(99.93)$ & 95 & 64 & 0 \\
\hline & CASE G & & & & & & & \\
\hline & Query Sequence & & & & & & & \\
\hline \multirow[t]{2}{*}{37} & $\begin{array}{l}{ }^{(\mathrm{H})} \text { AGCTGGCATTATTTATGGCTGTA } \\
\text { TGGCTGTATGGCTGTATGGCTG }^{(\mathrm{T})}\end{array}$ & & & & & & & \\
\hline & Reflector Sequence & & & & & & & \\
\hline \multirow[t]{3}{*}{38} & $\begin{array}{l}{ }^{(\mathrm{H})} \text { TTCTGGCATTATTTATGGCTGTA } \\
\text { TGGCTGTATGGCTGTATGGCTG }^{(\mathrm{T})}\end{array}$ & $1.0225(91.58)$ & $1.0007(99.70)$ & $1.0027(98.92)$ & $1.00011(99.95)$ & 96 & 80 & 0 \\
\hline & CASE H & & & & & & & \\
\hline & Query Sequence & & & & & & & \\
\hline \multirow[t]{2}{*}{39} & $\begin{array}{c}{ }^{(\mathrm{H})} \text { AGCTGGCATTATTTATGGCTGTA } \\
\text { TGGCTGTATGGCTGTATGGCTGTA } \\
\text { TGGCTG }^{(\mathrm{T})} \\
\end{array}$ & & & & & & & \\
\hline & Reflector Sequence & & & & & & & \\
\hline 40 & $\begin{array}{c}{ }^{(\mathrm{H})} \text { TTCTGGCATTATTTATGGCTGTA } \\
\text { TGGCTGTATGGCTGTATGGCTGTA } \\
\text { TGGCTG }^{(\mathrm{T})}\end{array}$ & $1.0191(92.79)$ & $1.0005(99.79)$ & $1.0023(99.07)$ & $1.00008(99.97)$ & 96 & 96 & 0 \\
\hline
\end{tabular}

H-H = Head-to-head Pairing ; T-T = Tail-totail Pairing; NW = Needleman-Wunsch; ID = Identity; SIM = Similarity

RMMGA = Reflective Match-mismatch-gab Approach; MMSA = Molecular mass Score Approach

Note: Type I Resolution Rule is considered for the polymorphic cluster 


\section{OPTINALYSIS}

Table 31: Results of the Geometrical Optinalysis of the Nucleotide Base Sequences and other Standard Methods

\begin{tabular}{|c|c|c|c|c|c|c|c|c|}
\hline & & RCMMGA & RCM-(io) FA & RCMis-(io) FA & RCG-(io) FA & $\begin{array}{l}\text { \% ID and } \\
\text { SIM. }\end{array}$ & $\begin{array}{c}\text { NW } \\
\text { Score } \\
\end{array}$ & $\begin{array}{l}\text { \% Gab } \\
\text { Score }\end{array}$ \\
\hline & CASE A & H-H Pairing & H-H Pairing & H-H Pairing & H-H Pairing & & & \\
\hline Item & Query Sequence & & & & & & & \\
\hline \multirow[t]{2}{*}{1} & ${ }^{(\mathrm{H})} \mathrm{AGC}^{*} \mathrm{TGG}^{*} \mathrm{CAT}^{*} \mathrm{TAT}^{*} \mathrm{TTA}^{*} \mathrm{TGG}^{*} \mathrm{CTG}^{(\mathrm{T})}$ & & & & & & & \\
\hline & Reflector Sequence & & & & & & & \\
\hline 2 & ${ }^{(\mathrm{H})} \mathrm{AGC}^{*} \mathrm{TGG}^{*} \mathrm{CAT}^{*} \mathrm{TAT}^{*} \mathrm{TTA}^{*} \mathrm{TGG}^{*} \mathrm{CTG}^{(\mathrm{T})}$ & $1.0000(100)$ & $1.0000(100)$ & $2.0000(0.00)$ & $2.0000(0.00)$ & 100 & 42 & 0 \\
\hline 3 & ${ }^{(\mathrm{H})} \mathrm{CGC}^{*} \mathrm{TGG}^{*} \mathrm{CAT} * \mathrm{TAT} * \mathrm{TTA} * \mathrm{TGG}^{*} \mathrm{CTG}^{(\mathrm{T})}$ & $1.0722(76.27)$ & $1.0218(91.81)$ & $1.7778(6.67)$ & $2.0000(0.00)$ & 95 & 37 & 0 \\
\hline 4 & ${ }^{(\mathrm{H})} \mathrm{AGC}^{*} \mathrm{TGG}^{*} \mathrm{CAT}^{*} \mathrm{TCT}^{*} \mathrm{TTA} * \mathrm{TGG}^{*} \mathrm{CTG}^{(\mathrm{T})}$ & $1.0400(85.71)$ & $1.0123(95.24)$ & $1.8333(4.76)$ & $2.0000(0.00)$ & 95 & 37 & 0 \\
\hline 5 & ${ }^{(\mathrm{H})} \mathrm{AGC}^{*} \mathrm{TGG}^{*} \mathrm{CAT}^{*} \mathrm{TAT}^{*} \mathrm{TTA}^{*} \mathrm{TGG}^{*} \mathrm{CTT}^{(\mathrm{T})}$ & $1.0097(96.23)$ & $1.0031(98.79)$ & $1.8925(2.92)$ & $2.0000(0.00)$ & 95 & 37 & 0 \\
\hline 6 & ${ }^{(\mathrm{H})} \mathrm{AGC}^{*} \mathrm{TGG}^{*} \mathrm{CAT}^{*} \mathrm{TAT}^{*} \mathrm{TTA}^{*} \mathrm{TGG}^{*} \mathrm{CAA}^{(\mathrm{T})}$ & $1.0097(96.23)$ & $1.0063(97.53)$ & $1.8039(5.75)$ & $2.0000(0.00)$ & 90 & 32 & 0 \\
\hline 7 & ${ }^{(\mathrm{H})}$ AGC $^{*} \mathrm{TGG}^{*} \mathrm{CAT}^{*} \mathrm{TGG}^{*} \mathrm{TTA}^{*} \mathrm{TGG}^{*} \mathrm{CTG}^{(\mathrm{T})}$ & $1.0400(85.71)$ & $1.0256(90.48)$ & $1.7037(9.52)$ & $2.0000(0.00)$ & 90 & 32 & 0 \\
\hline 8 & ${ }^{(\mathrm{H})} \mathrm{GAC}^{*} \mathrm{TGG}^{*} \mathrm{CAT}^{*} \mathrm{TAT}^{*} \mathrm{TTA}^{*} \mathrm{TGG}^{*} \mathrm{CTG}^{(\mathrm{T})}$ & $1.0722(76.27)$ & $1.0458(83.91)$ & $1.6140(13.58)$ & $2.0000(0.00)$ & 90 & 32 & 0 \\
\hline 9 & ${ }^{(\mathrm{H})}{ }^{\mathrm{TCG}} * \mathrm{AGG}^{*} \mathrm{CAT}^{*} \mathrm{TAT}^{*} \mathrm{TTA}^{*} \mathrm{TGG}^{*} \mathrm{CTG}^{(\mathrm{T})}$ & $1.1566(57.38)$ & $1.0975(69.83)$ & $1.3986(27.39)$ & $2.0000(0.00)$ & 81 & 22 & 0 \\
\hline 10 & ${ }^{(\mathrm{H})} \mathrm{AGC}^{*} \mathrm{TGG}^{*} \mathrm{CAG}^{*} \mathrm{CTG}^{*} \mathrm{TTA}^{*} \mathrm{TGG}^{*} \mathrm{CTG}^{(\mathrm{T})}$ & $1.1034(68.42)$ & $1.0592(79.88)$ & $1.5038(19.76)$ & $2.0000(0.00)$ & 81 & 22 & 0 \\
\hline 11 & ${ }^{(\mathrm{H})} \mathrm{AGC}^{*} \mathrm{TGG}^{*} \mathrm{CAT}^{*} \mathrm{TAT}^{*} \mathrm{TTA}^{*} \mathrm{TGT}^{*} \mathrm{TAT}^{(\mathrm{T})}$ & $1.0323(88.24)$ & $1.0167(93.63)$ & $1.6529(11.73)$ & $2.0000(0.00)$ & 81 & 22 & 0 \\
\hline 12 & $\left.{ }^{(\mathrm{H})}\right)_{T A} * \mathrm{TAC}^{*} \mathrm{TCG} * \mathrm{TCT}^{*} \mathrm{TTA}^{*} \mathrm{TGG}^{*} \mathrm{CTG}^{(\mathrm{T})}$ & $1.3478(31.91)$ & $1.1071(67.57)$ & $1.0100(96.13)$ & $1.0036(98.58)$ & 57 & -3 & 0 \\
\hline 13 & ${ }^{(\mathrm{H})} \mathrm{CAG}^{*} \mathrm{TGG}^{*} \mathrm{CAT}^{*} \mathrm{GGC}^{*} \mathrm{TTA}^{*} \mathrm{TGG}^{*} \mathrm{TCA}^{(\mathrm{T})}$ & $1.1579(57.14)$ & $1.1579(57.14)$ & $1.2500(42.86)$ & $2.0000(0.00)$ & 57 & -3 & 0 \\
\hline \multirow[t]{3}{*}{14} & ${ }^{(\mathrm{H})} \mathrm{TGC}^{*} \mathrm{AAG}^{*} \mathrm{CAT}^{*} \mathrm{CGC}^{*} \mathrm{TTA}^{*} \mathrm{CGG}^{*} \mathrm{ATG}^{(\mathrm{T})}$ & $1.3846(28.57)$ & $1.1429(60.00)$ & $1.2747(39.76)$ & $2.0000(0.00)$ & 62 & 2 & 0 \\
\hline & CASE B & & & & & & & \\
\hline & $\begin{array}{c}\text { Query Sequence } \\
\end{array}$ & & & & & & & \\
\hline \multirow[t]{2}{*}{15} & ${ }^{(\mathrm{H})} \mathrm{AGC}^{*} \mathrm{TGG}^{*} \mathrm{CAT}^{*} \mathrm{TAT}^{*} \mathrm{TTA}^{*} \mathrm{TGG}^{*} \mathrm{CTG}^{(\mathrm{T})}$ & & & & & & & \\
\hline & Reflector Sequence & & & & & & & \\
\hline 16 & ${ }^{(\mathrm{H})}{ }_{-}$- $^{*} \mathrm{TGG}^{*} \mathrm{CAT}^{*} \mathrm{TAT}^{*} \mathrm{TTA}^{*} \mathrm{TGG}^{*} \mathrm{CTG}^{(\mathrm{T})}$ & $1.1707(54.84)$ & $1.0722(76.27)$ & $2.0000(0.00)$ & $1.4884(20.75)$ & 86 & 25 & 14 \\
\hline 17 & ${ }^{(\mathrm{H})} \mathrm{AGC}^{*} \mathrm{TGG}^{*} \mathrm{CAT}^{*} \ldots$ _ $\ldots$ *TTA*TGG$* \mathrm{CTG}^{(\mathrm{T})}$ & $1.0909(71.43)$ & $1.0400(85.71)$ & $2.0000(0.00)$ & $1.6000(14.29)$ & 86 & 25 & 14 \\
\hline 18 & ${ }^{(\mathrm{H})} \mathrm{AGC}^{*} \mathrm{TGG}^{*} \mathrm{CAT}^{*} \mathrm{TAT} * \mathrm{TTA}^{*} \mathrm{TGG}^{*}$. . - $^{(\mathrm{T})}$ & $1.0213(92.00)$ & $1.0097(96.23)$ & $2.0000(0.00)$ & $1.7297(8.47)$ & 86 & 25 & 14 \\
\hline 19 & ${ }^{(\mathrm{H})} \mathrm{AGC}^{*}-\mathrm{GG}^{*} \mathrm{CAT} *{ }_{-}-\mathrm{T} * \mathrm{TT}-* \mathrm{TGG}^{*} \mathrm{CTG}^{(\mathrm{T})}$ & $1.6842(10.34)$ & $1.0592(79.88)$ & $2.0000(0.00)$ & $1.5038(19.76)$ & 76 & 11 & 19 \\
\hline 20 & 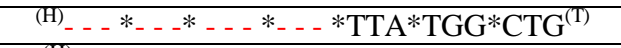 & $12.0000(-29.4) 1$ & $1.3793(29.03)$ & $2.0000(0.00)$ & $1.0732(76.00)$ & 43 & -11 & 57 \\
\hline \multirow[t]{3}{*}{21} & $(\mathrm{H}){ }_{-} *_{-} \ldots *_{-} \ldots *_{-}{ }_{-} *_{-} \ldots *_{-} \ldots * \mathrm{CTG}^{(\mathrm{T})}$ & $-0.4211(-74.19)$ & $1.6762(10.69)$ & $1.9487(1.33)$ & $0.9769(90.97)$ & 14 & -35 & 85 \\
\hline & CASE C & & & & & & & \\
\hline & Query Sequence & & & & & & & \\
\hline \multirow[t]{2}{*}{22} & ${ }^{(\mathrm{H})} \mathrm{A}^{-} \mathrm{C}^{*} \mathrm{TGG}^{*} \mathrm{CAT}^{*} \mathrm{TAT}^{*} \mathrm{TTA}^{*} \mathrm{TG}-* \mathrm{TG}^{(\mathrm{T})}$ & & & & & & & \\
\hline & Reflector Sequence & & & & & & & \\
\hline 23 & (H) _ _ *TGG*CAT*TAT*TTA*TGG*CTG ${ }^{(\mathrm{T})}$ & $0.8889(60.00)$ & $1.0592(79.88)$ & $1.7864(6.36)$ & $1.6140(13.58)$ & 80 & 14 & 20 \\
\hline 24 & ${ }^{(\mathrm{H})} \mathrm{AGC}^{*} \mathrm{TGG} * \mathrm{CAT} * \ldots$. $*$ TTA $* \mathrm{TGG}^{*} \mathrm{CTG}^{(\mathrm{T})}$ & $0.8000(33.33)$ & $1.0827(73.49)$ & $1.6271(12.94)$ & $1.6000(14.29)$ & 71 & 3 & 28 \\
\hline 25 & ${ }^{(\mathrm{H})} \mathrm{AGC}^{*} \mathrm{TGG}^{*} \mathrm{CAT} * \mathrm{TAT} * \mathrm{TTA}^{*} \mathrm{TGG}^{*} \ldots$. (T) & $0.7273(14.29)$ & $1.0375(86.50)$ & $1.6881(10.18)$ & $1.8039(5.75)$ & 89 & 20 & 10 \\
\hline \multirow[t]{3}{*}{26} & ${ }^{(\mathrm{H})} \mathrm{AGC}^{*}-\mathrm{GG}^{*} \mathrm{CAT}^{*}$ - - T*TT -*TGG*CTG ${ }^{(\mathrm{T})}$ & $1.6000(14.29)$ & $1.1067(67.66)$ & $1.6271(12.94)$ & $1.5038(19.76)$ & 67 & 2 & 5 \\
\hline & CASE D & & & & & & & \\
\hline & Query Sequence & & & & & & & \\
\hline \multirow[t]{2}{*}{27} & ${ }^{(\mathrm{H})} \mathrm{AGC}^{*} \mathrm{TGG}^{*} \mathrm{CAT}^{*} \mathrm{TAT}^{*} \mathrm{TTA}^{*} \mathrm{TGG}^{*} \mathrm{CTG}^{(\mathrm{T})}$ & & & & & & & \\
\hline & Reflector Sequence & & & & & & & \\
\hline 28 & ${ }^{(\mathrm{H})}$ - - $^{*}$ TGG*CGG*TAT*TTA*TAA*CTG ${ }^{(\mathrm{T})}$ & $1.3559(31.15)$ & $1.1429(60.00)$ & $1.5385(17.65)$ & $1.4884(20.75)$ & 67 & 5 & 14 \\
\hline 29 & ${ }^{(\mathrm{H})} \mathrm{AGC}^{*} \mathrm{TGG}^{*} \mathrm{CAT}^{*} \ldots$. - *TTA*TGT*${ }^{*} \mathrm{CTG}^{(\mathrm{T})}$ & $1.2698(40.35)$ & $1.0764(75.15)$ & $1.6881(10.18)$ & $1.6000(14.29)$ & 81 & 20 & 14 \\
\hline
\end{tabular}




\section{OPTINALYSIS}

\begin{tabular}{|c|c|c|c|c|c|c|c|c|}
\hline 30 & ${ }^{(\mathrm{H})} \mathrm{AGC}^{*} \mathrm{TGG}^{*} \mathrm{GTC} * \mathrm{GTC} * \mathrm{TTA}^{*} \mathrm{TGG}^{*} \ldots{ }^{(\mathrm{T})}$ & $1.1594(56.86)$ & $1.1282(62.96)$ & $1.3585(30.91)$ & $1.7297(8.47)$ & 57 & -5 & 14 \\
\hline 31 & ${ }^{(\mathrm{H})} \mathrm{AGC}^{*}-\mathrm{GG}^{*} \mathrm{CAT}^{*}-\mathrm{I}^{*} \mathrm{TT}-* \mathrm{TGG}^{*} \mathrm{CAT}^{(\mathrm{T})}$ & $1.9310(1.82)$ & $1.0706(76.69)$ & $1.8039(5.75)$ & $1.5038(19.76)$ & 67 & 1 & 19 \\
\hline
\end{tabular}

RCMMGA = Reflective Cluster Match-mismatch-gab Approach; RCM-(io) FA = Reflective Match-(in order) Frequency Approach;

RCMm-(io) FA = Reflective Mismatch-(in order) Frequency Approach; RCG-(io) FA = Reflective Gab-(in order) Frequency Approach

H-H = Head-to-head Pairing; NW = Needleman-Wunsch; ID = Identity; SIM = Similarity

Note: Type I Resolution Rule is considered for the polymorphic cluster. 


\section{OPTINALYSIS}

\section{Protein Sequence}

Table 32: Kabirian Algorithmic Transformations of the Amino Acid Sequences and the Results of the Geometrical Optinalysis and other Standard Methods

\begin{tabular}{|c|c|c|c|c|c|c|c|}
\hline & RMMGA & H-H Pairing & T-T Pairing & NW & $\begin{array}{c}\text { Identity } \\
(\%)\end{array}$ & $\begin{array}{c}\text { Positives } \\
(\%)\end{array}$ & $\begin{array}{c}\text { Gabs } \\
(\%)\end{array}$ \\
\hline \multicolumn{8}{|l|}{ CASE I } \\
\hline Query Sequence & Transformed Query Sequence & & & & & & \\
\hline${ }^{(\mathrm{H})}$ MARNDCEQGHILKFPSTWYV $^{(\mathrm{T})}$ & $(1,1,1,1,1,1,1,1,1,1,1,1,1,1,1,1,1,1,1,1)$ & & & & & & \\
\hline Reflector Sequence & Transformed Reflector Sequence & & & & & & \\
\hline${ }^{(\mathrm{H})}$ MARNDCEQGHILKFPSTWYV $^{(\mathrm{T})}$ & $(1,1,1,1,1,1,1,1,1,1,1,1,1,1,1,1,1,1,1,1)$ & $1.00000(100 \%)$ & $1.00000(100 \%)$ & 116 & 100 & 100 & 0 \\
\hline${ }^{(\mathrm{H})}$ MARNDCEQGHILKFPSTYVW ${ }^{(\mathrm{T})}$ & $(1,1,1,1,1,1,1,1,1,1,1,1,1,1,1,1,1,0,0,1)$ & $1.00631(97.53 \%)$ & $1.04862(83.03 \%)$ & 92 & 85 & 90 & 0 \\
\hline${ }^{(\mathrm{H})}$ RMANDCEQGHILKFPSTWYV $^{(\mathrm{T})}$ & $(1,0,0,1,1,1,1,1,1,1,1,1,1,1,1,1,1,1,1,1)$ & $1.04862(83.03 \%)$ & $1.00631(97.53 \%)$ & 99 & 85 & 85 & 0 \\
\hline${ }^{(\mathrm{H})}$ NDMARCEQGHILKFPSTWYV ${ }^{(\mathrm{T})}$ & $(0,0,0,0,0,1,1,1,1,1,1,1,1,1,1,1,1,1,1,1)$ & $1.13953(60.66 \%)$ & $1.02083(92.16 \%)$ & 81 & 75 & 75 & 0 \\
\hline${ }^{(\mathrm{H})}$ MARTWCEQGHILKFPSNDYV ${ }^{(\mathrm{T})}$ & $(1,1,1,0,0,1,1,1,1,1,1,1,1,1,1,1,0,0,1,1)$ & $1.05587(80.86 \%)$ & $1.06180(79.15 \%)$ & 80 & 80 & 80 & 0 \\
\hline${ }^{(\mathrm{H})}$ YVRNDCEQGHILKFPSTWMA $^{(\mathrm{T})}$ & $(0,0,1,1,1,1,1,1,1,1,1,1,1,1,1,1,1,1,0,0)$ & $1.05882(80.00 \%)$ & $1.05882(80.00 \%)$ & 94 & 80 & 80 & 0 \\
\hline Query Sequence & Transformed Query Sequence & & & & & & \\
\hline${ }^{(\mathrm{H})}$ MARNDCEQGHILKFPSTWYV ${ }^{(\mathrm{T})}$ & $(1,1,1,1,1,1,1,1,1,1,1,1,1,1,1,1,1,1,1,1)$ & & & & & & \\
\hline Reflector Sequence & Transformed Reflector Sequence & & & & & & \\
\hline${ }^{(\mathrm{H})}$ MARNDCEQGHILKF - . _ _ _ (T) & $(1,1,1,1,1,1,1,1,1,1,1,1,1,1,-1,-1,-1,-1,-1,-1)$ & $1.07692(75.00 \%)$ & $1.55556(16.67 \%)$ & 61 & 70 & 70 & 30 \\
\hline${ }^{(\mathrm{H})}$ MARNDC - - - - - - PSTWYV ${ }^{(\mathrm{T})}$ & $(1,1,1,1,1,1,-1,-1,-1,-1,-1,-1,-1,-1,1,1,1,1,1,1)$ & $1.50000(20.00 \%)$ & $1.50000(20.00 \%)$ & 54 & 60 & 60 & 40 \\
\hline (H) - - - - CEQGHILKFPSTWYV ${ }^{(\mathrm{T})}$ & $(-1,-1,-1,-1,-1,1,1,1,1,1,1,1,1,1,1,1,1,1,1,1)$ & $1.40000(27.27 \%)$ & $1.05000(82.61 \%)$ & 74 & 75 & 75 & 25 \\
\hline${ }^{(\mathrm{H})}$ MAR - - CEQGHILKFPS - - YV $\mathrm{V}^{(\mathrm{T})}$ & $(1,1,1,-1,-1,1,1,1,1,1,1,1,1,1,1,1,-1,-1,1,1)$ & $1.13514(61.54 \%)$ & $1.15068(58.49 \%)$ & 62 & 80 & 80 & 20 \\
\hline (H) - RNDCEQGHILKFPSTW - - ${ }^{(\mathrm{T})}$ & $(-1,-1,1,1,1,1,1,1,1,1,1,1,1,1,1,1,1,1,-1,-1)$ & $1.14286(60.00 \%)$ & $1.14286(60.00 \%)$ & 70 & 80 & 80 & 20 \\
\hline Query Sequence & Transformed Query Sequence & & & & & & \\
\hline${ }^{(\mathrm{H})}$ MARNDCEQGHILKFPSTWYV $^{(\mathrm{T})}$ & $(1,1,1,1,1,1,1,1,1,1,1,1,1,1,1,1,1,1,1,1)$ & & & & & & \\
\hline Reflector Sequence & Transformed Reflector Sequence & & & & & & \\
\hline${ }^{(\mathrm{H})}$ MARNDCEQGHILKF - - STPV ${ }^{(\mathrm{T})}$ & $(1,1,1,1,1,1,1,1,1,1,1,1,1,1,-1,-1,0,0,0,0)$ & $1.05000(82.61 \%)$ & $1.25373(42.37 \%)$ & 68 & 75 & 80 & 10 \\
\hline${ }^{(\mathrm{H})}$ MARNDCKEILH - - - PSTWYV ${ }^{(\mathrm{T})}$ & $(1,1,1,1,1,1,0,0,0,0,0,-1,-1,-1,1,1,1,1,1,1)$ & $1.21557(47.64 \%)$ & $1.25309(42.46 \%)$ & 61 & 60 & 75 & 15 \\
\hline (H) - - RMACEQGHILKFPSTWYV ${ }^{(\mathrm{T})}$ & $(-1,-1,0,0,0,1,1,1,1,1,1,1,1,1,1,1,1,1,1,1)$ & $1.22872(45.74 \%)$ & $1.02667(90.12 \%)$ & 78 & 80 & 80 & 10 \\
\hline${ }^{(\mathrm{H})}$ MAR - WCEQGHILKFPSN - YV ${ }^{(\mathrm{T})}$ & $(1,1,1,-1,0,1,1,1,1,1,1,1,1,1,1,1,0,-1,1,1)$ & $1.09174(71.22 \%)$ & $1.10185(68.79 \%)$ & & & & \\
\hline (H) - - RNDCEQGHILKFPSTWMA ${ }^{(\mathrm{T})}$ & $(-1,-1,1,1,1,1,1,1,1,1,1,1,1,1,1,1,1,1,-1,-1)$ & $1.14286(60.00 \%)$ & $1.14286(60.00 \%)$ & 82 & 80 & 80 & 10 \\
\hline
\end{tabular}

H-H = Head-to-head Pairing ; T-T = Tail-totail Pairing; RMMGA = Reflective Match-mismatch-gab Approach; NW = Needleman-Wunsch 


\section{OPTINALYSIS}

\subsection{Example 8: Ecological Data}

Ecologist are very interested in any quantification that measure the abundance and spread of biological species within an ecosystem. Table 32 recorded the frequency of six (6) species per unit cluster of $1000 \mathrm{~m}^{2}$ area, in a systematic order moving A-H to the left and $A^{\prime}-H^{\prime}$ to the right from an origin "O”. Two-way Optinalysis (Species freq. as the elemet $\times$ area in $\mathrm{m}^{2}$ as the co - element) was used to calculate the goemetric, geostatistical and statistical similarity in the species abundace between each cluster. The Optinalysis results in Tables 34-36 shows that the distribution and abundance of the species are significantly (P>0.95) dissimilar geometrically, geostatistically and statistically between the studied clusters.

Table 33: Ecological Survey Data

\begin{tabular}{|c|c|c|c|c|c|c|c|c|c|c|c|c|c|c|c|c|c|}
\hline $\begin{array}{c}\text { Area }\left(\times 10^{3} m^{2}\right) \\
\text { Clusters }\end{array}$ & $\begin{array}{c}\mathbf{1} \\
{ }_{(\mathbf{H})} \mathbf{H}\end{array}$ & $\begin{array}{l}\mathbf{1} \\
\mathbf{G}\end{array}$ & $\begin{array}{l}1 \\
F\end{array}$ & $\begin{array}{l}1 \\
\mathbf{E}\end{array}$ & $\begin{array}{l}1 \\
\text { D }\end{array}$ & $\begin{array}{l}1 \\
\mathrm{C}\end{array}$ & $\begin{array}{l}\mathbf{1} \\
\text { B }\end{array}$ & $\begin{array}{c}1 \\
\mathbf{A}^{(\mathbf{T})}\end{array}$ & $\begin{array}{l}\mathbf{0} \\
\mathbf{O}\end{array}$ & $\begin{array}{c}\mathbf{1} \\
{ }^{(\mathbf{T})} \mathbf{A}^{\prime}\end{array}$ & $\begin{array}{c}\mathbf{1} \\
\mathbf{B}^{\backslash}\end{array}$ & $\begin{array}{c}\mathbf{1} \\
\mathbf{C}^{\prime}\end{array}$ & $\begin{array}{c}1 \\
D^{\prime}\end{array}$ & $\begin{array}{c}\mathbf{1} \\
\mathbf{E}^{\prime}\end{array}$ & $\begin{array}{c}\mathbf{1} \\
\mathbf{F}^{\prime}\end{array}$ & $\begin{array}{c}\mathbf{1} \\
\mathbf{G}^{\prime}\end{array}$ & $\underset{\mathbf{H}^{(\mathbf{H})}}{\mathbf{1}}$ \\
\hline & \multicolumn{17}{|c|}{ Species frequencies per unit cluster $\left(\times 10^{3} \mathrm{~m}^{2}\right)$} \\
\hline Spp. 1 & 1.32 & 5.43 & 9.84 & 16.93 & 23.05 & 24.83 & 26.47 & 27.03 & & 27.03 & 26.47 & 24.83 & 23.05 & 16.93 & 9.84 & 5.43 & 1.32 \\
\hline Spp. 2 & 19.32 & 23.43 & 40.84 & 56.93 & 43.05 & 44.83 & 36.47 & 27.03 & & 27.03 & 26.47 & 24.83 & 23.05 & 16.93 & 9.84 & 5.43 & 1.32 \\
\hline Spp. 3 & 1.32 & 5.43 & 9.84 & 16.93 & 23.05 & 24.83 & 26.47 & 27.03 & & 27.03 & 36.47 & 44.83 & 43.05 & 56.93 & 40.84 & 23.43 & 19.32 \\
\hline Spp. 4 & 0 & 0 & 0 & 0 & 0 & 0 & 2.1 & 3.5 & & 9.34 & 9.64 & 10.23 & 11.04 & 15.34 & 15.94 & 17.34 & 18.60 \\
\hline Spp. 5 & 0 & 3 & 0 & 0 & 7 & 9 & 0 & 1 & & 0 & 0 & 4 & 3 & 0 & 0 & 0 & 0 \\
\hline Spp. 6 & 0 & 5 & 0 & 0 & 0 & 0 & 0 & 0 & & 0 & 5 & 0 & 0 & 0 & 0 & 0 & 0 \\
\hline
\end{tabular}

Species distribution, pattern and direction of the distribution

Table 34: Results of Geometrical Optinalysis of the Ecological Data

\begin{tabular}{lllllllll}
\hline \multicolumn{7}{c}{ Two-way Geometrical Analysis } \\
\hline Pairing & \multicolumn{7}{c}{ Head-to-head pairing } & \multicolumn{5}{c}{ Tail-to-tail pairing } \\
\hline Results & Kc-value & Kc-value $(\mathrm{CR})$ & $\mathrm{P}_{\text {Sim. }}$-value & $\mathrm{P}_{\text {Dsim.-value }}$ & Kc-value & Kc-value $(\mathrm{CR})$ & $\mathrm{P}_{\text {Sim.-value }}$ & $\mathrm{P}_{\text {Dsim.-value }}$ \\
\hline Spp. 1 & 1 & 1 & 1 & 0 & 1 & 1 & 1 & 0 \\
Spp. 2 & 1.2697 & 0.8248 & 0.4036 & 0.5964 & 1.1840 & 0.8655 & 0.5257 & 0.4743 \\
Spp. 3 & 0.8248 & 1.2697 & 0.4036 & 0.5964 & 0.8655 & 1.1840 & 0.5257 & 0.4743 \\
Spp. 4 & 0.6540 & 2.1230 & -0.0281 & -0.9730 & 0.7289 & 1.5923 & 0.1468 & 0.8532 \\
Spp. 5 & 1.2789 & 0.8209 & 0.3926 & 0.6074 & 1.3575 & 0.7915 & 0.3100 & 0.6900 \\
Spp. 6 & 1.3846 & 0.7826 & 0.2857 & 0.7143 & 0.7826 & 1.3846 & 0.2857 & 0.7143 \\
\hline
\end{tabular}




\section{OPTINALYSIS}

Table 35: Results of Geostatistical Optinalysis of the Ecological Data

\begin{tabular}{lllllllll}
\hline \multicolumn{7}{c}{ Two-way Geostatistical Optinalysis } \\
\hline Pairing & \multicolumn{7}{c}{ Head-to-head pairing } & \multicolumn{5}{c}{ Tail-to-tail pairing } \\
\hline Results & Kc-value & Kc-value $(\mathrm{CR})$ & $\mathrm{P}_{\text {Sim.-value }}$ & $\mathrm{P}_{\text {Dsim.-value }}$ & Kc-value & Kc-value $(\mathrm{CR})$ & $\mathrm{P}_{\text {Sim.-value }}$ & $\mathrm{P}_{\text {Dsim.-value }}$ \\
\hline Spp. 1 & 1 & 1 & 1 & 0 & 1 & 1 & 1 & 0 \\
Spp. 2 & 1.0535 & 0.9516 & 0.8155 & 0.1845 & 1.0371 & 0.9655 & 0.8666 & 0.1334 \\
Spp. 3 & 0.9516 & 1.0535 & 0.8155 & 0.1845 & 0.9655 & 1.0371 & 0.8666 & 0.1334 \\
Spp. 4 & 0.8875 & 1.1452 & 0.5955 & 0.4045 & 0.9215 & 1.0932 & 0.7088 & 0.2912 \\
Spp. 5 & 1.0534 & 0.9518 & 0.8160 & 0.1840 & 1.0668 & 0.9411 & 0.7773 & 0.2227 \\
Spp. 6 & 1.0794 & 0.9315 & 0.7436 & 0.2564 & 0.9315 & 1.0794 & 0.7436 & 0.2564 \\
\hline
\end{tabular}

Table 36: Results of Statistical Optinalysis of the Ecological Data

\begin{tabular}{llllllll}
\multicolumn{2}{l}{ Type (I) Two-way Statistical Optinalysis } & \multicolumn{3}{c}{ TypeS (II) Two-way Statistical Optinalysis } \\
\hline Results & Kc-value & $\mathrm{P}_{\text {Sim.-value }}$ & $\mathrm{P}_{\text {Dsim.-value }}$ & Kc-value & $\mathrm{P}_{\text {Dsim.-value }}$ & $\mathrm{P}_{\text {Dsim.-value }}$ \\
\hline Spp. 1 & 0.9317 & 0.7443 & 0.2558 & 1.0791 & 0.7442 & 0.2558 \\
Spp. 2 & 0.9358 & 0.7586 & 0.2414 & 1.0772 & 0.7493 & 0.2507 \\
Spp. 3 & 0.9331 & 0.7493 & 0.2507 & 1.0772 & 0.7493 & 0.2507 \\
Spp. 4 & 0.8875 & 0.5955 & 0.4045 & 1.1452 & 0.5955 & 0.4045 \\
Spp. 5 & 0.8504 & 0.4795 & 0.5206 & 1.2135 & 0.4795 & 0.5205 \\
Spp. 6 & 0.8293 & 0.4167 & 0.5833 & 1.2593 & 0.4167 & 0.5833 \\
\hline
\end{tabular}




\section{OPTINALYSIS}

\subsection{Example 9: Experimental Data (I)}

Tables 37 and 38 recorded the effect of substance addition at different concentrations aim to promote the metabolism of a given living process. The result was measured in three replicates. The Optinalysis calculated results were compared with the ANOVA result using graphad Prism, version 8.0.2. Comparatively, statistical Optinalysis shows some similarities in results with ANOVA and Turkey's multiple as shown in Tables 39-41.

Table 37: Experimental Data (Ia), the Different Methods of Data Sequence Re-organizations, and the Different Approach of Establishing a Reflector Sequences

\begin{tabular}{|c|c|c|c|c|c|c|c|c|c|c|c|c|}
\hline & & \multicolumn{6}{|c|}{ Query sequences } & \multicolumn{4}{|c|}{ Reflector sequences } & \multirow[b]{2}{*}{$\begin{array}{l}\text { Reference } \\
\text { value }\end{array}$} \\
\hline Treatmant & Repl. & Obs. & \multirow{7}{*}{ 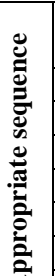 } & ${ }^{1 *}$ Obs. & ${ }^{2 *}$ Obs. & ${ }^{3 *}$ Obs. & ${ }^{4 *}$ Obs. & $\begin{array}{l}\text { Aggregate } \\
\text { Mean }\end{array}$ & $\begin{array}{l}\text { Composite } \\
\text { Mean }\end{array}$ & $\begin{array}{l}\text { Mean } \\
\text { of } 0 \%\end{array}$ & $\begin{array}{l}\text { Mean } \\
\text { of } 1 \%\end{array}$ & \\
\hline \multirow[t]{3}{*}{${ }^{(\mathrm{H})} 0 \%$} & $\mathrm{R}_{1}$ & 1.24 & & 1.24 & 1.84 & 1.24 & 6.41 & 1.6067 & 3.2283 & 1.6067 & 2.5100 & 3.5 \\
\hline & $\mathrm{R}_{2}$ & 1.84 & & 1.74 & 1.74 & 1.74 & 6.11 & 1.6067 & 3.2283 & 1.6067 & 2.5100 & 3.5 \\
\hline & $\mathrm{R}_{3}$ & 1.74 & & 1.84 & 1.24 & 1.84 & 5.81 & 1.6067 & 3.2283 & 1.6067 & 2.5100 & 3.5 \\
\hline \multirow[t]{3}{*}{$1 \%$} & $\mathrm{R}_{1}$ & 2.81 & & 2.21 & 2.81 & 2.01 & 3.71 & 2.5100 & 3.2283 & 1.6067 & 2.5100 & 3.5 \\
\hline & $\mathrm{R}_{2}$ & 2.21 & & 2.51 & 2.51 & 2.21 & 3.63 & 2.5100 & 3.2283 & 1.6067 & 2.5100 & 3.5 \\
\hline & $\mathrm{R}_{3}$ & 2.51 & & 2.81 & 2.21 & 2.31 & 3.49 & 2.5100 & 3.2283 & 1.6067 & 2.5100 & 3.5 \\
\hline \multirow[t]{3}{*}{$2 \%$} & $\mathrm{R}_{1}$ & 3.71 & \multirow{7}{*}{ 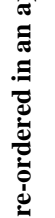 } & 3.11 & 3.71 & 2.51 & 3.41 & 3.4100 & 3.2283 & 1.6067 & 2.5100 & 3.5 \\
\hline & $\mathrm{R}_{2}$ & 3.41 & & 3.41 & 3.41 & 2.62 & 3.14 & 3.4100 & 3.2283 & 1.6067 & 2.5100 & 3.5 \\
\hline & $\mathrm{R}_{3}$ & 3.11 & & 3.71 & 3.11 & 2.81 & 3.11 & 3.4100 & 3.2283 & 1.6067 & 2.5100 & 3.5 \\
\hline \multirow[t]{3}{*}{$3 \%$} & $\mathrm{R}_{1}$ & 2.01 & & 2.01 & 2.62 & 3.11 & 2.81 & 2.3133 & 3.2283 & 1.6067 & 2.5100 & 3.5 \\
\hline & $\mathrm{R}_{2}$ & 2.61 & & 2.31 & 2.31 & 3.14 & 2.62 & 2.3133 & 3.2283 & 1.6067 & 2.5100 & 3.5 \\
\hline & $\mathrm{R}_{3}$ & 2.32 & & 2.62 & 2.01 & 3.41 & 2.51 & 2.3133 & 3.2283 & 1.6067 & 2.5100 & 3.5 \\
\hline \multirow[t]{3}{*}{$4 \%$} & $\mathrm{R}_{1}$ & 3.49 & & 3.14 & 3.63 & 3.49 & 2.31 & 3.4200 & 3.2283 & 1.6067 & 2.5100 & 3.5 \\
\hline & $\mathrm{R}_{2}$ & 3.14 & \multirow{5}{*}{ 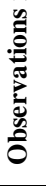 } & 3.49 & 3.49 & 3.63 & 2.21 & 3.4200 & 3.2283 & 1.6067 & 2.5100 & 3.5 \\
\hline & $\mathrm{R}_{3}$ & 3.63 & & 3.63 & 3.14 & 3.71 & 2.01 & 3.4200 & 3.2283 & 1.6067 & 2.5100 & 3.5 \\
\hline \multirow[t]{3}{*}{$5 \%^{(\mathrm{T})}$} & $\mathrm{R}_{1}$ & 5.81 & & 5.81 & 6.41 & 5.81 & 1.84 & 6.1100 & 3.2283 & 1.6067 & 2.5100 & 3.5 \\
\hline & $\mathrm{R}_{2}$ & 6.41 & & 6.11 & 6.11 & 6.11 & 1.74 & 6.1100 & 3.2283 & 1.6067 & 2.5100 & 3.5 \\
\hline & $\mathrm{R}_{3}$ & 6.11 & & 6.41 & 5.81 & 6.41 & 1.24 & 6.1100 & 3.2283 & 1.6067 & 2.5100 & 3.5 \\
\hline
\end{tabular}

${ }^{1 *}$ Sequence order: Ascend within;

${ }^{3 *}$ Sequence order: Ascend within and between;

${ }^{2 *}$ Sequence order: Descend within;

${ }^{4 *}$ Sequence order: Descend within and between;

Table 38: Experimental Data (Ib)

\begin{tabular}{clccccc}
\hline & & \multicolumn{5}{c}{ Samples } \\
\hline Treatmants & Repl. & $\mathbf{A}$ & $\mathbf{B}$ & $\mathbf{C}$ & $\mathbf{D}$ & $\mathbf{E}$ \\
\hline${ }^{(\mathbf{H})} \mathbf{0 \%}$ & $\mathrm{R}_{1}$ & 10.24 & 5.24 & 71.84 & 1.78 & 8.63 \\
& $\mathrm{R}_{2}$ & 10.84 & 5.74 & 81.74 & 1.74 & 8.69 \\
& $\mathrm{R}_{3}$ & 10.74 & 4.84 & 61.24 & 1.74 & 8.63 \\
$\mathbf{1 \%}$ & $\mathrm{R}_{1}$ & 20.81 & 9.21 & 20.81 & 2.61 & 8.65 \\
& $\mathrm{R}_{2}$ & 20.21 & 8.51 & 29.51 & 2.65 & 8.63 \\
& $\mathrm{R}_{3}$ & 20.51 & 9.81 & 40.21 & 2.63 & 8.67 \\
& $\mathrm{R}_{1}$ & 30.71 & 14.11 & 3.71 & 2.91 & 8.61 \\
& $\mathrm{R}_{2}$ & 30.41 & 15.41 & 12.51 & 2.92 & 8.63 \\
& $\mathrm{R}_{3}$ & 30.11 & 14.71 & 5.91 & 2.94 & 8.65 \\
& $\mathrm{R}_{1}$ & 50.01 & 15.01 & 60.62 & 3.11 & 8.62 \\
& $\mathrm{R}_{2}$ & 50.61 & 16.31 & 30.31 & 3.14 & 8.63 \\
& $\mathrm{R}_{3}$ & 50.32 & 15.62 & 10.01 & 3.32 & 8.69 \\
& $\mathrm{R}_{1}$ & 70.49 & 9.14 & 56.63 & 4.39 & 8.60 \\
& $\mathrm{R}_{2}$ & 70.14 & 9.49 & 78.49 & 4.33 & 8.63 \\
& $\mathrm{R}_{3}$ & 70.63 & 8.63 & 23.14 & 4.31 & 8.67 \\
& $\mathrm{R}_{1}$ & 25.81 & 4.81 & 76.41 & 6.81 & 8.64 \\
& $\mathrm{R}_{2}$ & 25.41 & 5.11 & 6.11 & 6.78 & 8.64 \\
& $\mathrm{R}_{3}$ & 25.11 & 5.41 & 23.81 & 6.83 & 8.69 \\
\hline
\end{tabular}


OPTINALYSIS

Table 39: Results of Optinalysis of the Experimental Data (Ia)

\begin{tabular}{|c|c|c|c|c|c|c|}
\hline & \multirow[t]{3}{*}{ P-value } & \multicolumn{5}{|c|}{$\begin{array}{c}\text { One-way ANOVA } \\
<0.0001\end{array}$} \\
\hline & & \multicolumn{5}{|c|}{ Optinalysis Reflectors } \\
\hline \multirow{4}{*}{$\begin{array}{l}{ }^{1 *} \text { Type (I) One-way } \\
\text { Geostatistical } \\
\text { Optinalysis }\end{array}$} & & $\begin{array}{l}\text { Aggregate } \\
\text { Mean }\end{array}$ & $\begin{array}{l}\text { Composite } \\
\text { Mean }\end{array}$ & $\begin{array}{l}\text { Mean of } \\
0 \%\end{array}$ & $\begin{array}{l}\text { Mean of } \\
1 \%\end{array}$ & $\begin{array}{l}\text { Reference } \\
\text { value }\end{array}$ \\
\hline & Kc-value & 0.99842 & 0.95166 & 1.11094 & 1.00546 & 0.93551 \\
\hline & $P_{\text {Sim. }}$-value & 0.99368 & 0.81554 & 0.66706 & 0.97851 & 0.75766 \\
\hline & $\mathrm{P}_{\text {Dsim.-value }}$ & 0.00632 & 0.18446 & 0.33294 & 0.02149 & 0.24234 \\
\hline \multirow{3}{*}{$\begin{array}{l}{ }^{2 *} \text { Type (II) One-way } \\
\text { Geostatistical } \\
\text { Optinalysis }\end{array}$} & Kc-value & 1.00159 & 0.95454 & 1.11619 & 1.00908 & 0.93818 \\
\hline & $\mathrm{P}_{\text {Sim. }}$-value & 0.99368 & 0.82605 & 0.65538 & 0.96464 & 0.76711 \\
\hline & $\mathrm{P}_{\text {Dsim.-value }}$ & 0.00632 & 0.17395 & 0.34462 & 0.03536 & 0.23289 \\
\hline \multirow{4}{*}{$\begin{array}{l}{ }^{3 *} \text { Type (I) One-way } \\
\text { Statistical } \\
\text { Optinalysis }\end{array}$} & & \multicolumn{5}{|c|}{ Optinalysis Reflectors } \\
\hline & Kc-value & $\begin{array}{l}\text { Aggregate } \\
\text { Mean }\end{array}$ & $\begin{array}{l}\text { Composite } \\
\text { Mean } \\
0.94619\end{array}$ & $\begin{array}{l}\text { Mean of } \\
\mathbf{0 \%} \\
1.10102\end{array}$ & $\begin{array}{l}\text { Mean of } \\
\mathbf{1 \%} \\
0.99861\end{array}$ & $\begin{array}{l}\text { Reference } \\
\text { value } \\
0.93044\end{array}$ \\
\hline & $\mathrm{P}_{\text {Sim. }}$-value & & 0.79576 & 0.68989 & 0.99443 & 0.73986 \\
\hline & $\mathrm{P}_{\text {Dsim--value }}$ & & 0.20424 & 0.31011 & 0.00557 & 0.26014 \\
\hline \multirow{3}{*}{ 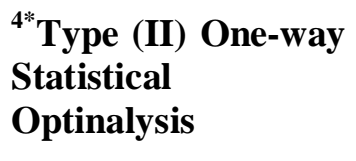 } & Kc-value & & 1.06030 & 1.32212 & 1.14492 & 1.03561 \\
\hline & $\mathrm{P}_{\text {Sim. }}$-value & & 0.79576 & 0.34474 & 0.59597 & 0.87131 \\
\hline & $\mathrm{P}_{\text {Dsim--value }}$ & & 0.20424 & 0.65526 & 0.40403 & 0.12869 \\
\hline
\end{tabular}

Table 40: Turkey's Multiple Comparisons of the Experimental Data (Ia)

\begin{tabular}{lcccccc}
\hline Treatments & $\mathbf{0 \%}$ & $\mathbf{1 \%}$ & $\mathbf{2 \%}$ & $\mathbf{3 \%}$ & $\mathbf{4 \%}$ & $\mathbf{5 \%}$ \\
\hline \multicolumn{7}{c}{ \%) } \\
$\mathbf{0 \%}$ & 0. & 0.0518 & 0.0004 & 0.1592 & 0.0004 & $<0.0001$ \\
$\mathbf{1 \%}$ & 0 & 0.0528 & 0.9700 & 0.0498 & $<0.0001$ \\
$\mathbf{2 \%}$ & & 0 & 0.0169 & $>0.9999$ & $<0.0001$ \\
$\mathbf{3 \%}$ & & 0 & 0.0160 & $<0.0001$ \\
$\mathbf{4 \%}$ & & & 0 & $<0.0001$ \\
$\mathbf{5 \%}$ & & & & & 0 \\
\hline
\end{tabular}


OPTINALYSIS

Table 41: Multiple Comparisons in Pairewise Manner by One-way Type (I) Statistical Optinalysis of the Experimental Data (Ia)

\begin{tabular}{|c|c|c|c|c|c|c|c|}
\hline & & $0 \%$ & $1 \%$ & $2 \%$ & $3 \%$ & $4 \%$ & $5 \%$ \\
\hline \multirow[t]{3}{*}{$0 \%$} & Kc-value & 0.98253 & 0.97045 & 0.95766 & 0.97403 & 0.95803 & 0.93788 \\
\hline & $\mathrm{P}_{\text {Sim. }}$-value & 0.93131 & 0.88519 & 0.83753 & 0.89874 & 0.83886 & 0.76607 \\
\hline & $P_{\text {Dsim.-value }}$ & 0.06869 & 0.11481 & 0.16247 & 0.10126 & 0.16114 & 0.23393 \\
\hline \multirow[t]{3}{*}{$1 \%$} & Kc-value & 0.97045 & 0.98875 & 0.97932 & 0.98678 & 0.97961 & 0.95414 \\
\hline & $\mathrm{P}_{\text {Sim. }}$-value & 0.88519 & 0.95548 & 0.91896 & 0.94779 & 0.92006 & 0.82461 \\
\hline & $P_{\text {Dsim.-value }}$ & 0.11481 & 0.04452 & 0.08104 & 0.05221 & 0.07994 & 0.17539 \\
\hline \multirow[t]{3}{*}{$2 \%$} & Kc-value & 0.95766 & 0.97932 & 0.99169 & 0.97507 & 0.99213 & 0.96769 \\
\hline & $\mathrm{P}_{\text {Sim. }}$-value & 0.83753 & 0.91896 & 0.96704 & 0.90272 & 0.96877 & 0.87481 \\
\hline & $P_{\text {Dsim.-value }}$ & 0.16247 & 0.08104 & 0.03296 & 0.09728 & 0.03123 & 0.12519 \\
\hline \multirow[t]{3}{*}{$3 \%$} & Kc-value & 0.97403 & 0.98678 & 0.97507 & 0.98760 & 0.97537 & 0.95083 \\
\hline & $\mathrm{P}_{\text {Sim. }}$-value & 0.89874 & 0.94779 & 0.90272 & 0.95100 & 0.90386 & 0.81254 \\
\hline & $P_{\text {Dsim.-value }}$ & 0.10126 & 0.05221 & 0.09728 & 0.04900 & 0.09614 & 0.18746 \\
\hline \multirow[t]{3}{*}{$4 \%$} & Kc-value & 0.95803 & 0.97961 & 0.99213 & 0.97537 & 0.99322 & 0.96809 \\
\hline & $\mathrm{P}_{\text {Sim. }}$-value & 0.83886 & 0.92006 & 0.96877 & 0.90386 & 0.97308 & 0.87629 \\
\hline & $P_{\text {Dsim.-value }}$ & 0.16114 & 0.07994 & 0.03123 & 0.09614 & 0.02692 & 0.12371 \\
\hline \multirow[t]{3}{*}{$5 \%$} & Kc-value & 0.93788 & 0.95414 & 0.96769 & 0.95083 & 0.96809 & 0.99535 \\
\hline & $\mathrm{P}_{\text {Sim. }}$-value & 0.76607 & 0.82461 & 0.87481 & 0.81254 & 0.87629 & 0.98147 \\
\hline & $P_{\text {Dsim.-value }}$ & 0.23393 & 0.17539 & 0.12519 & 0.18746 & 0.12371 & 0.01853 \\
\hline
\end{tabular}

Table: Results of Optinalysis of the Experimental Data (Ib)

Analysis Results

\begin{tabular}{|c|c|c|c|c|c|}
\hline \multirow[b]{2}{*}{ Populations } & \multicolumn{5}{|c|}{ Samples } \\
\hline & $\mathbf{A}$ & B & $\mathbf{C}$ & D & $\mathbf{E}$ \\
\hline \multicolumn{6}{|c|}{ Statistical ANOVA } \\
\hline $\mathbf{P}_{\text {Sim.-value }}$ & & & & & \\
\hline $\mathbf{P}_{\text {Dsim. }}$-value & $<0.0001$ & $<0.0001$ & 0.0631 & $<0.0001 *$ & 0.8669 \\
\hline \multicolumn{6}{|c|}{ Two-way Type (I) Statistical Optinalysis } \\
\hline Kc-value & 0.93030 & 0.94722 & 0.91419 & 0.94687 & 0.99960 \\
\hline P $_{\text {Sim.-value }}$ & 0.73936 & 0.79947 & 0.68387 & 0.79818 & 0.99840 \\
\hline $\mathbf{P}_{\text {Dsim. }}$-value & 0.26064 & 0.20053 & 0.31613 & 0.20182 & 0.00160 \\
\hline \multicolumn{6}{|c|}{ Two-way Type (II) Statistical Optinalysis } \\
\hline Kc-value & 1.08099 & 1.05901 & 1.10359 & 1.05945 & 1.00040 \\
\hline $\mathbf{P}_{\text {Sim. }}$-value & 0.73936 & 0.79947 & 0.68387 & 0.79818 & 0.99840 \\
\hline $\mathbf{P}_{\text {Dsim. }}$-value & 0.26064 & 0.20053 & 0.31613 & 0.20182 & 0.00160 \\
\hline \multicolumn{6}{|c|}{ Two-way Type (I) Geostatistical Optinalysis } \\
\hline Kc-value & 0.95558 & 0.99919 & 1.00633 & 0.94687 & 0.99994 \\
\hline $\mathbf{P}_{\text {Sim. }}$-value & 0.82986 & 0.99678 & 0.97514 & 0.79818 & 0.99978 \\
\hline $\mathbf{P}_{\text {Dsim. }}$-value & 0.17014 & 0.00322 & 0.02486 & 0.20182 & 0.00022 \\
\hline \multicolumn{6}{|c|}{ Two-way Type (II) Geostatistical Optinalysis } \\
\hline Kc-value & 1.04876 & 1.00081 & 0.99375 & 1.05945 & 1.00006 \\
\hline $\mathbf{P}_{\text {Sim. }}$-value & 0.82986 & 0.99677 & 0.97514 & 0.79818 & 0.99978 \\
\hline $\mathbf{P}_{\text {Dsim. }}$-value & 0.17014 & 0.00323 & 0.02486 & 0.20182 & 0.00022 \\
\hline
\end{tabular}




\section{OPTINALYSIS}

\subsection{Example 10: Experimental Data (II)}

An illustration below represent a balanced meter rule $(100 \mathrm{~cm}$ in length) on a pivot at the central gravity $(50 \mathrm{~cm}$ mid-point). Different set of masses where placed at different points distanced away $25 \mathrm{~cm}$ and $50 \mathrm{~cm}$ from the pivot. Given that masses on X and Y points where used as tabulated in the Table 39 .

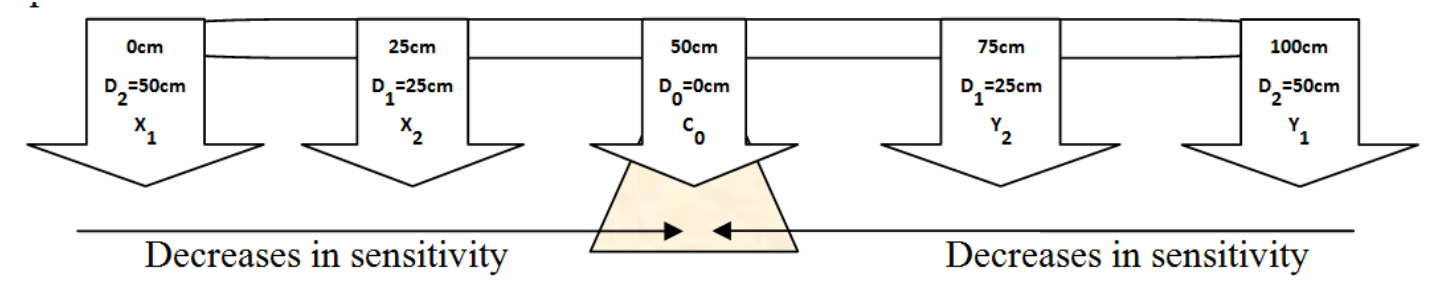

Note: $\mathbf{D}_{\mathbf{n}}=$ Displacements; $\mathbf{X}$ and $\mathbf{Y}$ are masses; and $\mathbf{C}=$ Central mid-point (at the pivot)

Figure 39: Moment of Forces about a Point

Two-way geometrical Optinalysis (masses as the elements, $\mathrm{x}$ and $\mathrm{y}$, and the internodal distance = $25 \mathrm{~cm}$ as the co-element) was used here to calculate the percentage balance (symmetry/similarity) between the right and the left suspended masses. The results attached in Table 43 shows that Optinalysis confirm a symmetrically significant if total clocwise moment and total anticlocwise moments are equal about central pivot. Using the principle of moment, it is justified that Optinalysis pricipally operates by the principles of moment and reflection, and in addtion it presented an advanced approach for calculating the level of balanced or imbalances by quantifying the probability or percentage symmetry or similarity that exits between the exerting masses about a central pivot point.

Table 43: Results of Optinalysis of the Moment Designed Data

\begin{tabular}{|c|c|c|c|c|c|c|c|c|c|}
\hline \multirow[b]{2}{*}{$\mathbf{S} / \mathbf{N}$} & \multirow[b]{2}{*}{$\begin{array}{l}{ }^{(\mathrm{H})} \mathbf{X}_{1} \\
{ }^{(\mathbf{H})} \mathbf{D}=\mathbf{5 0}\end{array}$} & \multirow[b]{2}{*}{$\begin{array}{l}X_{2}^{(T)} \\
D=25^{(T)}\end{array}$} & \multirow[b]{2}{*}{$\begin{array}{l}{ }^{(\mathrm{T})} \mathbf{Y}_{2} \\
{ }^{(\mathrm{T})} \mathrm{D}=\mathbf{2 5}\end{array}$} & \multirow[b]{2}{*}{$\begin{array}{l}Y_{1}{ }^{(H)} \\
D=50^{(H)}\end{array}$} & \multicolumn{5}{|c|}{ Two-way Geometrical Optinalysis } \\
\hline & & & & & Moments & Kc-value & $\mathbf{P}_{\text {Sim. }}$-value & $\mathbf{P}_{\text {Dsim. }}$-value & Remarks \\
\hline 1 & 50 & 15 & 15 & 50 & $2875: 2875$ & 1.00000 & 1.00000 & 0.00000 & $* * 1$ \\
\hline 2 & 15 & 50 & 50 & 15 & 2000:2000 & 1.0000 & 1.00000 & 0.00000 & $* * 1$ \\
\hline 3 & 40 & 10 & 80 & 5 & 2250:2250 & 1.00000 & 1.00000 & 0.00000 & $* * 2$ \\
\hline 4 & 20 & 12 & 40 & 6 & 1300:1300 & 1.00000 & 1.00000 & 0.00000 & $* * 2$ \\
\hline 5 & 30 & 25 & 10 & 5 & $2125: 500$ & 1.44828 & 0.23529 & 0.76471 & \#\# \\
\hline 6 & 2 & 6 & 15 & 20 & $250: 1375$ & 0.74138 & 0.17808 & 0.82192 & \#\# \\
\hline 7 & 10 & 0 & 5 & 0 & $500: 125$ & 1.50000 & 0.20000 & 0.80000 & \#\# \\
\hline 8 & -20 & -35 & 35 & 20 & $-1875: 1875$ & 0 & -1 & 2.00000 & \#\# \\
\hline 9 & -20 & 35 & 35 & -20 & $-125:-125$ & 1 & 1 & 0.00000 & \#\# \\
\hline 10 & 20 & 35 & 35 & -20 & $1875:-125$ & 1.615385 & 0.135135 & 0.86486 & \#\# \\
\hline 11 & -20 & 35 & 35 & 20 & $-125: 1875$ & 0.724138 & 0.135135 & 0.86486 & \#\# \\
\hline 12 & 20 & 35 & -35 & 20 & $1875: 125$ & 2.4 & -0.07692 & 1.07692 & \#\# \\
\hline 13 & 20 & -35 & 35 & 20 & $125: 1875$ & 0.631579 & -0.07692 & 1.07692 & \#\# \\
\hline
\end{tabular}




\section{OPTINALYSIS}

\subsection{Example 11: Experimental Data (III)}

Table 44 recorded the 2 theta angle and the diffration intensity from XRD machine. Using two-way geometric Optinalysis Optinalysis (diffration intensity as the elements and the internodal distance $=5$ units of 2theta angle as the co-element), conclude which of the samples are closely similar to sample A?. The Optinalysis results in Table 45 by multiple comparison shows that sample $\mathrm{B}$ is significantly $(\mathrm{P}>0.95)$ similar to sample A geometrically while Dare not similar geometrically $(\mathrm{P}>0.95)$.

Table 44: 2Theta Angles and the Diffraction Intensity of Samples

\begin{tabular}{|c|c|c|c|c|}
\hline \multirow[b]{2}{*}{2 theta Angle } & \multicolumn{4}{|c|}{ Diffraction Intensity } \\
\hline & Sample A & Sample B & Sample C & Sample D \\
\hline$(\mathrm{H}) 5$ & 34 & 34 & 64 & 34 \\
\hline 10 & 56 & 56 & 56 & 56 \\
\hline 15 & 87 & 87 & 87 & 87 \\
\hline 20 & 46 & 46 & 46 & 46 \\
\hline 25 & 87 & 87 & 87 & 87 \\
\hline 30 & 45 & 45 & 45 & 45 \\
\hline 35 & 77 & 77 & 77 & 77 \\
\hline 40 & 66 & 66 & 66 & 66 \\
\hline 45 & 99 & 99 & 99 & 74 \\
\hline 50 & 95 & 93 & 48 & 68 \\
\hline 55 & 78 & 78 & 78 & 78 \\
\hline 60 & 55 & 55 & 55 & 55 \\
\hline 65 & 89 & 89 & 89 & 89 \\
\hline 70 & 65 & 65 & 65 & 65 \\
\hline 75 & 9 & 9 & 9 & 27 \\
\hline 80 & 66 & 66 & 66 & 66 \\
\hline $85^{(\mathrm{T})}$ & 57 & 57 & 57 & 57 \\
\hline
\end{tabular}

Table 45: Multiple Comparison by Two-way Geometrical Optinalysis (Head-to-head pairing)

\begin{tabular}{|c|c|c|c|c|c|}
\hline & Samples & $\overline{\mathbf{A}}$ & B & $\mathbf{C}$ & D \\
\hline \multirow[t]{3}{*}{$\mathbf{A}$} & Kc-value (HH) & 1.00000 & 1.00040 & 0.99664 & 1.00992 \\
\hline & $\mathrm{P}_{\text {Sim. }}$-value & 1.00000 & 0.99840 & 0.98659 & 0.96145 \\
\hline & $\mathrm{P}_{\text {Dsim.-value }}$ & 0.00000 & 0.00160 & 0.01341 & 0.03855 \\
\hline \multirow[t]{3}{*}{ B } & Kc-value $(\mathrm{HH})$ & 0.99960 & 1.00000 & 0.99623 & 1.00952 \\
\hline & $\mathrm{P}_{\text {Sim. }}$-value & 0.99840 & 1.00000 & 0.98498 & 0.96298 \\
\hline & $\mathrm{P}_{\text {Dsim.-value }}$ & 0.00160 & 0.00000 & 0.01502 & 0.03702 \\
\hline \multirow[t]{3}{*}{$\mathbf{C}$} & Kc-value $(\mathrm{HH})$ & 1.00339 & 1.00380 & 1.00000 & 1.01351 \\
\hline & $\mathrm{P}_{\text {Sim. }}$-value & 0.98659 & 0.98498 & 1.00000 & 0.94806 \\
\hline & $P_{\text {Dsim.-value }}$ & 0.01341 & 0.01502 & 0.00000 & 0.05194 \\
\hline \multirow[t]{3}{*}{ D } & Kc-value $(\mathrm{HH})$ & 0.99027 & 0.99066 & 0.98684 & 1.00000 \\
\hline & $\mathrm{P}_{\text {Sim. }}$-value & 0.96145 & 0.96298 & 0.94806 & 1.00000 \\
\hline & $P_{\text {Dsim.-value }}$ & 0.03855 & 0.03702 & 0.05194 & 0.00000 \\
\hline
\end{tabular}


OPTINALYSIS

\subsection{Example 12: Morphometric Shape Data (I)}

In this paper, most of the illustrative examples used are geometrical in sense. Specifically, in Biosystematics, leaf geometric mophormetry is an essential tool in biosystematics of quantitative characters of plant species.

Table 46 recorded the partioned leaf surface area from the left and from the right portion of the laef lamina about a laeves' mid-ribs, as shown in Figure 40. Correspondence started from petiole base $\left(A_{1}: B_{1}\right)$ to the apex of the leaf $\left(A_{10}: B_{10}\right)$. Following head-to-head (petiole-topetiole) pairing style and a horizontalups numbering style, the geometric symmetric status of the leaf from each species was computed by geometric Optinalysis, and compared with Root mean squared error (RMSE), and Areal ratio (AR) methods as described in Shi et. al., (2018). The results in Tables 47 and 48 of the geometric Optinalysis and in comparison with other methods of leaf symmetry detection shows that Optinalysis is also a very suitable approach of leaf symmetry detection.

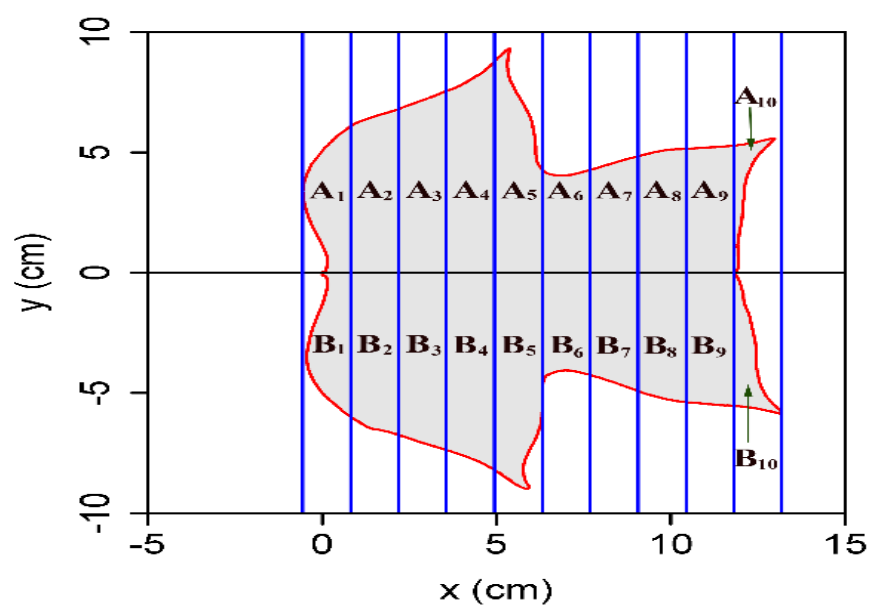

Source: Shi et. al., (2018)

Figure 40: Partitioning of leaf surface area into discrete geometric marks 


\section{OPTINALYSIS}

Table 46: Morphometric Mean Measurement of Leaves Partioned Surface Area of the Six Different Plant Species

\begin{tabular}{|c|c|c|c|c|c|c|}
\hline Points & Spp. 1 & Spp. 2 & Spp. 3 & Spp. 4 & Spp. 5 & Spp. 6 \\
\hline & \multicolumn{6}{|c|}{ Leaf Surface Area of the Left Correspondence } \\
\hline${ }^{(\mathbf{H})} \mathbf{A}_{1}$ & 35.67 & 67.98 & 206.78 & 69.45 & 59.45 & 30.56 \\
\hline $\mathbf{A}_{2}$ & 35.87 & 45.89 & 200.09 & 65.35 & 58.67 & 45.34 \\
\hline $\mathbf{A}_{3}$ & 37.78 & 98.45 & 198.56 & 68.45 & 58.89 & 45.67 \\
\hline $\mathbf{A}_{4}$ & 38.96 & 56.87 & 192.45 & 98.46 & 58.34 & 43.76 \\
\hline $\mathbf{A}_{5}$ & 57.36 & 98.46 & 187.45 & 78.45 & 57.89 & 46.57 \\
\hline $\mathbf{A}_{6}$ & 60.34 & 46.46 & 176.48 & 78.34 & 57.34 & 52.54 \\
\hline $\mathbf{A}_{7}$ & 64.23 & 45.89 & 158.34 & 24.76 & 55.34 & 65.54 \\
\hline $\mathbf{A}_{8}$ & 94.65 & 46.89 & 150.04 & 65.76 & 55.23 & 67.55 \\
\hline $\mathbf{A}_{9}$ & 97.66 & 77.56 & 146.38 & 45.89 & 51.34 & 34.32 \\
\hline \multirow[t]{2}{*}{$\mathbf{A}_{10}^{(T)}$} & 99.99 & 56.89 & 141.89 & 76.45 & 50.23 & 23.12 \\
\hline & \multicolumn{6}{|c|}{ Leaf Surface Area of the Right Correspondence } \\
\hline${ }^{(\mathbf{H})} \mathbf{B}_{1}$ & 35.77 & 77.68 & 206.74 & 69.49 & 59.45 & 34.56 \\
\hline $\mathbf{B}_{2}$ & 35.88 & 55.89 & 200.08 & 65.35 & 58.57 & 46.34 \\
\hline $\mathbf{B}_{3}$ & 37.79 & 88.75 & 198.56 & 68.47 & 58.89 & 46.67 \\
\hline $\mathbf{B}_{4}$ & 38.96 & 67.97 & 192.45 & 98.46 & 58.24 & 43.77 \\
\hline $\mathbf{B}_{5}$ & 57.35 & 108.46 & 187.44 & 78.45 & 57.89 & 46.67 \\
\hline $\mathbf{B}_{6}$ & 60.34 & 52.56 & 176.48 & 78.35 & 57.44 & 52.54 \\
\hline $\mathbf{B}_{7}$ & 64.26 & 55.89 & 158.34 & 24.76 & 55.44 & 65.52 \\
\hline $\mathbf{B}_{8}$ & 94.61 & 57.69 & 150.14 & 65.76 & 55.23 & 67.56 \\
\hline $\mathbf{B}_{9}$ & 97.62 & 88.56 & 146.31 & 45.89 & 51.35 & 34.33 \\
\hline $\mathbf{B}_{10}{ }^{(T)}$ & 99.97 & 61.79 & 141.84 & 76.46 & 50.21 & 23.22 \\
\hline
\end{tabular}


OPTINALYSIS

Table 47: Results of Symmetry Detection by Different Methods

\begin{tabular}{|c|c|c|c|c|c|c|}
\hline & \multicolumn{6}{|c|}{ One-way geometrical Optinalysis } \\
\hline & Spp. 1 & Spp. 2 & Spp. 3 & Spp. 4 & Spp. 5 & Spp. 6 \\
\hline & \multicolumn{6}{|c|}{ One-away Geometric Optinalysis (Head-to-head pairing) } \\
\hline Kc-value & 0.99993 & 0.97536 & 1.00001 & 0.99995 & 1.00006 & 0.99430 \\
\hline $\mathbf{P}_{\text {Sim.-value }}$ & 0.99971 & 0.90383 & 0.99995 & 0.99983 & 0.99977 & 0.97734 \\
\hline \multirow[t]{2}{*}{ P $_{\text {Dsim.-value }}$} & 0.00029 & 0.09617 & 0.00005 & 0.00017 & 0.00023 & 0.02266 \\
\hline & \multicolumn{6}{|c|}{ Root Mean Squared Error (RMSE) } \\
\hline \multirow[t]{2}{*}{ Value } & 0.038471 & 9.540702 & 0.043818 & 0.014832 & 0.06364 & 1.342412 \\
\hline & \multicolumn{6}{|c|}{ Areal Ratio (AR) } \\
\hline Value & 0.999936 & 0.896678 & 1.000045 & 0.999881 & 1.000018 & 0.986535 \\
\hline
\end{tabular}

Table 48: Multiple comparison of the leaf morphometric characters of the six species by Oneway Geometric Optinalysis (head-to-head pairing)

\begin{tabular}{|c|c|c|c|c|c|c|c|}
\hline & & Spp. 1 & Spp. 2 & Spp. 3 & Spp. 4 & Spp. 5 & Spp. 6 \\
\hline \multirow[t]{3}{*}{ Spp. 1} & Kc-value $(\mathrm{HH})$ & 1.00000 & 0.95848 & 0.79024 & 0.95254 & 0.99442 & 1.04909 \\
\hline & $\mathrm{P}_{\text {Sim. }}$-value & 1.00000 & 0.84054 & 0.30644 & 0.81875 & 0.97780 & 0.82885 \\
\hline & $P_{\text {Dsim.-value }}$ & 0.00000 & 0.15946 & 0.69356 & 0.18125 & 0.02220 & 0.17115 \\
\hline \multirow[t]{3}{*}{ Spp. 2} & Kc-value $(\mathrm{HH})$ & 1.04528 & 1.00000 & 0.80890 & 0.99402 & 1.04172 & 1.10386 \\
\hline & $\mathrm{P}_{\text {Sim. }}$-value & 0.84054 & 1.00000 & 0.35825 & 0.97621 & 0.85169 & 0.68326 \\
\hline & $P_{\text {Dsim.-value }}$ & 0.15946 & 0.00000 & 0.64175 & 0.02379 & 0.14831 & 0.31674 \\
\hline \multirow[t]{3}{*}{ Spp. 3} & Kc-value $(\mathrm{HH})$ & 1.36136 & 1.30931 & 1.00000 & 1.30474 & 1.36876 & 1.44498 \\
\hline & $\mathrm{P}_{\text {Sim. }}$-value & 0.30644 & 0.35825 & 1.00000 & 0.36320 & 0.29969 & 0.23771 \\
\hline & $P_{\text {Dsim.-value }}$ & 0.69356 & 0.64175 & 0.00000 & 0.63680 & 0.70031 & 0.76229 \\
\hline \multirow[t]{3}{*}{ Spp. 4} & Kc-value $(\mathrm{HH})$ & 1.05244 & 1.00605 & 0.81066 & 1.00000 & 1.04916 & 1.11340 \\
\hline & $\mathrm{P}_{\text {Sim. }}$-value & 0.81875 & 0.97621 & 0.36320 & 1.00000 & 0.82865 & 0.66154 \\
\hline & $P_{\text {Dsim.-value }}$ & 0.18125 & 0.02379 & 0.63680 & 0.00000 & 0.17135 & 0.33846 \\
\hline \multirow[t]{3}{*}{ Spp. 5} & Kc-value $(\mathrm{HH})$ & 1.00564 & 0.96149 & 0.78777 & 0.95524 & 1.00000 & 1.05938 \\
\hline & $\mathrm{P}_{\text {Sim. }}$-value & 0.97780 & 0.85169 & 0.29969 & 0.82865 & 1.00000 & 0.79840 \\
\hline & $\mathrm{P}_{\text {Dsim.-value }}$ & 0.02220 & 0.14831 & 0.70031 & 0.17135 & 0.00000 & 0.20160 \\
\hline \multirow[t]{3}{*}{ Spp. 6} & Kc-value $(\mathrm{HH})$ & 0.95530 & 0.91401 & 0.76456 & 0.90756 & 0.94692 & 1.00000 \\
\hline & $\mathrm{P}_{\text {Sim.-value }}$ & 0.82885 & 0.68326 & 0.23771 & 0.66154 & 0.79840 & 1.00000 \\
\hline & $P_{\text {Dsim.-value }}$ & 0.17115 & 0.31674 & 0.76229 & 0.33846 & 0.20160 & 0.00000 \\
\hline
\end{tabular}

\subsection{Example 13: Morphometric Shape Data (II)}

Multidimensional scaling (MDS) or Euclidean distance matrix analysis plot of the male gorilla data and 13 means using Riemannian distance to form the dissimilarity matrix was calculated as explained by Dryden and Mardia (2016). The sample means for the male gorilla data was calculated to have small shape variability. There are $\mathrm{k}=8$ landmarks in $\mathrm{m}=2$ dimensions on $n=29$ male gorillas (Dryden and Mardia, 2016). In comparison to Optinalysis, 


\section{OPTINALYSIS}

the 8 landmarks were appropriately numbered by horizontal style, scale edited (on a positive scaling), paired (head-to-head, starting from $\mathrm{a}_{1}$ numbered landmark) and computed for Kabirian coefficients of similarity, percentage similarity and dissimilarity between the two shapes. The two shapes are graphically shown in Figure 41 and 42.

Following Riemannian shape distance, the two mean shapes A and B are very similar, with 0.0009 apart (Dryden and Mardia, 2016). On the other hand, following two-way geometric Optinalysis, shape A and B are significantly ( $\mathrm{P}>0.999$ or $\mathrm{P}<0.00081)$ similar geometrically with a Kabirian coefficient of similarity 0.999796 (Table 49). Therefore, the two methods have almost same conclusion, but Optinalysis is very probabilistic, more sensitive and specific.

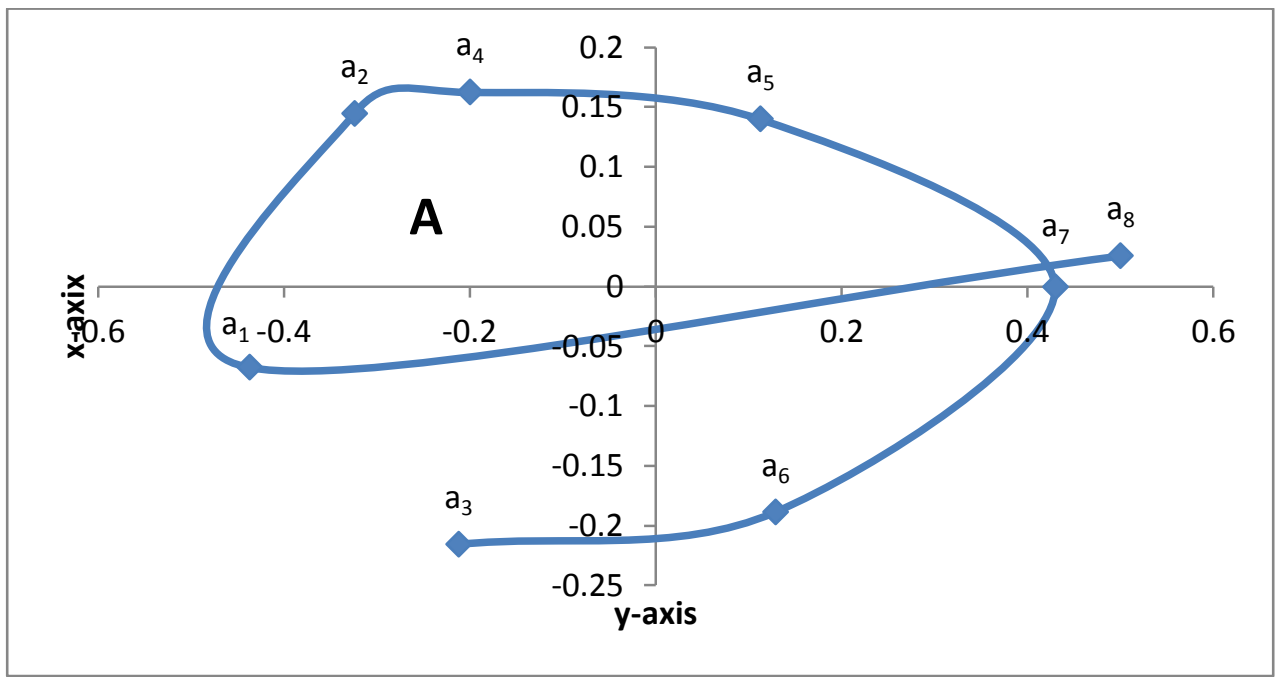

Figure 41: Geometrical shape coordinates of Male Gorilla A.

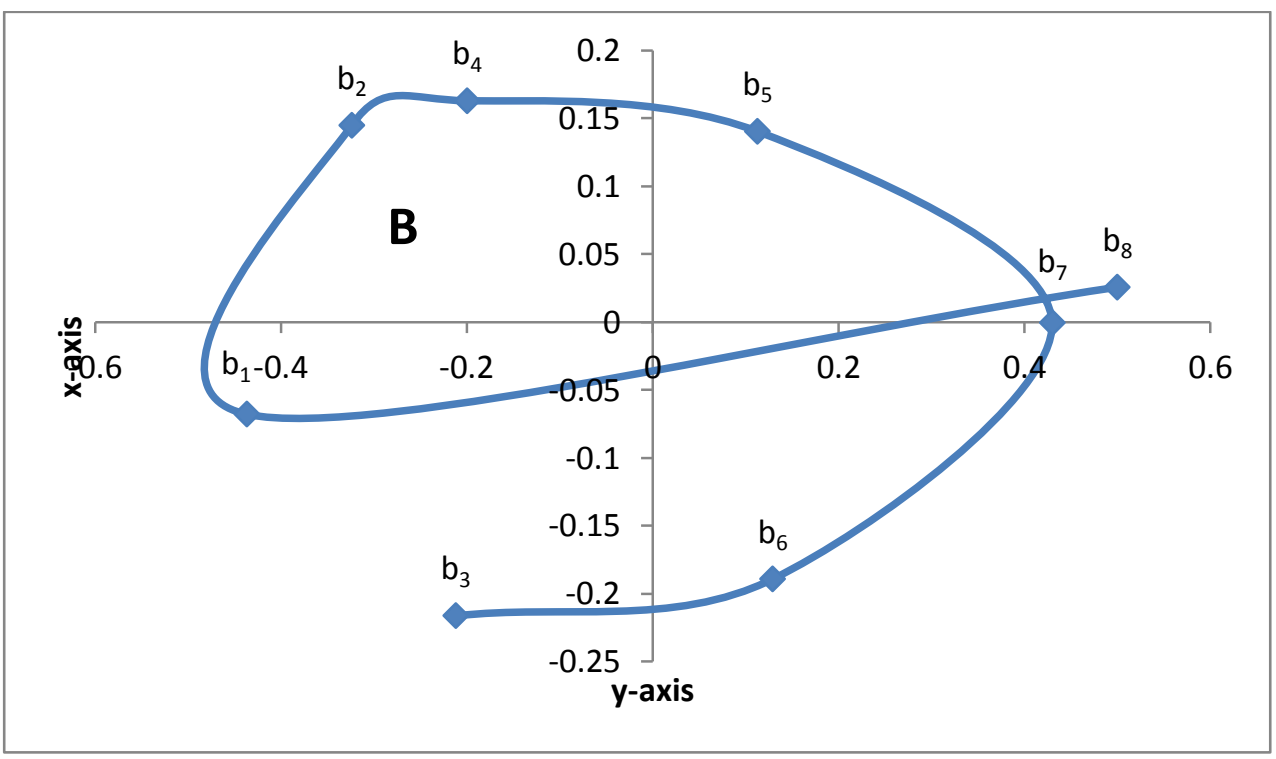

Figure 42: Geometrical shape coordinates of Male Gorilla B. 
OPTINALYSIS

\begin{tabular}{|c|}
\hline Data(gorm.dat) \\
$>$ A $<-M D S$ A \\
{$[, 1][, 2]$} \\
{$[1] 0.50025870 .0255867592$,} \\
{$[2]-0.4369590-0.0676547676$,} \\
{$[3]-,0.32393410 .1445435828$} \\
{$[4]-,0.19975950 .1625496138$} \\
{$[5] 0.11279590 .1400977827$,} \\
{$[6] 0.4304058-0.0005215325$,} \\
{$[7] 0.1291547-0.1888126195$,} \\
{$[8]-0.2119625-0.2157888189$,} \\
B $<-$ MDSshape(gorm.dat,alpha $=1$, projalpha $=1)$ \\
$>$ B \\
{$[, 1][, 2]$} \\
{$[1] 0.50006160 .0256419012$,} \\
{$[3]-0.4367869-0.0678005703$,} \\
{$[4]-,0.19968080 .1628999242$} \\
{$[5] 0.11275150 .1403997073$,} \\
{$[6] 0.4302363-0.0005226565$,} \\
{$[7] 0.1291038-0.1892195293$,} \\
{$[8]-0.2118790-0.2162538651$,} \\
$>$ riemdist(A,B) \\
[1] 0.0009210365 \\
(Dryden and Mardia, 2016) \\
\end{tabular}




\section{OPTINALYSIS}

Table 49: Results of Geometrical Optinalysis between the two structures of a Male Gorilla

\begin{tabular}{ccccccc}
\hline \multicolumn{3}{c}{ Normal Coordinates } & \multicolumn{2}{c}{$\begin{array}{c}\text { Scale Edited } \\
\text { Coordinates }\end{array}$} & $\begin{array}{c}\text { Geometrical Resolution } \\
\text { of Elements }\end{array}$ & $\begin{array}{c}\text { Resultant } \\
\text { Elements }\end{array}$ \\
\hline Numbering & $\boldsymbol{x}_{\boldsymbol{n}}\left(\boldsymbol{D}_{\boldsymbol{n}}\right)$ & $\boldsymbol{y}_{\boldsymbol{n}}\left(\boldsymbol{a}_{\boldsymbol{n}}\right)$ & $\boldsymbol{x}_{\boldsymbol{n}}\left(\boldsymbol{D}_{\boldsymbol{n}}\right)$ & $\boldsymbol{y}_{\boldsymbol{n}}\left(\boldsymbol{a}_{\boldsymbol{n}}\right)$ & $\boldsymbol{D}_{\boldsymbol{i}}-\boldsymbol{D}_{\mathbf{0}}=\left(\boldsymbol{d}_{\boldsymbol{n}}\right)$ & $\boldsymbol{a}_{\boldsymbol{n}} \times \boldsymbol{d}_{\boldsymbol{n}}$ \\
$\mathbf{a}_{\mathbf{1}}$ & -0.436959 & -0.0676548 & 0.436959 & -0.0676548 & 0.1130249 & -0.00765 \\
$\mathbf{a}_{\mathbf{2}}$ & -0.3239341 & 0.1445436 & 0.3239341 & 0.1445436 & 0.1119716 & 0.016185 \\
$\mathbf{a}_{\mathbf{3}}$ & -0.2119625 & -0.2157888 & 0.2119625 & -0.2157888 & 0.012203 & -0.00263 \\
$\mathbf{a}_{\mathbf{4}}$ & -0.1997595 & 0.1625496 & 0.1997595 & 0.1625496 & 0.0869636 & 0.014136 \\
$\mathbf{a}_{\mathbf{5}}$ & 0.1127959 & 0.1400978 & 0.1127959 & 0.1400978 & 0.0163588 & 0.002292 \\
$\mathbf{a}_{\mathbf{6}}$ & 0.1291547 & -0.1888126 & 0.1291547 & -0.1888126 & 0.3012511 & -0.05688 \\
$\mathbf{a}_{\mathbf{7}}$ & 0.4304058 & -0.0005215 & 0.4304058 & -0.0005215 & 0.0698529 & $-3.6 \mathrm{E}-05$ \\
$\mathbf{a}_{\mathbf{8}}$ & 0.5002587 & 0.0255868 & 0.5002587 & 0.0255868 & 0.5002587 & 0.0128 \\
\hline Numbering & $\boldsymbol{x}_{\boldsymbol{n}}\left(\boldsymbol{D}_{\boldsymbol{n}}\right)$ & $\boldsymbol{y}_{\boldsymbol{n}}\left(\boldsymbol{a}_{\boldsymbol{n}}\right)$ & $\boldsymbol{x}_{\boldsymbol{n}}\left(\boldsymbol{D}_{\boldsymbol{n}}\right)$ & $\boldsymbol{y}_{\boldsymbol{n}}\left(\boldsymbol{a}_{\boldsymbol{n}}\right)$ & $\boldsymbol{D}_{\boldsymbol{i}}-\boldsymbol{D}_{\mathbf{0}}=\left(\boldsymbol{d}_{\boldsymbol{n}}\right)$ & $\boldsymbol{a}_{\boldsymbol{n}} \times \boldsymbol{d}_{\boldsymbol{n}}$ \\
$\mathbf{b}_{\mathbf{1}}$ & -0.4367869 & -0.0678006 & 0.4367869 & -0.0678006 & 0.1129804 & -0.00766 \\
$\mathbf{b}_{\mathbf{2}}$ & -0.3238065 & 0.1448551 & 0.3238065 & 0.1448551 & 0.1119275 & 0.016213 \\
$\mathbf{b}_{\mathbf{3}}$ & -0.211879 & -0.2162539 & 0.211879 & -0.2162539 & 0.0121982 & -0.00264 \\
$\mathbf{b}_{\mathbf{4}}$ & -0.1996808 & 0.1628999 & 0.1996808 & 0.1628999 & 0.0869293 & 0.014161 \\
$\mathbf{b}_{\mathbf{5}}$ & 0.1127515 & 0.1403997 & 0.1127515 & 0.1403997 & 0.0163523 & 0.002296 \\
$\mathbf{b}_{\mathbf{6}}$ & 0.1291038 & -0.1892195 & 0.1291038 & -0.1892195 & 0.3011325 & -0.05698 \\
$\mathbf{b}_{\mathbf{7}}$ & 0.4302363 & -0.0005227 & 0.4302363 & -0.0005227 & 0.0698253 & $-3.6 \mathrm{E}-05$ \\
$\mathbf{b}_{\mathbf{8}}$ & 0.5000616 & 0.0256419 & 0.5000616 & 0.0256419 & 0.5000616 & 0.012823 \\
\hline
\end{tabular}

Result of Two-way Geometric Optinalysis

Head-to-head Pairing Style

Head-to-head Pairing Style

\begin{tabular}{llllll}
\hline Kc-value & $\mathrm{P}_{\text {Sim.-value }}$ & $\mathrm{P}_{\text {Dsim.-value }}$ & Kc-value & $\mathrm{P}_{\text {Sim.-value }}$ & $\mathrm{P}_{\text {Dsim.-value }}$ \\
0.999796 & 0.999184 & 0.000815 & 0.999287 & 0.997150 & 0.002849 \\
\hline
\end{tabular}

\section{Summary}

Optinalysis can be summarized in the following items:

- Optinalysis, as method of symmetry detection, intrametrically or intermetrically computes and compares two or more multivariate sequences in an unclustered or clustered manner as a mirror-like reflection (optics-like manner).

- Elements of symmetrical structures reflect in same moment (or in same total moments) about a symmetrical plane.

- Structures can be symmetrically compared intrametrically or intermetrically and analyzed geometrically, geostatistically, and statistically.

- Lack of symmetry (asymmetry) exists when reflection is not in same moment (or toal moments) about a symmetrical plane.

- Symmetry reflection can occur on one or more symmetrical planes, hence is classified as mono-planal (bilateral) or poly-planal (radial) symmetry.

- Numbering style define what symmetry plane is considered. 


\section{OPTINALYSIS}

- Symmetrical structures may or may not loss (instable and stable respectively) its symmetrical status under E-rotation, hence is classified as eu-symmetrical and pseudosymmetrical structures.

- Each point (node) of a symmetry group has its own characteristics sensitivity, which increases away from the central node.

- Symmetry can be optinalytically detected in one-way, two-way and three-way based on the influence of the dimensional co-elements. The co-elements harmonized the variations due to other dimensional axis.

- Kabirian coefficient of symmetry or similarity is the fundamental value that explains a lot about the features and characteristics of symmetrical structures.

- Symmetry detection reflects similarity measurement.

\section{Acknowledgement}

I thank for the motivations and encouragement received from Zahara'u Abdulhamid Bugaje and Abubakar Bello. This research did not receive any specific grant from funding agencies in the public, commercial, or not-for-profit sectors.

\section{Conflict of interest}

The author declares no conflict of interest.

Correspondence: Correspondence should be address to Kabir Bindawa Abdullahi, Department of Biology, Faculty of Natural and Applied Sciences, Umaru Musa Yar'adua University, P.M.B., 2218 Katsina, Katsina State, Nigeria.

\section{References}

Abdullahi, K.B. (2019a). Optimization of Value Measurement Methods. Preprints, 2019010107 (doi: 10.20944/preprints201901.0107.v2).

Abdullahi, K.B. (2019b). Socio-Demographic Status: Theory, Methods and Applications. Preprints, 2019020051 (doi: 10.20944/preprints201902.0051.v1).

Bookstein, F. L. (1986). Size and shape spaces for landmark data in two dimensions (with discussion). Statistical Science, 1: 181-242.

Bookstein, F. L. (1991). Landmark methods for forms without landmarks: localizing group differences in outline shape. Medical Image Analysis, 1(3):225-244.

Cootes, T. F. and Taylor, C. J. (Oct 2001). Statistical Models of Appearance for Computer Vision. Tech. Report. University of Manchester,

Darvas G. (2007). Symmetry, Basel-Boston-Berlin: Birkhäuser, xi + 504 pp.

Dryden, I. L. and Mardia, K. V. (1998). Statistical Shape Analysis. John Wiley \& Sons.

Dryden, I. L., and Mardia, K. V. (2016). Statistical Shape Analysis, with Applications in R, Second Edition, John Wiley \& Sons, Ltd. 


\section{OPTINALYSIS}

Dryden, I. L., Kume, A., Le, H., and Wood, A. T. A. (2008). A multi-dimensional scaling approach to shape analysis. Biometrika, 95(4): 779-798.

Fraasen, V., and Bsa, c. (1989). Laws and Symmetry. Oxford University press Inc., New York

Goodall, C. Procrustes methods in the statistical analysis of shape. Jour. Royal Statistical Society, Series B, 1991, 53:285-339.

Kendall, D. G. (1984). Shape manifolds, Procrustean metrics and complex projective spaces. Bulletin of the London Mathematical Society, 16: 81-121.

Kent, J. T. (1994). The complex Bingham distribution and shape analysis. Journal of the Royal Statistical Society, Series B, 56: 285-299.

Lele, S. and Richtsmeier, J. T. (1991). Euclidean distance matrix analysis: a coordinate-free approach for comparing biological shapes using landmark data. American Journal of Physical Anthropology, 86: 415-427.

Lunter, G., Rocco, A., Mimouni, N., Heger, A., Caldeira, A., and Hein, J. (2008). Uncertainty in homology inferences: Assessing and improving genomic sequence alignment, Genome Res., 18(2): 298-309. doi: 10.1101/gr.6725608

Mardia, K.V.; Bookstein, F.L.; Moreton, I. J. (2000). Statistical assessment of bilateral symmetry of shapes. Biometrika, 87, 285-300.

Petitjean M. A. (2007). Definition of Symmetry. Symmetry: Culture and Science, 18 (2-3), pp.99 $-119$.

Watson, G. S. (1986). The shape of a random sequence of triangles. Advances in Applied Probability,18: 156-169.

Weyl H. (1952). Symmetry, Princeton, N.J: Princeton University Press.

Zheng, G. and S. Szekely, Li; G. (2017). Statistical Shape and Deformation Analysis. Academic Press. ISBN 9780128104941. 